\title{
FEATURES OF THE MORPHOLOGY AND TEXTURE OF SILICA AND CARBON ADSORBENTS
}

\author{
V.M. Gun'ko \\ Chuiko Institute of Surface Chemistry, 17 General Naumov Street, 03164 Kyiv, Ukraine \\ e-mail: vlad_gunko@ukr.net
}

The morphological and textural characteristics of various silicas $(93$ fumed silicas and 56 porous silicas), different carbons (230), and porous polymers (53) are analyzed using probe (nitrogen, argon, benzene, $n$-decane, water) adsorption, small angle X-ray scattering (SAXS), and transition (TEM), scanning (SEM) electron and atom force (AFM) microscopies. There are certain correlations between pore volume $\left(V_{p}\right)$ and specific surface area $\left(S S A, S_{B E T}\right)$ for these materials. Synthesis and treatment temperatures affect this relationship since a linear $V_{p}-S_{B E T}$ approximation scatter decreases with decreasing these temperatures. Silicas are composed of nonporous nanoparticles (NPNP), but activated carbons (AC) are composed of porous nanoparticles (PNP). For different materials, NP are weakly or strongly packed in secondary structures. However, there are general features of pore size distributions (PSD) for NP-based materials, e.g., minimal contribution of narrow mesopores of 3-5 $\mathrm{nm}$ in radius due NP-packing effects. For AC produced using the same chars and activation agents but with varied activation time, the textural characteristics demonstrate smooth changes with increasing burn-off degree: nanopores partially transform into narrow mesopores with opposite PSD shifts of broad mesopores and macropores. Comparison of adsorption (open pores accessible for probes) and SAXS (both open and closed pores) data for carbons shows that the difference decreases with increasing burn-off degree due to decreasing contribution of closed pores. Most clear pictures on the particulate morphology and texture could be obtained in parallel analysis using adsorption, SAXS, and microscopic methods with appropriate data treatments.

Keywords: fumed nanosilicas; porous silicas; carbon adsorbents; particulate morphology; textural characteristics; surface area - pore volume relationships

\section{Introduction}

Different materials used as adsorbents, polymer fillers, thickening agents, drug carriers, etc. are typically characterized by developed specific surface area (SSA) due to the presence of various nano/microstructures in visible particles characterized by certain structural hierarchy of various nano-, micro-, macro-scaled elements weakly or strongly packed in separated visible particles [124]. The simplest nanostructures such as nonporous nanoparticles (NPNP) of a spherical-like shape are characteristic for fumed silicas and other fumed oxides [1-9,13,14]. Typically, the smaller the NPNP sizes, the greater is the SSA and volume $\left(V_{\mathrm{p}}\right)$ of textural pores $[13,14]$. The morphological and textural characteristics of fumed oxide powders are caused not only by features of the flame synthesis at high temperatures but also by post-synthesis treatment history because secondary (NPNP aggregates) and ternary (agglomerates of aggregates) are "soft" and unstable under any external action $[1-8,13,14]$. For silica gels and aerogels, mesoporous ordered and precipitated silicas, 
nanostructures such as NPNP are not free disperse, since they present in strongly bound, adherent state in visible particles $[5-7,13,18-20]$. In contrast to fumed oxides, the nano-structured elements (blocks) are tightly packed in porous micro or macroparticles of spherical-like or other shapes of silica gels and carbons. The thinner the pore walls, the greater the SSA and $V_{\mathrm{p}}$ values of these porous particles. NPNP traces can be found in the pore walls of porous silicas, and for various carbon materials, nano-structured elements are observed as for porous silicas [11-13,12-30]. There are carbons composed of nonporous particles (e.g., carbon blacks) or porous nanoparticles (PNP) characteristic for chars and activated carbons (AC) [11,12]. The carbon nano/microstructures are very manifold due to the presence of 2D flexible blocks (sheets), graphenes, and sheet stacks of various sizes, plane or bent, differently oxidized and functionalized upon activation and posttreatments [26-30].

Free disperse nanoparticles can be very active upon interactions with various bio-objects. Therefore, aspects of nanoparticle toxicity are of importance from a practical point of view since nanomaterials are widely used in numerous applications including industry, medicine, biotechnology, agriculture, etc. [1-10,31-33]. Some of nanomaterials such as fumed silicas can be used as food additives [33]; i.e., their toxicity should be very low. Activated carbons, as well as some other nanomaterials (e.g., clays), could be used as oral sorbents, drug additives, or drug carries. However, some nanomaterials could be toxic that depends on their chemical structure, crystallinity, morphology, texture, surface functionalities, etc. It should be noted that the possibility and efficiency of applications of nanomaterials depend not only on their chemical structure but also on their particulate morphology, texture, composition, etc. Therefore, a wide set of different characteristics are of importance for various practical applications of nanomaterials [1-6,9,34-36].

Besides SSA, the pore volume $\left(V_{\mathrm{p}}\right)$ and pore size distributions (PSD) with respect to pore volume and SSA are important textural characteristics [4-13,37-41], as well as the size and shape distributions of NPNP and PNP being in free disperse or bound states [13,14]. All these characteristics are not independent due to mutual influence. However, the relationships between them could be complex due to several factors: (i) features of weak and strong (adherent) contacts between weakly or strongly packed nano-elements in secondary and ternary structures characterized by a certain morphological or structural hierarchy; (ii) porosity of nano- and microstructures, pore and particle shapes, and pore size distributions; (iii) structure of pore walls; (iv) effects of environments, (v) morphological and textural features of disperse micro- or macro-particles and their stability and durability at all hierarchical levels [13,34-41]. Therefore, the aim of this work is a deep insight into the relationships of the morphological and textural characteristics of fumed and porous silicas, various carbons and porous polymers using different experimental data effectively treated using developed software for a large set (432 in total) of samples.

\section{Materials and methods Materials}

Four types of materials analyzed here: fumed (nanosilicas) and porous silicas, various carbons, and porous polymers. Studied materials are (i) fumed silicas including 93 samples (produced at Pilot plant of Chuiko Institute of Surface Chemistry (PP CISC, Kalush, Ukraine), Degussa, Evonik, Wacker, Cabot, and Nippon Aerosil); (ii) 56 samples of porous silicas (Merck, Crosfield, and CISC); (iii) 230 samples of various carbons (Carbo-Tech (Essen, Germany), MAST Carbon (UK), Westvaco, Norit NV (The Netherlands), PSO MASKPOL (Poland), HPSD (Hajnówka, Poland), Gryskaf (Poland), ThermoHypersil (UK), Carboprep (Restek, USA), and CISC); and (iv) 53 samples of polymers (Purolite, Merck, Fluka, Rohm and Haas (Philadelphia, USA), Maria CurieSkłodowska University (MCSU, Lublin, Poland), and CISC). The latter are used only upon the 
analysis of the relationships between the SSA and pore volume. The silica and carbon samples are compared in detail with respect to the main morphological (particle size distributions, PaSD) and textural (PSD, SSA, pore volume) characteristics determined using low-temperature nitrogen or argon adsorption-desorption isotherms and small angle X-ray scattering (SAXS) method. Some morphological and textural information has been also obtained from microscopic images. More detailed information on the used materials is given elsewhere [13,14,32,42-51].

\section{$S A X S$}

The differential PSD functions $f(r)$ based on the SAXS data (Empyrean diffractometer, PANalytical, $\mathrm{Cu} \mathrm{K} \mathrm{K}_{\alpha}$ radiation at $\lambda=0.15418 \mathrm{~nm}, 2 \theta=0.5-5^{\circ}$, narrow X-ray beam) have been calculated using Fredholm integral equation of the first kind (solved using modified CONTIN [52] algorithm) for scattering intensity $I(q)$, as well as the total surface area, pore wall and particle size distributions [42,43,49,53-57]. The main advantage of the SAXS method upon the textural characterization is due to that all open and closed pores could be analyzed in contrast to the adsorption methods giving the characteristics only on open pores accessible for probe molecules. The SAXS patterns could be used to compute the PaSD for spherical, cylindrical, or lamellar particles alone or in any mixture (see ESM file). For the complex particle models, the self-consistent regularization (SCR) procedure allows us to estimate contributions of particles of different shapes $[43,46]$. Some SAXS measurements were also carried out on the French CRG beamline D2AM at the European Synchrotron Radiation Facility (ESRF, Grenoble, France) [42,49].

The differential pore size distribution (PSD) functions $f(r)$ based on the small-angle X-ray scattering (SAXS) data may be calculated using Fredholm integral equation of the first kind for scattering intensity $I(q)$ [53]

$$
I(q)=C \int_{r_{\min }}^{r_{\max }} \frac{(\sin q r-q r \cos q r)^{2}}{(q r)^{2}} V(r) f(r) d r,
$$

where $C$ is a constant, $q=4 \pi \sin (\theta) / \lambda$ the scattering vector value, $2 \theta$ is the scattering angle, $\lambda$ is the wavelength of incident X-ray, $V(r)$ is the volume of a pore with radius $r$ (proportional to $r^{3}$ ), and $f(r) \mathrm{d} r$ represents the probability of having pores with radius from $r$ to $r+d r$. The values of $r_{\min }(=$ $\left.\pi / q_{\max }\right)$ and $r_{\max }\left(=\pi / q_{\min }\right)$ correspond to lower and upper limits of the resolvable real space due to instrument resolution. Equation (1) was solved using the CONTIN algorithm [52]. The $f(r)$ function could be converted into incremental PSD (IPSD) $\Phi\left(r_{i}\right)=\left(f\left(r_{i+1}\right)+f_{\mathrm{V}}\left(r_{i}\right)\right)\left(r_{\mathrm{i}+1}-r_{\mathrm{i}}\right) / 2$ for better view of the PSD at larger $r$ values.

To calculate the particle size distribution (PaSD) functions on the basis of the SAXS data, several models of particles (e.g., spherical, cylindrical, lamellar ones and various blends of them) could be used. For spherical particles, integral equation similar to Eq. (1) could be written as follows

$$
I(q)=C \int_{R_{\min }}^{R_{\max }} P(q, R) f(R) d R,
$$

where $C$ is a constant, $R$ is the radius of particles, $f(R)$ is the distribution function (differential $\mathrm{PaSD}$ ), and $P(R)$ is the form factor for spherical particles [54] (the kernel of the integral equation 2): $P(q, R)=\left(4 \pi R^{3} / 3\right)^{2}[\Phi(q)]^{2}$ and $\Phi(q, R)=\left(3 /(q R)^{3}\right)[\sin (q R)-q R \cos (q R)]$. as follows

The PaSD with respect to the volume of particles (as abundance in vol\%) could be calculated

$$
\text { abundance }(\operatorname{vol} \%)=R^{3} f(R) / \int R^{3} f(R) d R \text {. }
$$


The chord size distribution, $G(r)$ as a geometrical statistic description of a multiphase medium, can be calculated from the SAXS data $[55,56]$

$$
G(r)=C \int_{0}^{\infty}\left[K-q^{4} I(q)\right] \frac{d^{2}}{d r^{2}}\left(-4 \frac{\sin q r}{q r}\right) d q,
$$

where $K$ is the Porod constant corresponding to scattering intensity $I(q) \sim \mathrm{Kq}^{-4}$ in the Porod range.

The specific surface area from the SAXS data may be calculated (in $\mathrm{m}^{2} / \mathrm{g}$ ) using equation

$$
S_{\mathrm{SAXS}}=10^{4} \pi \phi(1-\phi) \frac{K}{Q \rho_{a}}
$$

where $\phi=\rho_{a} / \rho_{0}$ is the solid fraction of adsorbent, and $Q$ is the invariant

$$
Q=\int_{0}^{\infty} q^{2} I(q) d q .
$$

The $Q$ value is sensitive to the range used on integration of Eq. (6) (since experimental $q$ values are measured between the $q_{\min }$ and $q_{\max }$ values different from 0 and $\infty$ ). Therefore, the invariant value $Q$ can be calculated using equation [57]

$$
Q=\sum_{q_{\min }}^{q_{\max }}\left(I\left(q_{i}\right)-b\right) q_{i}^{2} \Delta q_{i}+K / q_{\max }
$$

where $b$ is a constant determined using equation

valid in the Porod range.

$$
I(q) q^{4}=K+b q^{4}
$$

\section{Nitrogen adsorption}

The adsorption of nitrogen (or argon) has been used to evaluate the accessible specific surface area (SSA), pore volume, and pore and particle size distributions [37-39]. The nitrogen adsorptiondesorption isotherms (Micromeritics ASAP 2010, 2020, 2405N, or 2420 and Quantachrome Autosorb adsorption analyzers), recorded for samples degassed at $80-100{ }^{\circ} \mathrm{C}$ (polymers and some carbons, e.g., graphene oxides) or $150-200{ }^{\circ} \mathrm{C}$ (disperse and porous oxides and carbons) for several hours, could be used to compute the pore size distributions (differential PSD $f_{\mathrm{V}}(R) \sim \mathrm{d} V_{\mathrm{p}} / \mathrm{d} R$ and $\left.f_{\mathrm{S}}(R) \sim \mathrm{d} S / \mathrm{d} R\right)$ using various approaches [42-51,58,59]. Some simple approaches could include various systematic errors caused by an inappropriate model of pores (e.g., cylindrical pores poorly model voids between NPNP in supra-NPNP structures), inappropriate parameters of solids (e.g., parameters of carbons poorly describe polymeric adsorbents), etc. As a whole, for materials with complex topology of pores or/and composed of several different phases (e.g., blends of fumed oxides, silica gels, polymers, carbons, etc.), firm (Micromeritics, Quantachrome, etc.) software can give incorrect results with systematic errors. Better results could be obtained using complex pore models with slit-shaped (S) and cylindrical (C) pores and voids (V) between spherical nanoparticles (SCV method) with the corresponding equation parameters for different phases [58,59]. Additionally, the chemical structure of a solid surface (e.g., hydroxyls or other functionalities) can affect the interactions (and orientation, i.e., effective area of a surface occupied by a molecule) of nitrogen or other probe molecules with a surface that can be studied using quantum chemistry methods (Fig. 1). 
(a)

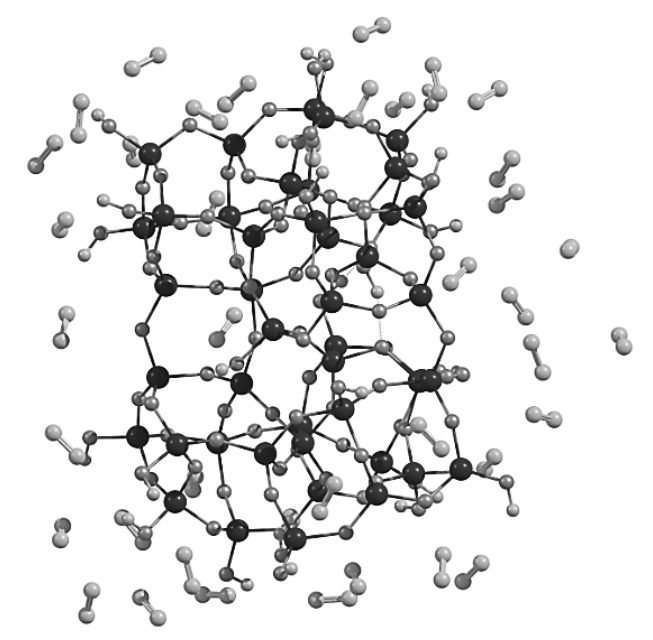

(b)

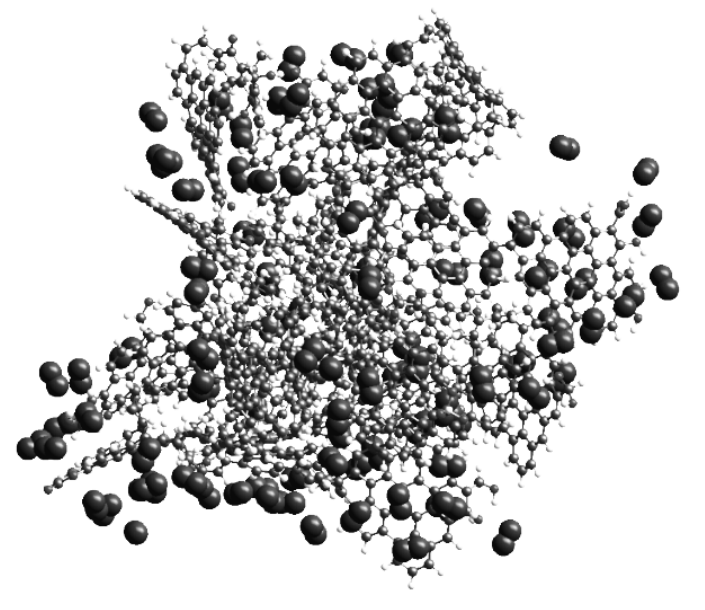

Fig. 1. Quantum chemical calculations of interaction of nitrogen molecules with (a) silica cluster (interaction energy $-6.9 \mathrm{~kJ} / \mathrm{mol}, \omega \mathrm{B} 97 \mathrm{X}-\mathrm{D} / \mathrm{cc}-\mathrm{pVDZ})$ and (b) activated carbon $(-4.6 \mathrm{~kJ} / \mathrm{mol}$, PM7)

The SCV method with a self-consistent regularization (SCR) procedure [58,59] allows one to consider the presence of several phases since the parameters of several types of surfaces (e.g., silica, carbon, carbohydrate polymers, etc.) could be simultaneously used with appropriate pore models for each component. The use of the SCR/SCV procedure gives information on contributions (weight coefficients) of different pore types and different components into the total porosity and SSA. As a whole, the model errors can remain upon the use of the SCV/SCR method because the texture of any adsorbent is not strongly ordered (pores can have very complex shapes) and affected by a surface roughness, etc. However, the SCV/SCR method reduces the systematic errors appearing upon the application of the firm software for complex materials.

The specific surface area $\left(S_{\varphi}\right)$ of materials composed of spherical nanoparticles (such as fumed silica) characterized by the particle size distribution $\varphi(a)$ (calculated using SCR for $f_{\mathrm{V}}(R)$ and $\varphi(a)$ (normalized to 1) with the model of voids between spherical particles) can be calculated with equation [13]

$$
S_{\varphi}=\int_{a_{\min }}^{a_{\max }} \frac{3}{2 a^{3} \rho}\left[2(a+t)^{2}+N r_{m} \arcsin \left(\frac{a}{A}\right) \sqrt{A^{2}-a^{2}}-N(a+t)\left(\frac{a r_{m}}{A}+t\right)\right] \varphi(a) d a
$$

where $A=a+t+r_{m}, a$ is the particle radius, $\rho$ the density of material, $N$ the average coordination number of nanoparticles in aggregates, $t$ the thickness of an adsorbed nitrogen layer, and $r_{\mathrm{m}}$ is the meniscus radius determined at the pressure range of $0.05<p / p_{0}<0.2$ corresponding to the effective radius $R$ of voids between spherical particles. Condition $S_{\varphi}=S_{\text {BET }}$ can be used to estimate the $N$ value. An additional criterion $\left|<S_{\varphi}>-S_{\mathrm{BET}}\right|<1 \mathrm{~m}^{2} / \mathrm{g}$ could be used to determine the $a_{\min }$ and $a_{\max }$ values for the $\varphi(a)$ distributions calculated at $p / p_{0}<0.5$ (i.e., before capillary condensation starts) with [13]

$$
<S_{\varphi}>=\frac{\iint S_{\varphi}\left(r_{m}, t\right) d t d r_{m}}{\iint d t d r_{m}}
$$


Note that the pore size distribution (PSD) functions could be calculated using molecular density functional theory (DFT) methods [60-64] such as nonlocal DFT (NLDFT) [65-68], quenched solid DFT (QSDFT) [69,70], 2D-NLDFT [71], well-developed modified Nguyen-Do (MND) methods [47,72-74] or others [13,14,32,42-51]. The DFT PSD may be calculated using overall equation [74]

$$
W(p)=v_{M}\left[\int_{\sigma_{s s} / 2}^{r_{k}(p)} \rho_{f}(R) f(R) d R+\int_{r_{k}(p)}^{R_{\max }} \frac{t}{R-\sigma_{s s} / 2} \rho_{M}(R) f(R) d R\right]
$$

where $W$ is the adsorption, where $v_{\mathrm{M}}$ the liquid molar volume, $\rho_{\mathrm{f}}$ the fluid density in occupied pores, $\rho_{\mathrm{m}}$ the density of the multi-layered adsorbate in pores, $r_{\mathrm{k}}$ the radius of pores occupied at the pressure $p, \sigma_{\mathrm{ss}}$ is the collision diameter of the surface atoms. To calculate the density of a gaseous adsorbate (nitrogen) at a given pressure $p$, Bender equation [75] may be used

$p=\rho T\left[R_{g}+B \rho+C \rho^{2}+D \rho^{3}+E \rho^{4}+F \rho^{5}+\left(G+H \rho^{2}\right) \rho^{2} \exp \left(-a_{20} \rho^{2}\right)\right]$,

where $B=a_{1}-a_{2} / T-a_{3} / T^{2}-a_{4} / T^{3}-a_{5} / T^{4} ; \quad C=a_{6}+a_{7} / T+a_{8} / T^{2} ; \quad D=a_{9}+a_{10} / T ; \quad E=a_{11}+$ $a_{12} / T ; F=a_{13} / T ; \quad G=a_{14} / T^{3}+a_{15} / T^{4}+a_{16} / T^{5} ; \quad H=a_{17} / T^{3}+a_{18} / T^{4}+a_{19} / T^{5} ; a_{20}=\rho_{c}^{-2} ; a_{i}$ are constants, and $R_{\mathrm{g}}$ is the gas constant. Transition from gas (subscript g) to liquid (1) or fluid in the form of multi-layered adsorbate in pores $(\mathrm{m})$ can be linked to the corresponding fugacity $f$

$$
\ln \frac{f(T, \rho)}{R_{g} T \rho}=\frac{p(T, \rho)}{R_{g} T \rho}-1+\frac{1}{R_{g} T} \int_{0}^{\rho}\left[p(T, \rho)-R_{g} T \rho\right] \frac{d \rho}{\rho^{2}}
$$

and

$$
f_{l, m}=f_{g} \exp \left(\frac{E_{i, m}}{R T}\right)
$$

where $E$ is the interaction energy of an adsorbate molecule with the pore walls and neighboring molecules calculated with the LD potentials [37,38].

The specific surface area determined under the complex pore model $\left(S_{\text {sum }}\right)$ can be calculated from the differential pore size distributions $f_{\mathrm{S}, j}(R)$ as follows

$$
S_{\text {sum }}=\sum_{j} c_{j} \int_{R_{\min }}^{R_{\max }} f_{S, j}(R) d R=\sum_{j} c_{j} \int_{R_{\min }}^{R_{\max }} \frac{w_{j}}{R}\left(f_{V, j}(R)-\frac{V_{j}}{R}\right) d R
$$

where $R_{\min }$ and $R_{\max }$ are the minimal and maximal values of pore radius (in this paper, $R_{\min }=0.35$ $\mathrm{nm}$ and $\left.R_{\max }=100 \mathrm{~nm}\right), w_{j}=1$ for ideal slitshaped pores, $w_{j}=2$ and 3 for cylindrical and spherical pores, respectively, and $w_{j} \approx 1.36$ for a cubic lattice with nonporous spherical particles. Effective $w_{\text {ef }}$ value for random aggregates with nonporous spherical particles under the SCR procedure can be estimated as follows

$$
w_{e f}=\frac{\int R f_{S}(R) d R}{\int f_{V}(R) d R}
$$

For evaluation of deviation $(\Delta w)$ of the pore shape from the model, a parameter

$$
\Delta w=\frac{S_{B E T}}{\int_{R_{\min }}^{R_{\max }} f_{S}(R) d R}-1
$$

where $R_{\max }$ and $R_{\min }$ are the maximal and minimal pore radii, respectively, may be used as a criterion of the reliability of the pore model, since $S_{B E T}$ is a conventional parameter independent of the pore shape and material type. 
According to quantum-chemical calculations, the orientation of the nitrogen molecules at a surface of various adsorbents depends on the chemical composition of the surface and the presence of functional groups ( $\operatorname{such}$ as $\mathrm{O}-\mathrm{H}, \mathrm{C}=\mathrm{O}, \mathrm{COOH}$, etc.) [5-9]. As an example, the orientation of the nitrogen molecules is shown upon the interaction with silica (Fig. 1a) and activated carbon (AC) (Fig. 1b). This effect leads to a decrease in the average value of the occupied surface area by nitrogen molecules $\left(\sigma_{0}\right)$. In other words, the specific surface area $\left(S_{\mathrm{BET}}\right)$ values are overestimated by ca. $15 \%$ for silicas, and the errors are slightly lower for carbons. This aspect should be taking into account if estimation of the $\mathrm{S}_{\mathrm{BET}}$ values should be maximum accurate. Another aspect of the textural characterization of fumed oxides is linked to the pore volume $\left(V_{\mathrm{p}}\right)$ estimated from the adsorption value at relative pressure $p / p_{0}=0.98-0.99$. For the loose powders of fumed silicas, the bulk density is typically low as $\rho_{b}=0.04-0.13 \mathrm{~g} / \mathrm{cm}^{3}$ depending on the average sizes of nanoparticles. This causes a great empty volume in the powders $V_{\mathrm{em}}=1 / \rho_{\mathrm{b}}-1 / \rho_{0}\left(\rho_{0} \approx 2.2 \mathrm{~g} / \mathrm{cm}^{3}\right.$ is the true density of amorphous silica) up to $24.5 \mathrm{~cm}^{3} / \mathrm{g}$, which is greater than the $V_{\mathrm{p}}$ value more than order of magnitude. Upon mechanical or hydro-compacting, the $V_{\mathrm{em}}$ value can be strongly decreased since the $\rho_{b}$ value increases up to $0.4-0.6 \mathrm{~g} / \mathrm{cm}^{3}$. This aspect is of importance on applications of intact or treated nanosilicas.

For better view of the PSD at large values of $R$, the differential PSD with respect to the pore volume $f_{\mathrm{V}}(R) \sim \mathrm{d} V / \mathrm{d} R, \int f_{\mathrm{V}}(R) \mathrm{d} R \sim V_{\mathrm{p}}$ could be recalculated to incremental PSD (IPSD) at $\Phi_{\mathrm{V}}\left(R_{i}\right)=$ $\left(f_{\mathrm{V}}\left(R_{i+1}\right)+f_{\mathrm{V}}\left(R_{i}\right)\right)\left(R_{\mathrm{i}+1}-R_{\mathrm{i}}\right) / 2$ at $\left.\sum \Phi_{\mathrm{V}}\left(R_{i}\right)=V_{\mathrm{p}}\right)$.

\section{Microscopy}

Atomic Force Microscopic (AFM) images were obtained using a NanoScope III (Digital Instruments, USA) apparatus with a tapping mode AFM measurement technique or using Nanoscope Multimode IIIa (Veeco, Santa Barbara, CA, USA). Before AFM scanning, powder samples of fumed silicas were slightly smoothed by hand pressing using a glass plate, which does not affect the structure of primary and secondary particles, changing only the structure of visible flocks. Software WSxM5, dev. 10.2 [76] has been used for quantitative analysis of AFM images.

Scanning electron microscopy (SEM) images of dried powder samples were recorded using a FE-SEM (Hitachi S-4700, Japan) or a Quanta 3D FEG (FEI, Japan) at an operating voltage of 5 or $15 \mathrm{kV}$ at the magnification range of 5000-100000.

Transmission electron microscopy (TEM) images of silica gels were recorded a BS 540 (Tesla) apparatus (accelerating voltage $80 \mathrm{kV}$, resolution $0.8 \mathrm{~nm}$ ). High resolution TEM (HRTEM) images of nanosilicas were recorded using a JEM-2100F apparatus (Japan). A powder sample was added to acetone (for chromatography) and sonicated. Then a drop of the suspension was deposited onto a copper grid with a thin carbon film. After acetone evaporation, sample particles remained on the film were studied with HRTEM. HRTEM images of various carbons were obtained using a JEOL 2010FX TEM apparatus operated at $200 \mathrm{kV}$ or a TECNAI G2 F30 microscope (FEI-Philips) at an operating voltage of $300 \mathrm{kV}$. Some TEM and SEM images were treated using Fiji (local thickness plugin) [77] and ImageJ (granulometry plugin) [78].

\section{Results and discussion Fumed silicas}

Fumed silica NPNP $\left(d=5-100 \mathrm{~nm}\right.$ in diameter and $\left.d \approx 6 /\left(\rho_{0} S_{\mathrm{BET}}\right)\right)$ as primary structures varied for different nanosilicas from A-50 $\left(S_{\mathrm{BET}} \approx 50 \mathrm{~m}^{2} / \mathrm{g}\right)$ to A-500 $\left(S_{\mathrm{BET}} \approx 500 \mathrm{~m}^{2} / \mathrm{g}\right)$ form aggregates $(<1 \mu \mathrm{m}$, secondary structures) and agglomerates of aggregates $(>1 \mu \mathrm{m}$, ternary structures). These hierarchical structures are well visible in AFM (Fig. 2), SEM (Fig. 3), and TEM 
(Fig. 4) images. The agglomerates form loose particles visible in the powders. Voids between NPNP in the aggregates and agglomerates provide large empty volume in the initial loose powders $V_{\mathrm{em}}=$ $1 / \rho_{\mathrm{b}}-1 / \rho_{0}$, where $\rho_{\mathrm{b}}$ and $\rho_{0}$ are the bulk $\left(0.04-0.13 \mathrm{~g} / \mathrm{cm}^{3}\right)$ and true density $\left(2.2 \mathrm{~g} / \mathrm{cm}^{3}\right)$ of nanosilicas that gives the $V_{\mathrm{em}}$ range of $24.5-7.2 \mathrm{~cm}^{3} / \mathrm{g}$. As a whole, the NPNP aggregation degree depends on several factors including the particle size distribution (PaSD), i.e., the SSA value, pretreatment type (heating, pressing, wetting-drying, chemical modification), time, temperature, and pressure during post-treatments, storage and aging. Typically, any treatment of fumed silicas results in increasing $\rho_{b}$ value, but changes in the PSD depend on the treatment type and a set of related conditions $[13,14]$.

Nanosilica NPNP are characterized by broader PaSD with increasing NPNP sizes (decreasing $S_{\mathrm{BET}}$ ) (Fig. 5). The SAXS PaSD (computed with a model of spherical particles) for A-300 is much broader (Fig. 5, A-300*) than the PaSD (A-300) computed from the nitrogen adsorption data using Eq. (9) with a self-consistent regularization procedure. This result is explained by NPNP aggregation (Figs. 2-4), since SAXS data for several neighboring particles in aggregates could be interpreted as for one larger particle. Thus, a long tail in the SAXS PaSD for A-300 (Fig. 5) corresponds to aggregates of NPNP observed in microscopic images. Besides NPNP and their secondary and ternary structures, there are nuclei (Fig. 6) in the NPNP that are formed in the turbulent flame during the nanosilica synthesis at high temperatures. Contacts between the nuclei in the NPNP are very tight because they are formed in the flame at high temperatures and covered by subsequent silica layers. However, these contacts as boundaries can provide scattering of X-ray beams (SAXS, Fig. 6b). Fumed silicas are amorphous (regarding coherent distances) with respect to the NPNP. However, it is possible that nuclei correspond to short coherent distances. Therefore, the full profile analysis of the XRD patterns [79] for nanosilicas gives the NSD function (Fig. 6b). High-resolution TEM (HRTEM) image treatment can be used to compute the NSD function too (Fig. 6b). As a whole, the results of the SAXS, XRD, and HRTEM methods are in agreement. Observed certain differences in the NSD function shapes (Fig. 6b) are due to the differences in the A-300 samples and features of the used experimental and treatment methods.

The secondary and ternary structures with NPNP are responsible for the textural porosity of the fumed silica powders. This porosity type causes a certain type of the nitrogen adsorptiondesorption isotherms with a weak adsorption increase with pressure up to $p / p_{0} \approx 0.8$ (IUPAC type II), narrow hysteresis loops with onset at relatively high pressures (Fig. 7a). In the case of such porous silicas as silica gels (Fig. 7b), the porosity is due to the formation of the secondary structures of NPNP but with tight contacts between neighboring nanoparticles, which are adherent in contract to more looser structures of fumed silicas. Therefore, the nitrogen adsorption-desorption isotherms are characterized by different types (type IV). In contrast to porous silicas with complete filing of pore volume (Fig. 7b), upon the nitrogen adsorption onto fumed silica only a small part $(<10 \%)$ of $V_{\mathrm{em}}$ is filled by the $\mathrm{N}_{2}$ molecules at relative pressures $p / p_{0}>0.98$ (Fig. 7a) because of very weak interactions between them and distant NPNP in macrovoids in the agglomerates. Nitrogen mainly fills nano/mesovoids and only partially fills macrovoids independent of the $S_{\mathrm{BET}}$ values (or PaSD) of nanosilicas and pretreatment history of samples, e.g., mechanical or hydro-compaction of fumed oxides $[13,14,80]$. 
(a)

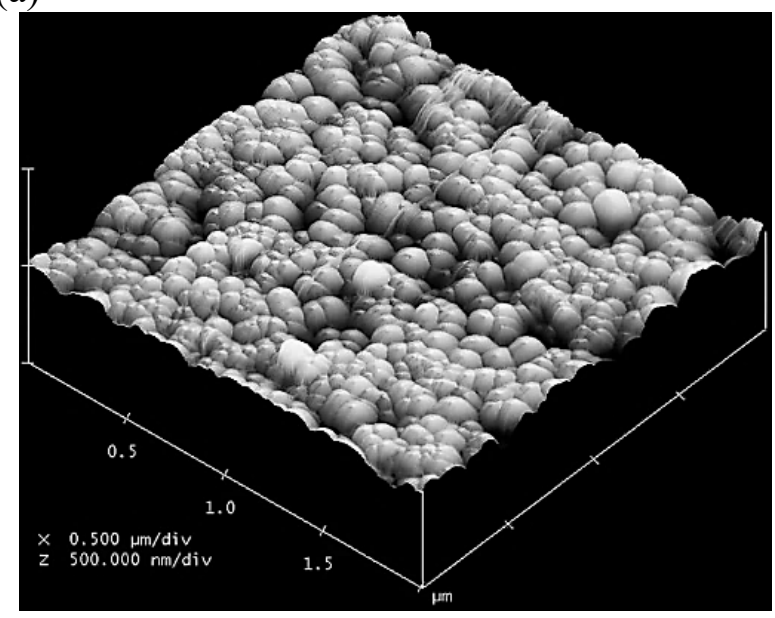

(c)

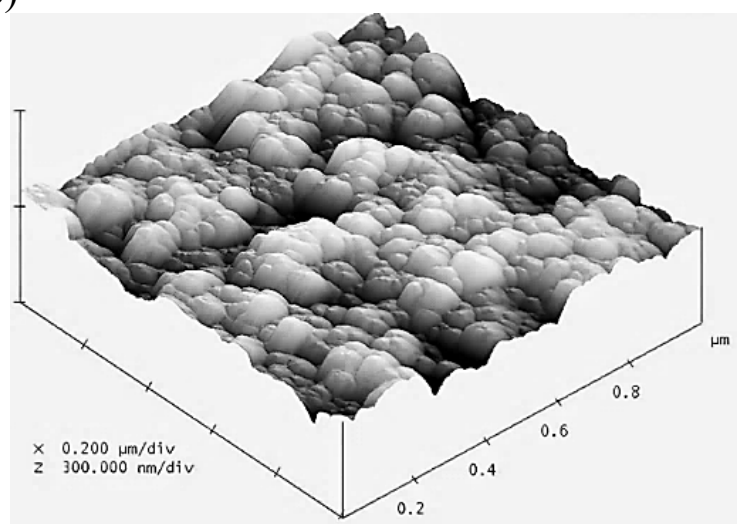

(e)

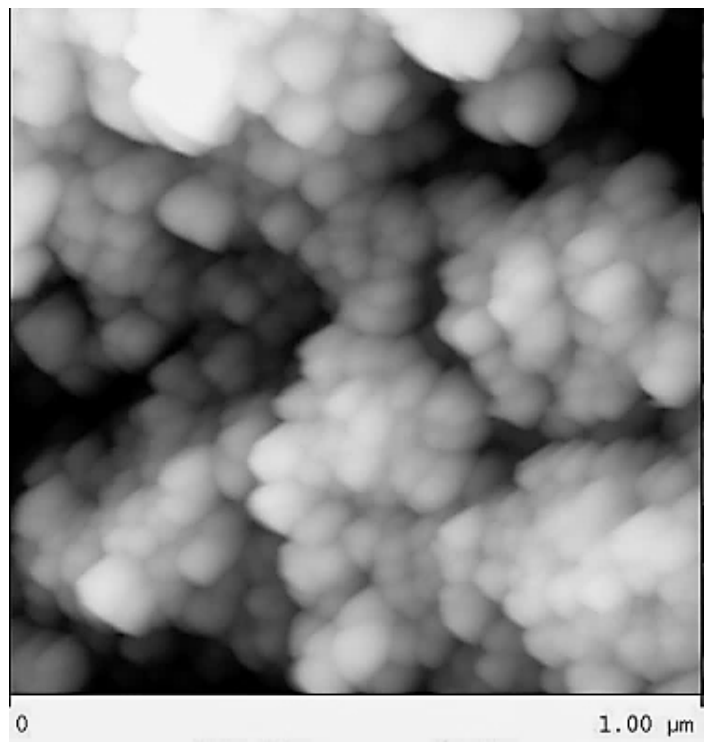

(b)

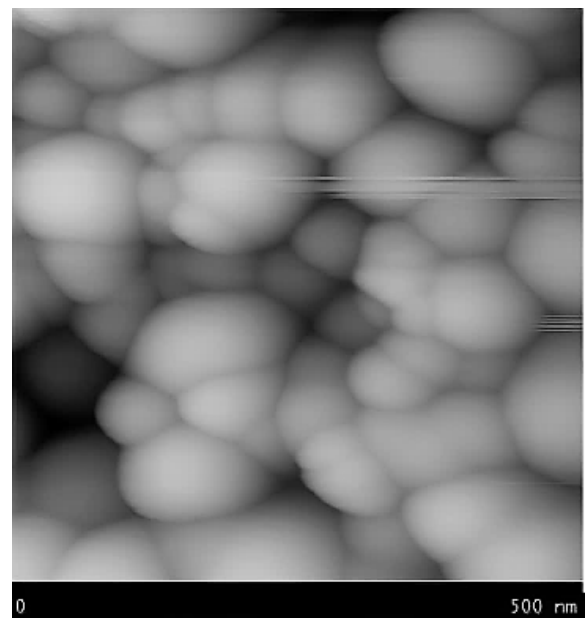

(d)

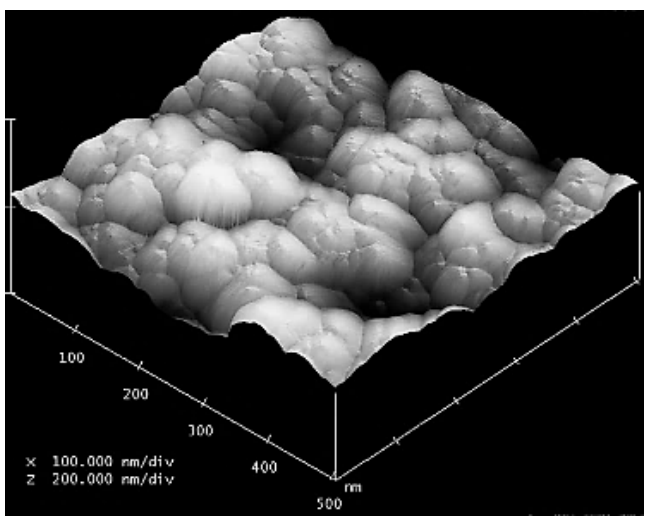

(f)

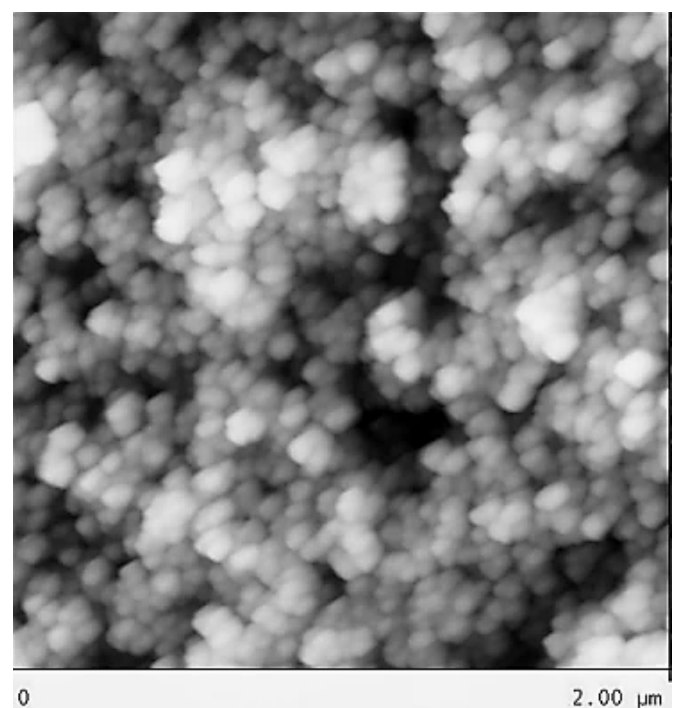

Fig. 2. AFM images of fumed nanosilicas (a, b) OX $-50\left(\mathrm{~S}_{\mathrm{BET}}=53 \mathrm{~m} / \mathrm{g}\right)$, (c, e, f) $\mathrm{A}-300\left(\mathrm{~S}_{\mathrm{BET}}=\right.$ $\left.281 \mathrm{~m}^{2} / \mathrm{g}\right)$, (d) A-400 ( $\left.\mathrm{S}_{\mathrm{BET}}=409 \mathrm{~m}^{2} / \mathrm{g}\right)$, dried $16.7 \mathrm{wt} . \%$ A-300 suspension: (e) nontreated and (f) sonicated for $5 \mathrm{~min}$. 

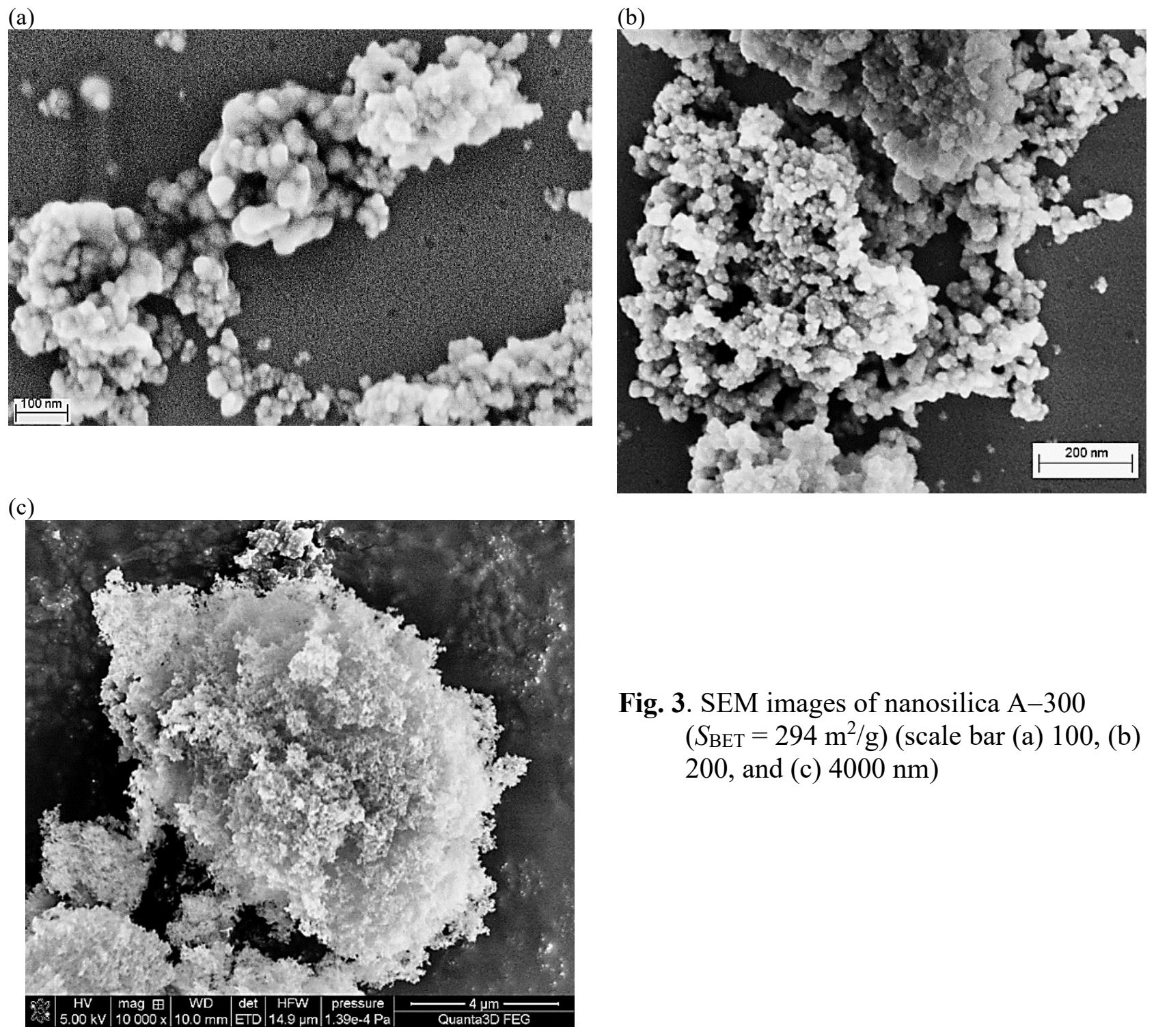

Fig. 3. SEM images of nanosilica A-300

$\left(S_{\mathrm{BET}}=294 \mathrm{~m}^{2} / \mathrm{g}\right)($ scale bar (a) 100, (b) 200, and (c) $4000 \mathrm{~nm}$ )

As a whole, there are several factors affecting computed SSA values of silicas. First, the orientation of adsorbed nitrogen molecules at a silica surface varies upon interactions with silanols and siloxane bridges (Fig. 1). For silanols, the effective surface area occupied by a nitrogen molecule $\left(\sigma_{0}\right)$ is smaller. Therefore, the greater the content of surface hydroxyls, the higher the overestimation of the $S_{\mathrm{BET}}$ value calculated with a fixed value of $\sigma_{0}=0.162 \mathrm{~nm}^{2}$ (appropriate for flat carbon sheets). A real value of $\sigma_{0}$ for silicas could be $0.13-0.14 \mathrm{~nm}^{2}$. Second, pretreatment conditions, e.g., temperature, can affect the $S_{\mathrm{BET}}$ value. This is clearly seen from 3D $S-T-t$ dependences (Fig. 8) for two nanosilica A-300 samples estimated using the Ar adsorption isotherms to avoid the adsorbate orientation effects. These changes are due to several processes caused by dehydration of silica nanoparticles. Intact water bound to NPNP desorbed mainly at $T<150{ }^{\circ} \mathrm{C}$ and samples preheated at $200{ }^{\circ} \mathrm{C}$ for several hours (typical pretreatment of silicas before the nitrogen adsorption measurements) do not practically include intact water at a surface [13]. However, there is water realized from nanoparticles volume upon heating. This water origin is linked to both 
hydroxyls and intact molecules. Note that a small fraction of hydroxyls can remain at a silica surface during treatment even at $1000{ }^{\circ} \mathrm{C}$ due to large distances between silanols for the condensation reaction $[4-9,13]$. Upon strong dehydration, NPNP sintering could occur (resulting in decreasing SSA), but NPNP dehydration per se causes an increase in the SSA value. Additionally, all these processes depend on synthesis features and sample prehistory $[13,14]$. Therefore, 3D picture of SSA vs. $T$ and heating time $(t)$ is relatively complex (Fig. 8).

(a)

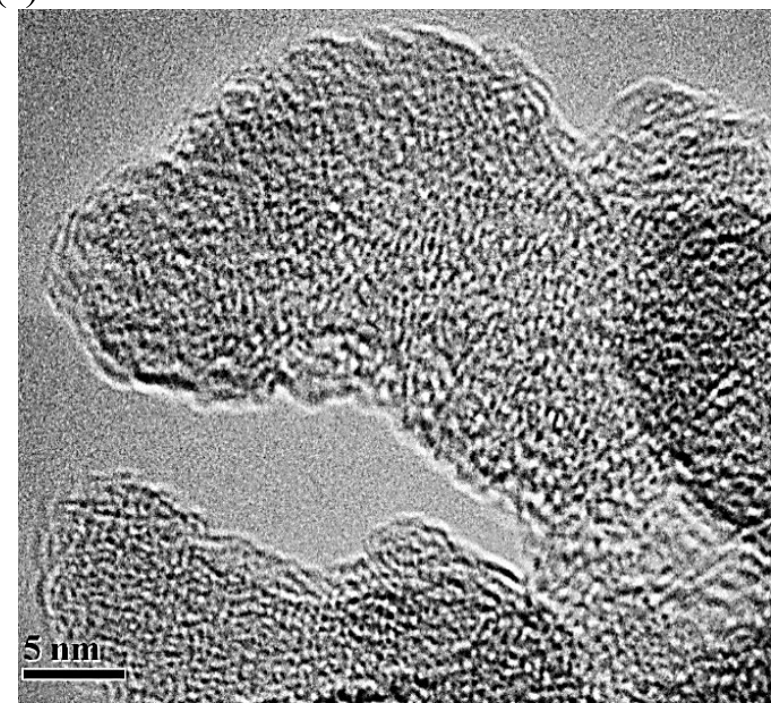

(c)

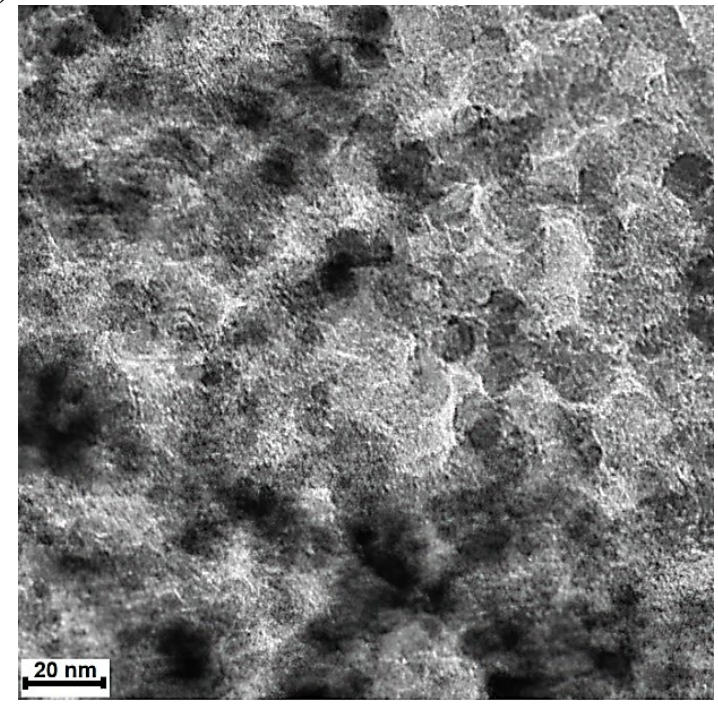

(b)

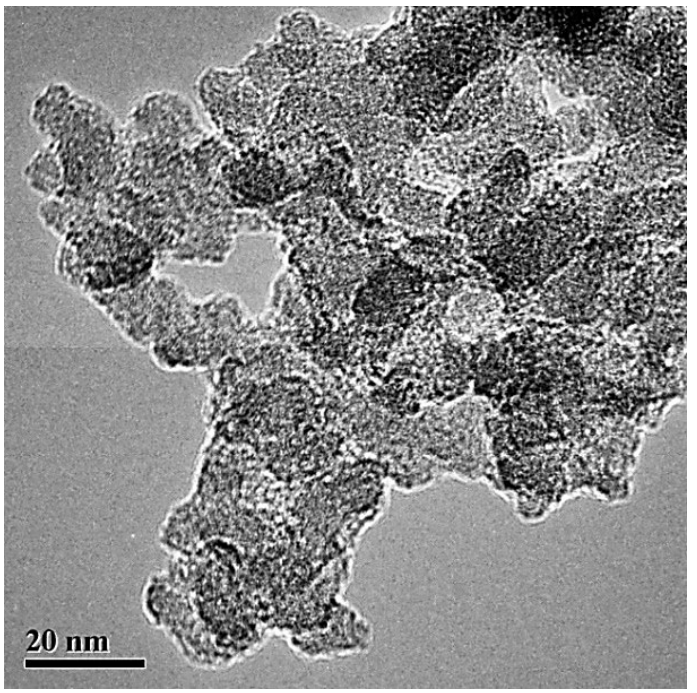

(d)

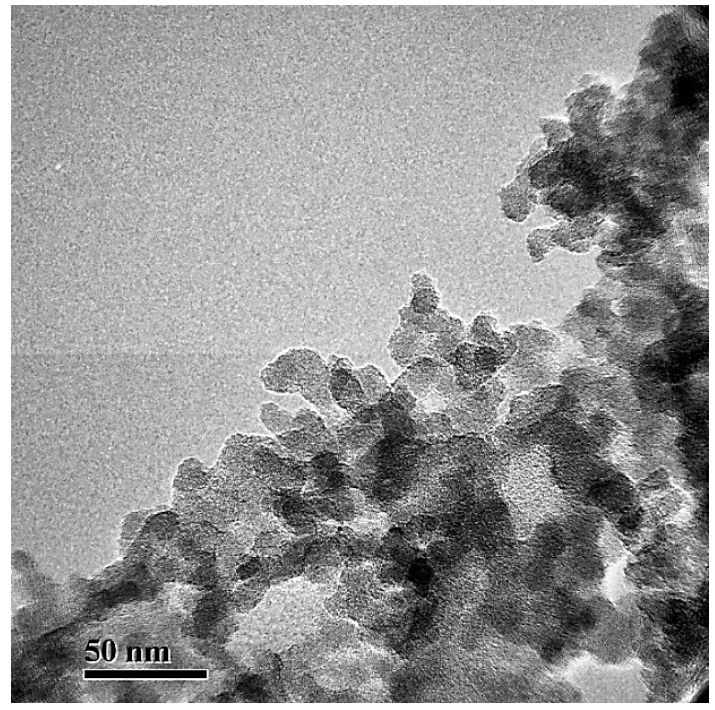

Fig. 4. HRTEM images of nanosilica A-300 with different magnifications (scale bar of (a) $5 \mathrm{~nm}$, (b, c) $20 \mathrm{~nm}$, and (d) $50 \mathrm{~nm}$ ); A-300 (a, b, d) initial and (c) after mechanochemical activation in a ball-mill for $2 \mathrm{~h}$ 

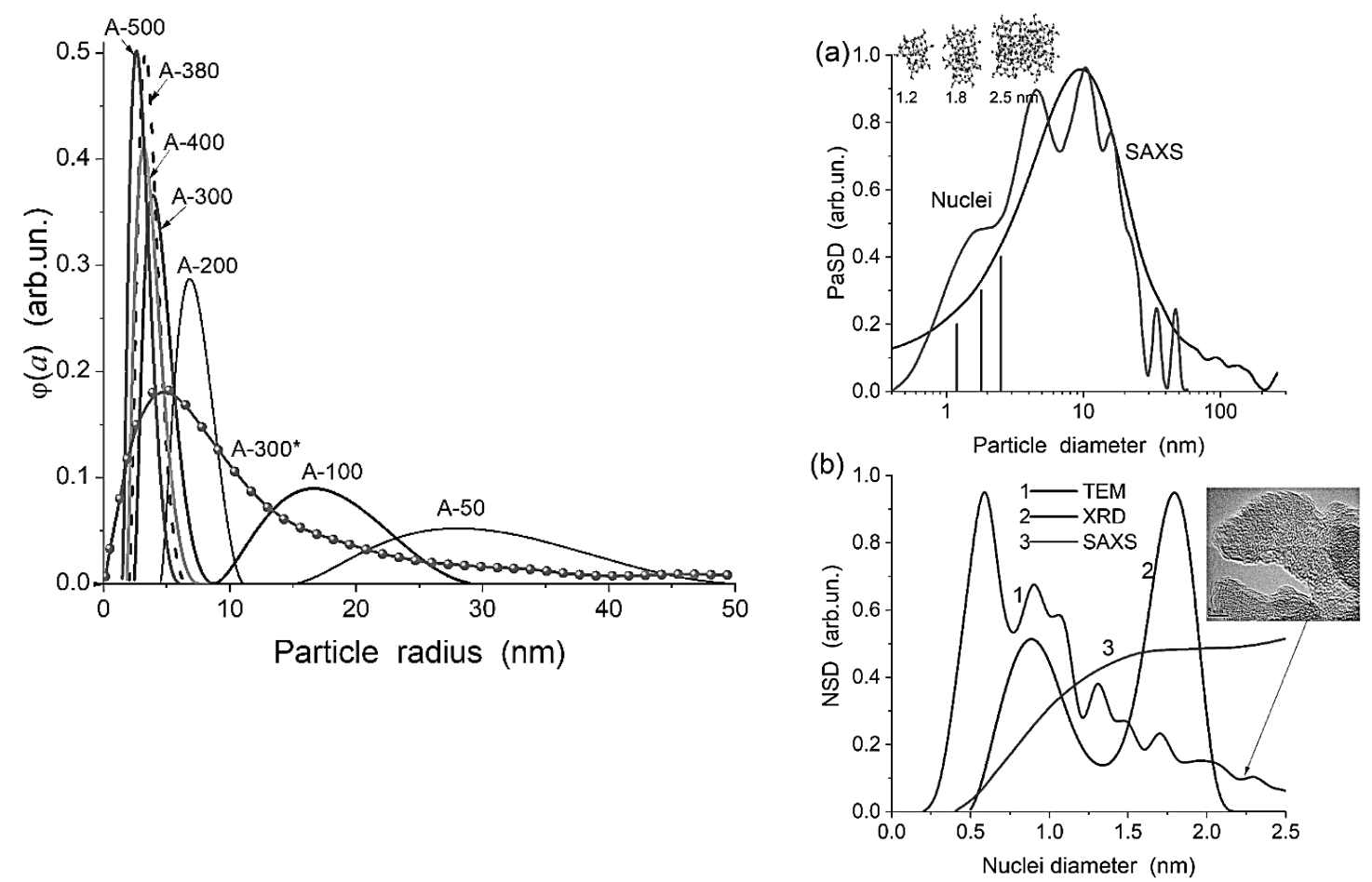

Fig. 5. Particle size distributions (PaSD) for fumed silicas calculated using the nitrogen adsorption isotherms and Eq. (9); and A-300 PaSD $\left(\mathrm{A}-300^{*}\right)$ is calculated using the SAXS data

Fig. 6. (a) PaSD computed using SAXS data for two samples of A-300 and model particles corresponding to nuclei presented in NPNP; (b) nuclei size distribution (NSD) functions computed using TEM image (Fig. 3a), XRD with full profile analysis, and SAXS data

(a)

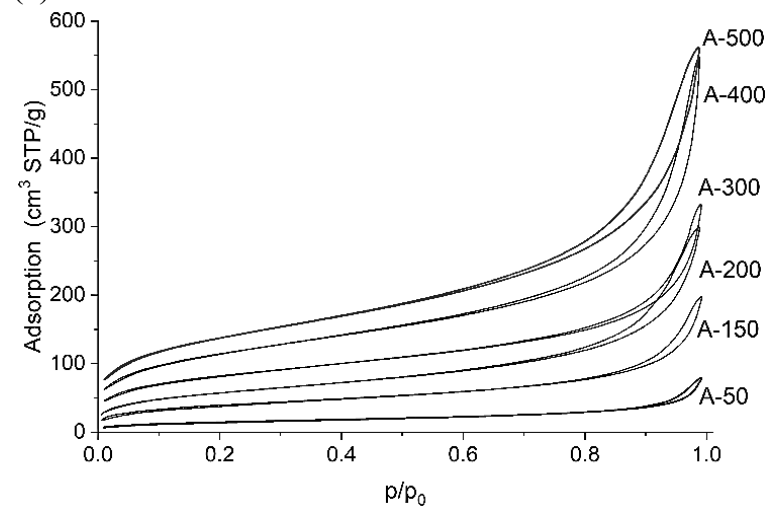

(b)

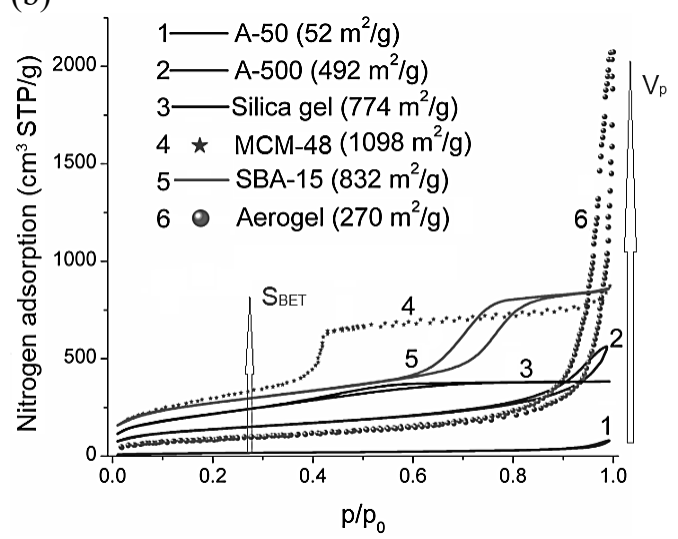

Fig. 7. Nitrogen adsorption isotherms for (a) nanosilicas $\mathrm{A}-50\left(\mathrm{~S}_{\mathrm{BET}}=52 \mathrm{~m}^{2} / \mathrm{g}, V_{\mathrm{p}}=0.13 \mathrm{~cm}^{3} / \mathrm{g}\right)$,

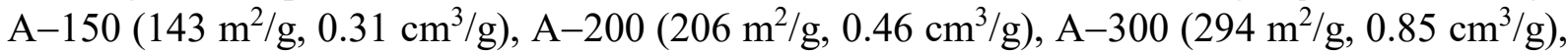
A-400 $\left(409 \mathrm{~m}^{2} / \mathrm{g}, 0.86 \mathrm{~cm}^{3} / \mathrm{g}\right)$, and A-500 $\left(492 \mathrm{~m}^{2} / \mathrm{g}, 0.87 \mathrm{~cm}^{3} / \mathrm{g}\right)$; (b) various silicas: nanosilicas A-50 (curve 1) and A-500 (2), silica gel Si-40 (3, $0.64 \mathrm{~cm}^{3} / \mathrm{g}$ ), templated mesoporous silicas MCM-48 $\left(4,0.87 \mathrm{~cm}^{3} / \mathrm{g}\right)$ and SBA-15 $\left(5,1.33 \mathrm{~cm}^{3} / \mathrm{g}\right)$, and aerogel $(6$, $3.20 \mathrm{~cm}^{3} / \mathrm{g}$ ) 


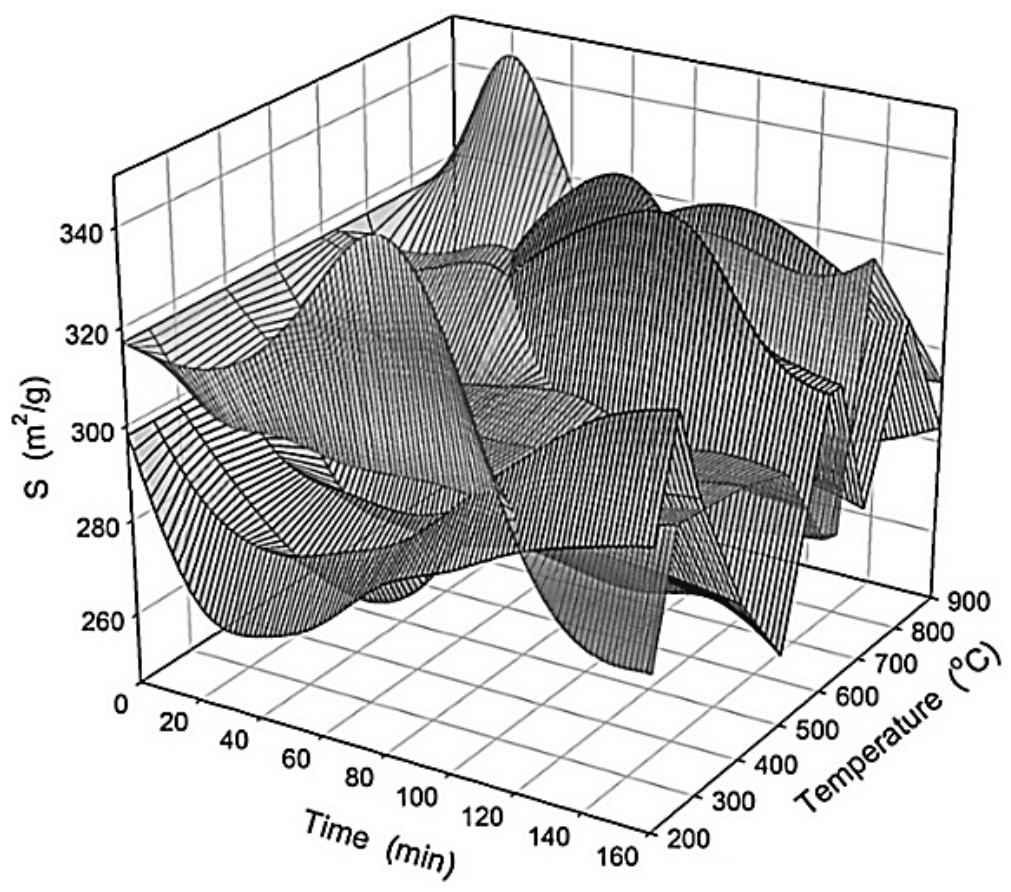

Fig. 8. Specific surface area, $S$ (Ar adsorption) vs. time and temperature of heating of A-300 (two samples)

The textural features of fumed silicas could be elucidated upon the analysis of 3D IPSD of nanosilicas (Fig. 9) showing that all studied nanosilicas (93 samples) are mainly meso/macroporous powders independent of the SSA values and sample history.

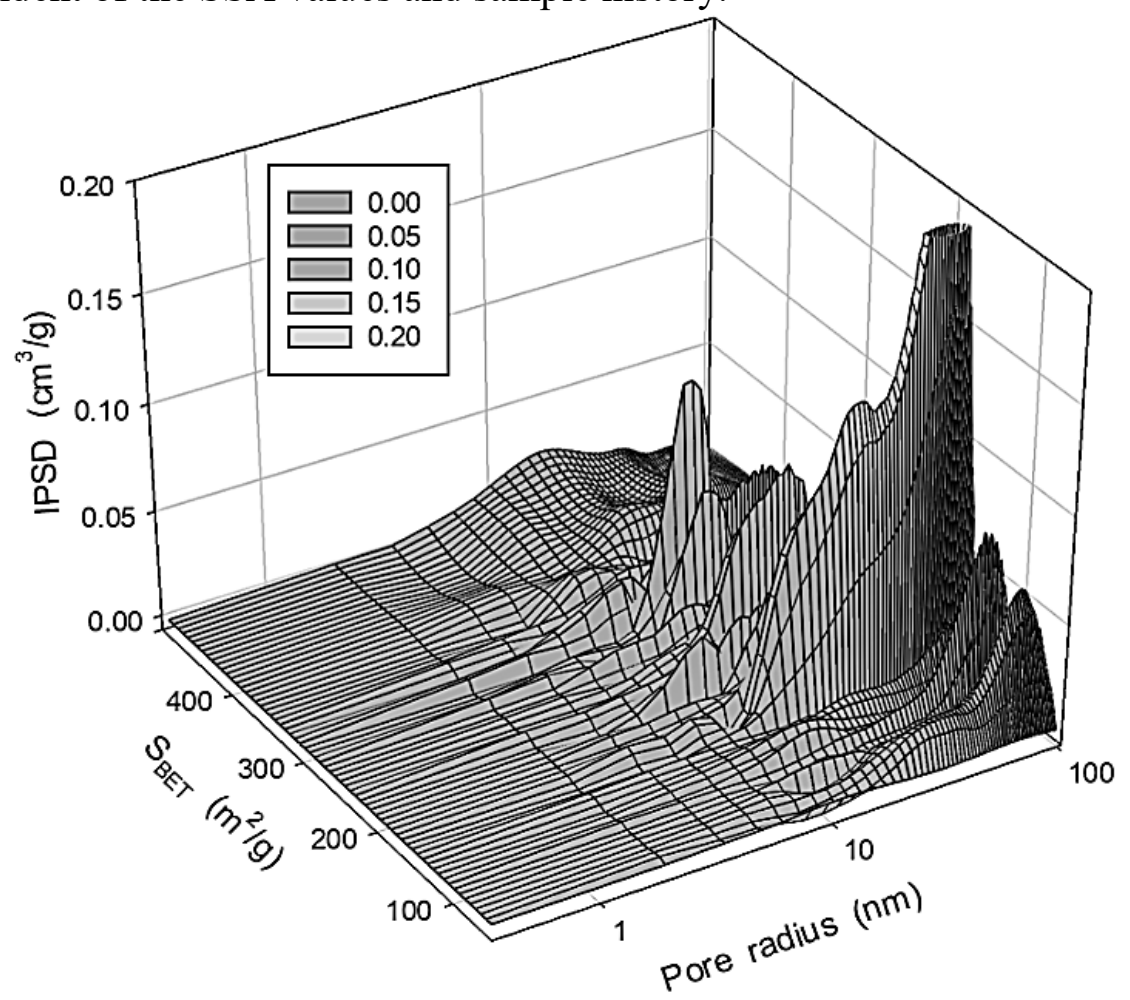

Fig. 9. 3D IPSD for fumed silicas (93 samples, DFT SCV/SCR) 


\section{Porous silicas}

The particle morphology (Figs. 2-4, 10), SSA and $V_{\mathrm{p}}$ values, and other textural features of silicas strongly affect the shape of the nitrogen adsorption-desorption isotherms (Figs. 7 and 11a). All these factors result in very different adsorption-desorption isotherms for fumed and porous silicas, which are characterized by different PSD (Figs. 9, 11b-13).

(a)

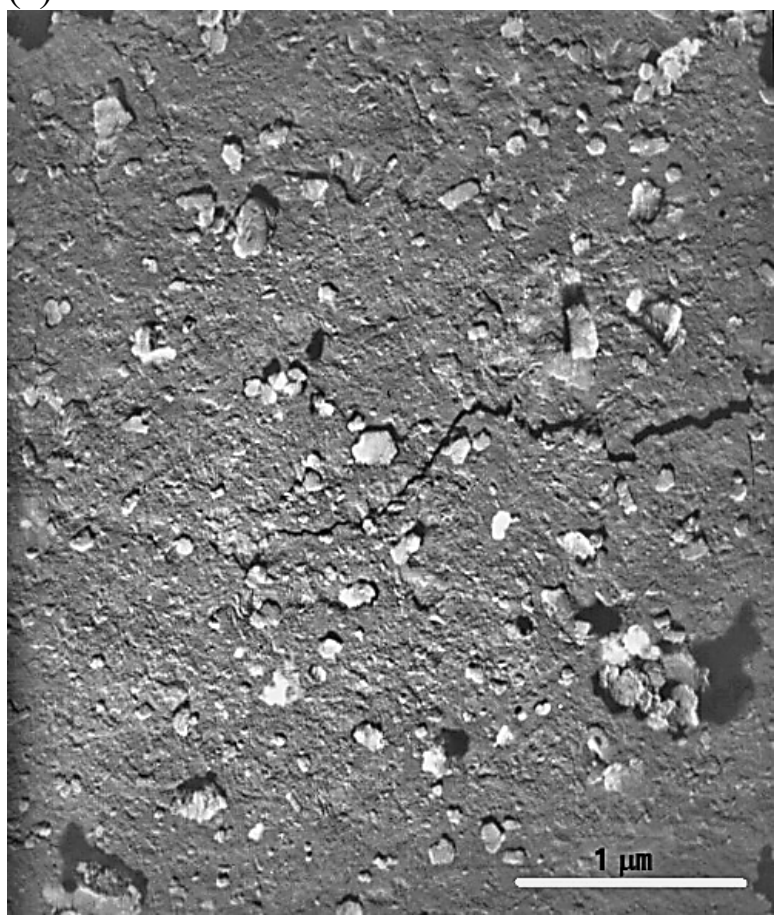

(c)

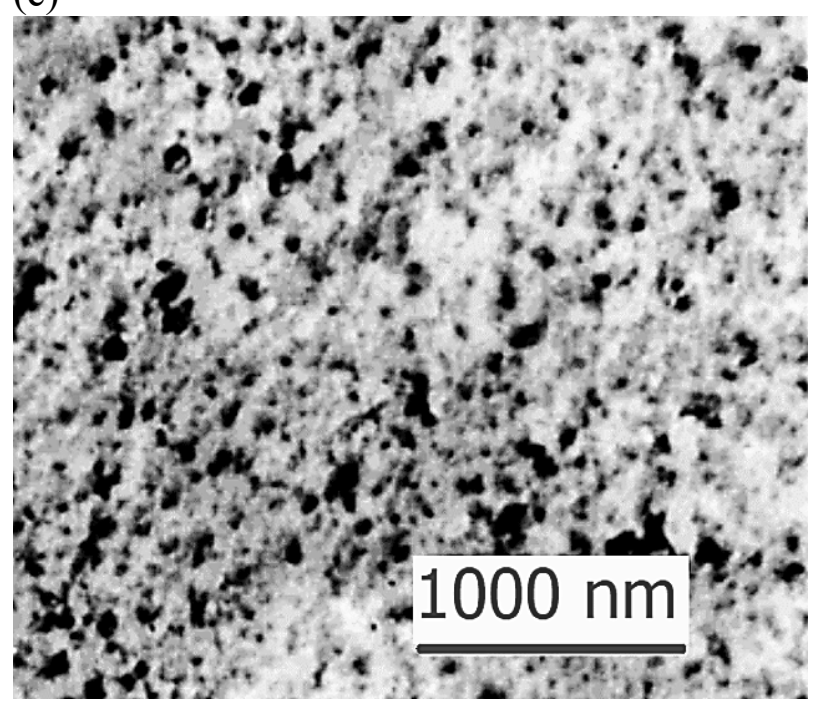

(b)

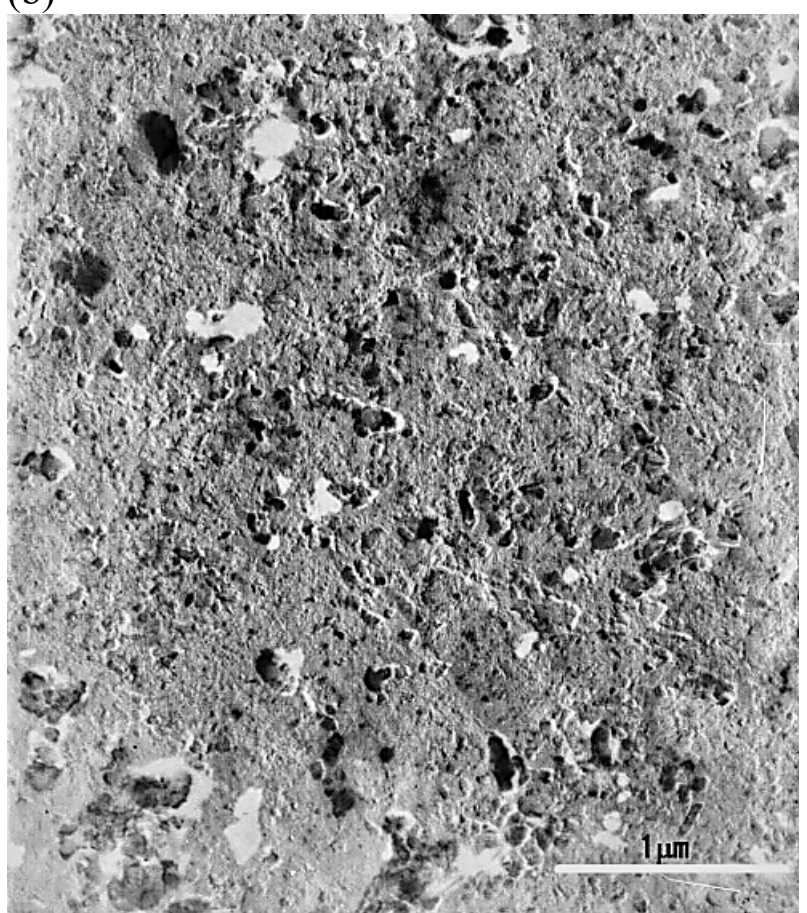

(d)

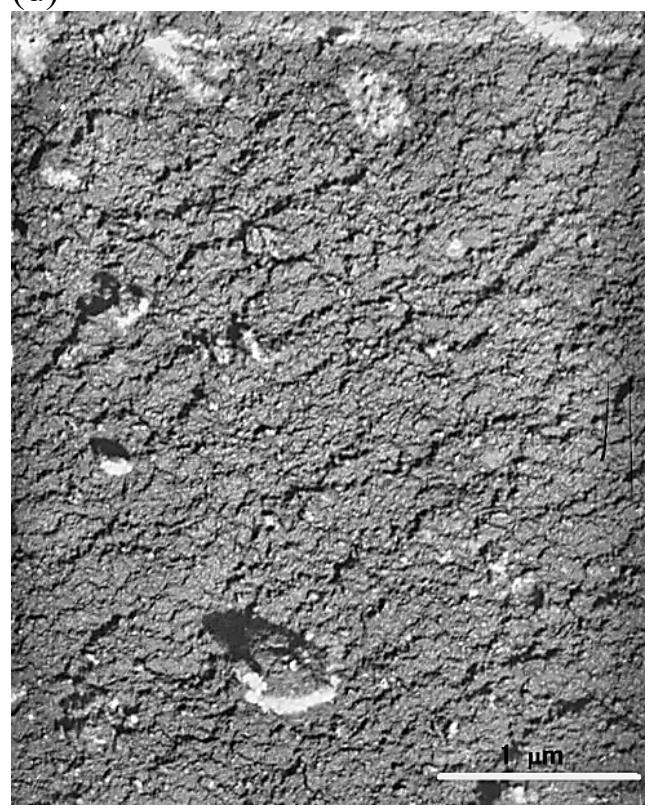

Fig. 10. TEM images of silica gels: $\mathrm{Si}-40$ (a) initial and (b) preheated at $800 \mathrm{~K}$ for $5 \mathrm{~h}$, and $\mathrm{Si}-60$ (c) initial and (d) preheated. 

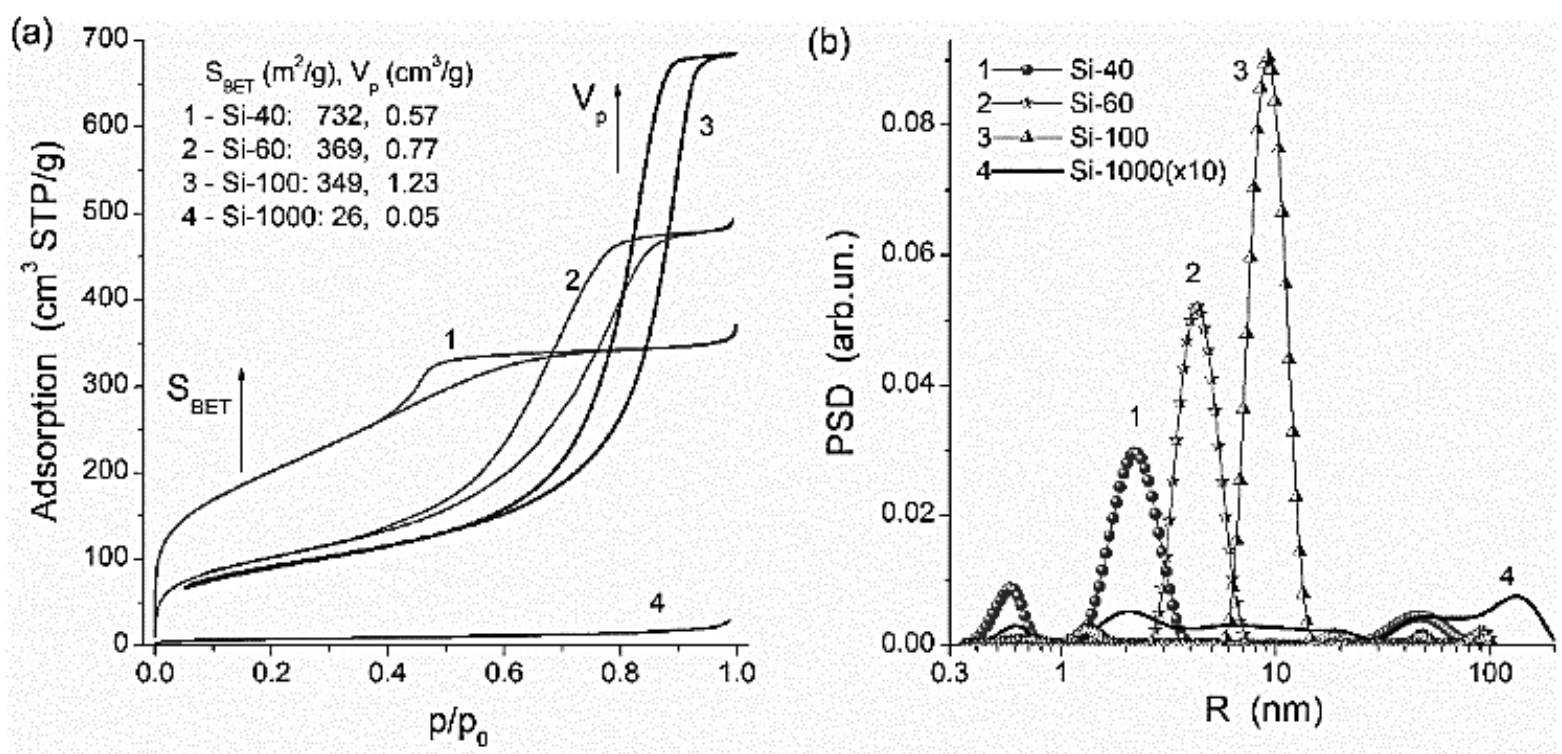

Fig. 11. (a) Nitrogen adsorption isotherms (STP - standard temperature and pressure conditions) and (b) pore size distributions for various silica gels.

The textural characteristics of various porous adsorbents could be estimated using a set of methods including NMR spectroscopy (NMR cryoporometry and NMR relaxometry), differential scanning calorimetry (DSC thermoporometry), thermogravimetry (TG thermoporometry), thermally stimulated depolarization current (TSDC relaxometry), etc. [13,14,32,37,42-51,79-81]. These additional characterizations (see, e.g., Fig. 12) are possible due to the dependence of the temperature behavior of probe adsorbates (water, alcohols, benzene, etc.) on the confined space effects, especially at temperatures below the freezing/melting points [13]. Note that the molecular sizes of probes can affect these characterization results due to changes in the accessibility of narrow pores vs. probe sizes.

(a)

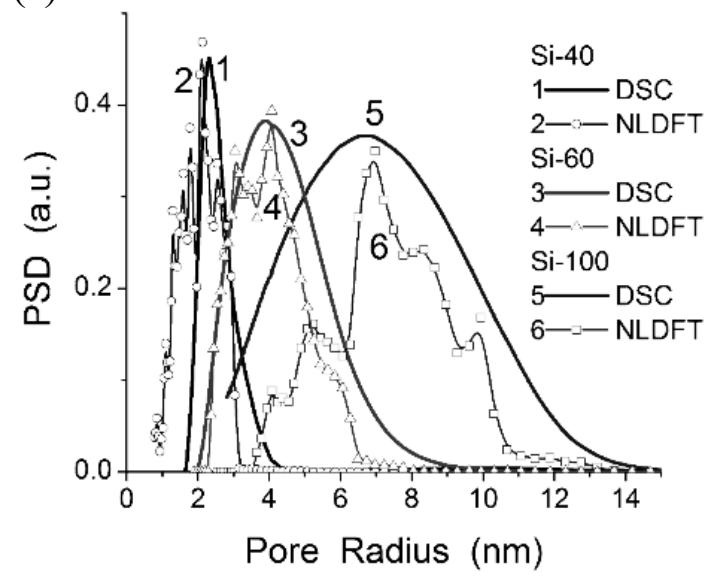

(b)

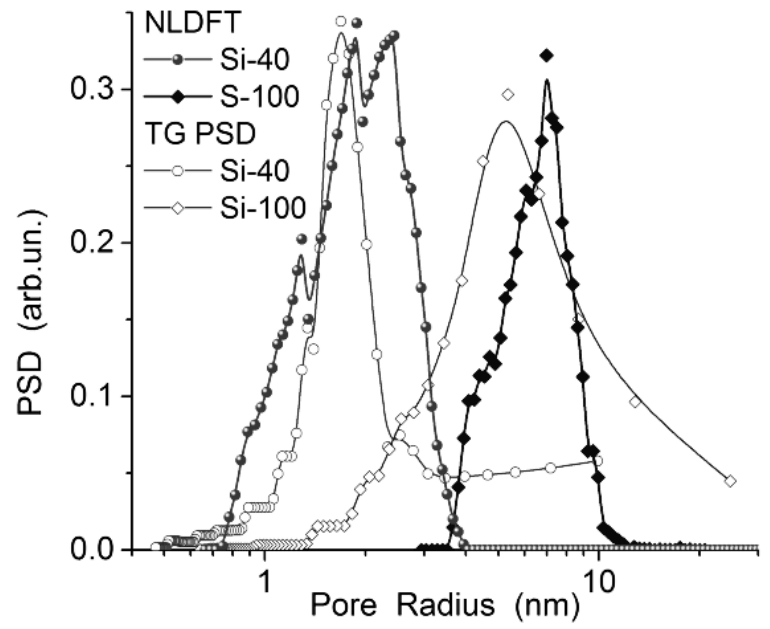

Fig. 12. PSD of silica gels with (a) $\mathrm{N}_{2}$ NLDFT (model of cylindrical pores) and the Gibbs-Thomson equation for $n$-decane with differential scanning calorimetry (DSC) melting curves, and (b) $\mathrm{N}_{2}$ NLDFT and thermoporometry with thermogravimetry (TG) data for desorbed water 
For various porous silicas, regularities in changes in the morphological and textural 3D characteristics (Fig. 13) are less clear than those for fumed silicas (Fig. 9) due to more complex morphology and texture of micro/macroparticles changing from sample to sample. However, for porous silicas, the position of the main PSD peaks has a tendency of shifting toward smaller $R$ values with increasing $S_{\mathrm{BET}}$, but the PSD could be not monomodal for many samples (Fig. 13).

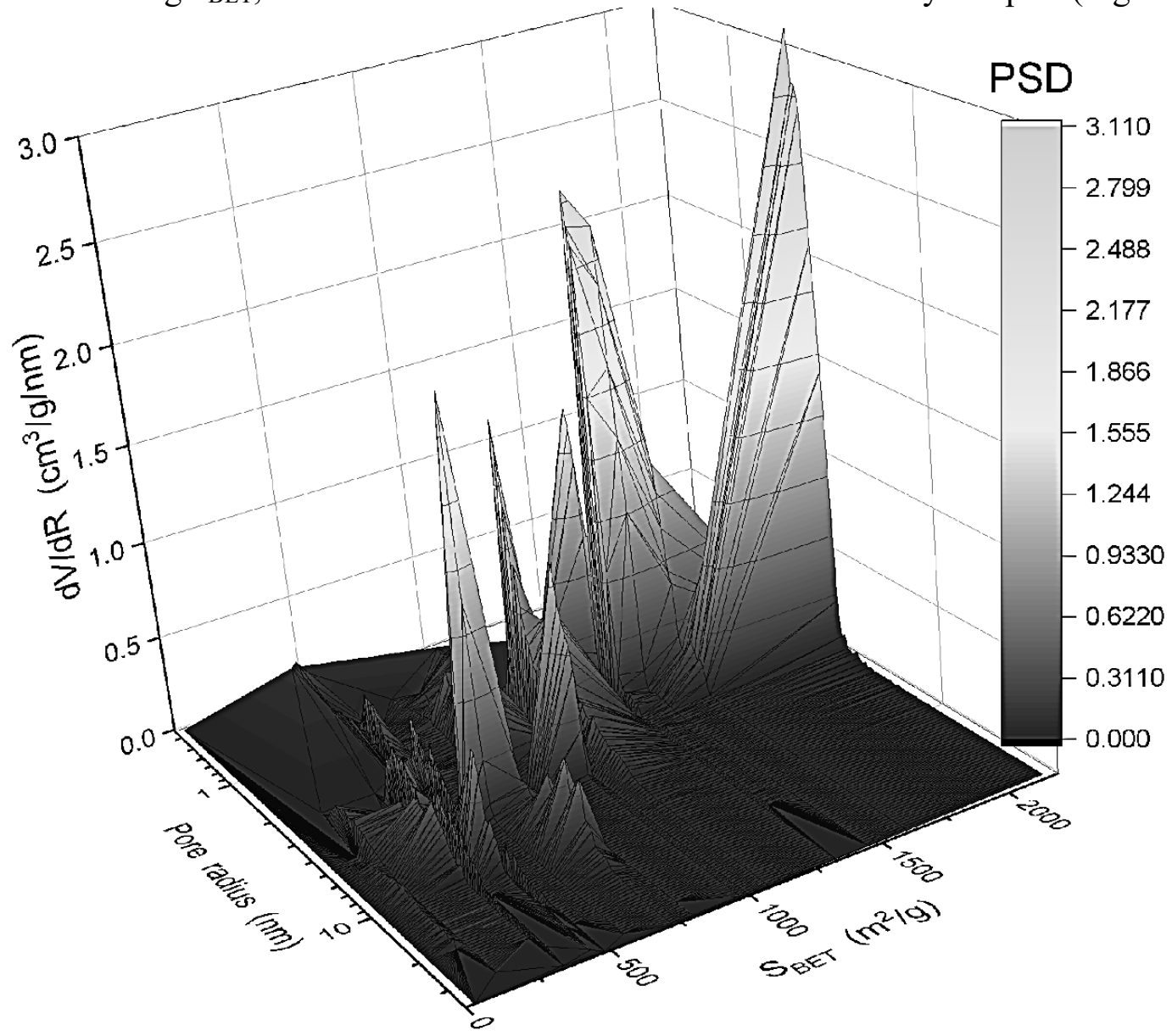

Fig. 13. NLDFT (cylindrical pores in silica) PSD for porous silicas (56 samples)

The adsorption and SAXS methods may give more correct results than other mentioned methods, whose results are more strongly dependent on probe features. For example, in the case of ${ }^{1} \mathrm{H}$ NMR cryoporometry with water as a probe, the textural characteristics of solid and polymeric adsorbents can strongly change upon water freezing because ice has larger volume than liquid water $[13,45,81]$. For some adsorbents, especially polymeric, these textural changes upon freezing-melting of probes could be irreversible. This aspect should be considered upon the use of the cryoporometry and relaxometry methods [13].

\section{Carbons}

In contrast to silicas, carbon adsorbents, especially activated carbons (Figs. 14-19) are composed with adherent porous nanoparticles forming larger structures (micro- and macroparticles). As a whole, the morphological and textural characteristics of various adsorbents, including silicas, carbons, polymers, etc., are not independent due to mutual influence of them. This influence could be analyzed using a wide set of methods. Activation of chars results in several 
morphological and textural changes of AC. Particles at all hierarchical levels become smaller (but they can be more strongly sintered), pore walls become thinner, pore volume and SSA values increase (Figs. 14-36, Tables 1 and 2). Different precursors, pore-forming agents, chars, and activation routes result in different textural changes affecting the shapes of the nitrogen adsorptiondesorption isotherms (Fig. 20). As a whole, the intraparticle organization of carbons looks like random (Figs. 14-19) in contract to spherical-like shapes of separated (visible) carbon particles (Fig. 17).

(a)

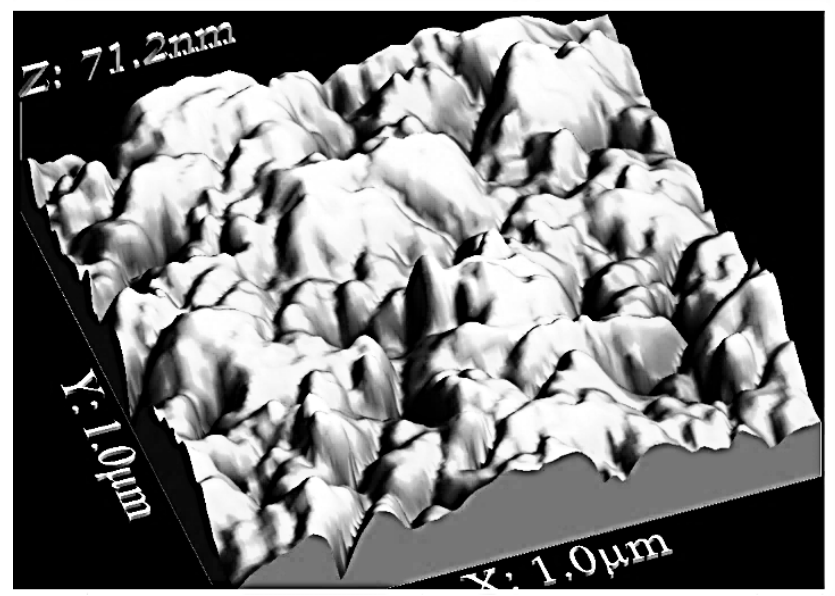

(c)

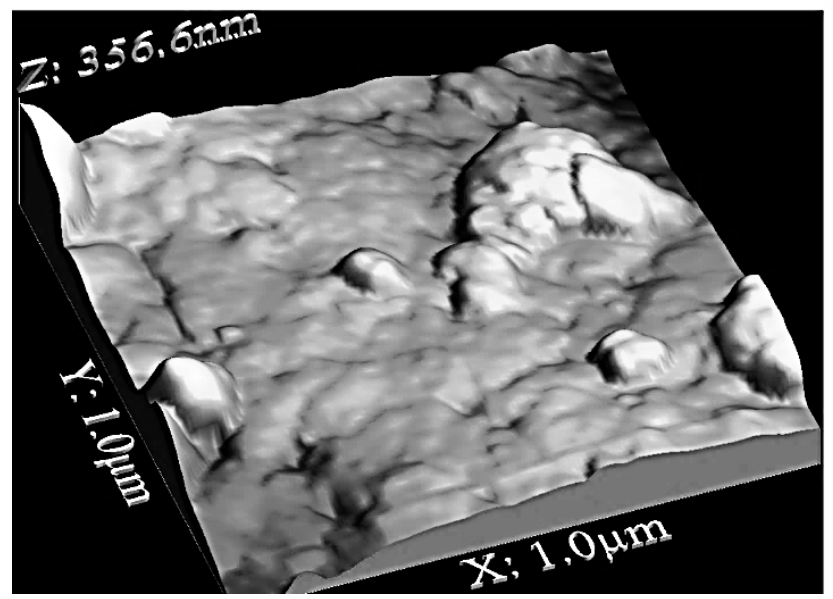

(b)

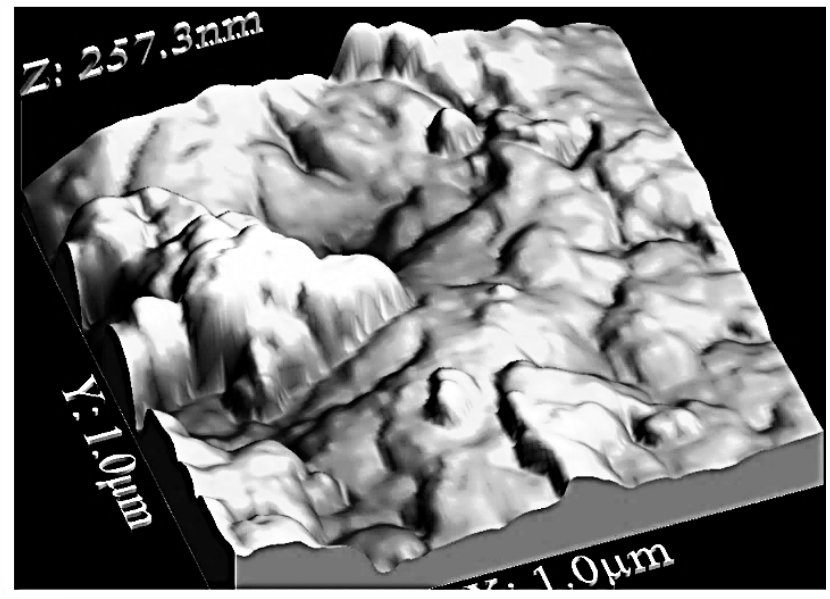

(d)

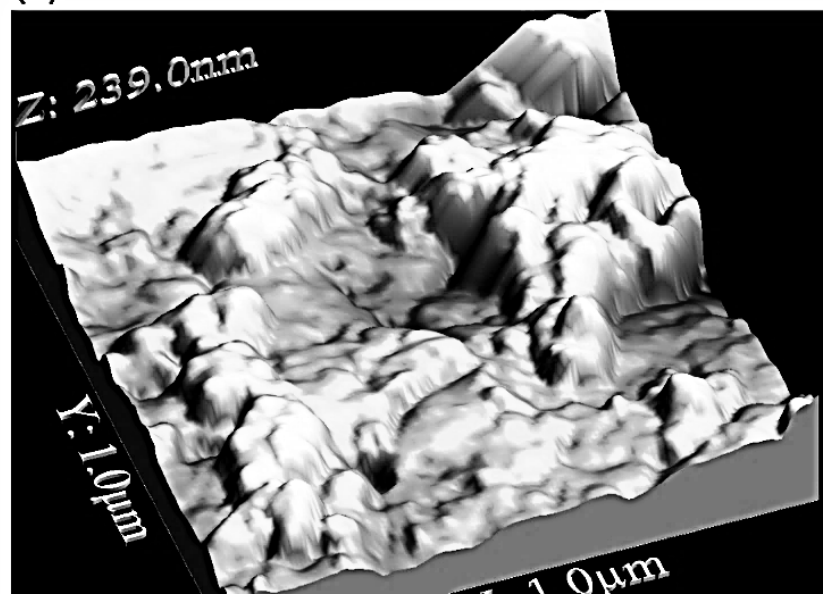

Fig. 14. AFM 3D images of (a) char (carbonized phenol formaldehyde resin, $S_{\mathrm{BET}}=534 \mathrm{~m}^{2} / \mathrm{g}, V_{\mathrm{p}}=$ $\left.0.902 \mathrm{~cm}^{3} / \mathrm{g}\right)$, and AC with different burn-off degree: (b) $29 \%\left(S_{\mathrm{BET}}=1042 \mathrm{~m}^{2} / \mathrm{g}, V_{\mathrm{p}}=\right.$ $\left.1.310 \mathrm{~cm}^{3} / \mathrm{g}\right)$, (c) $47 \%\left(1433 \mathrm{~m}^{2} / \mathrm{g}, 1.675 \mathrm{~cm}^{3} / \mathrm{g}\right)$, and (d) $65 \%\left(2019 \mathrm{~m}^{2} / \mathrm{g}, 1.857 \mathrm{~cm}^{3} / \mathrm{g}\right)$; (WSxM5, dev. 10.2 [76] was used to analyze AFM images).

The PaSD function shapes show that the char burn-off activation results in broadening of the distributions (Fig. 15) since both smaller (due to burn-off) and larger (due to sintering) structures appear. These processes affect the PSD, SSA, porosity and other characteristics of carbons. HRTEM images (Figs. 18 and 19) show that both chars and AC are amorphous because the graphitization can occur at much higher temperatures than that used for burn-off activation [11,12,25-29,82,83]. 

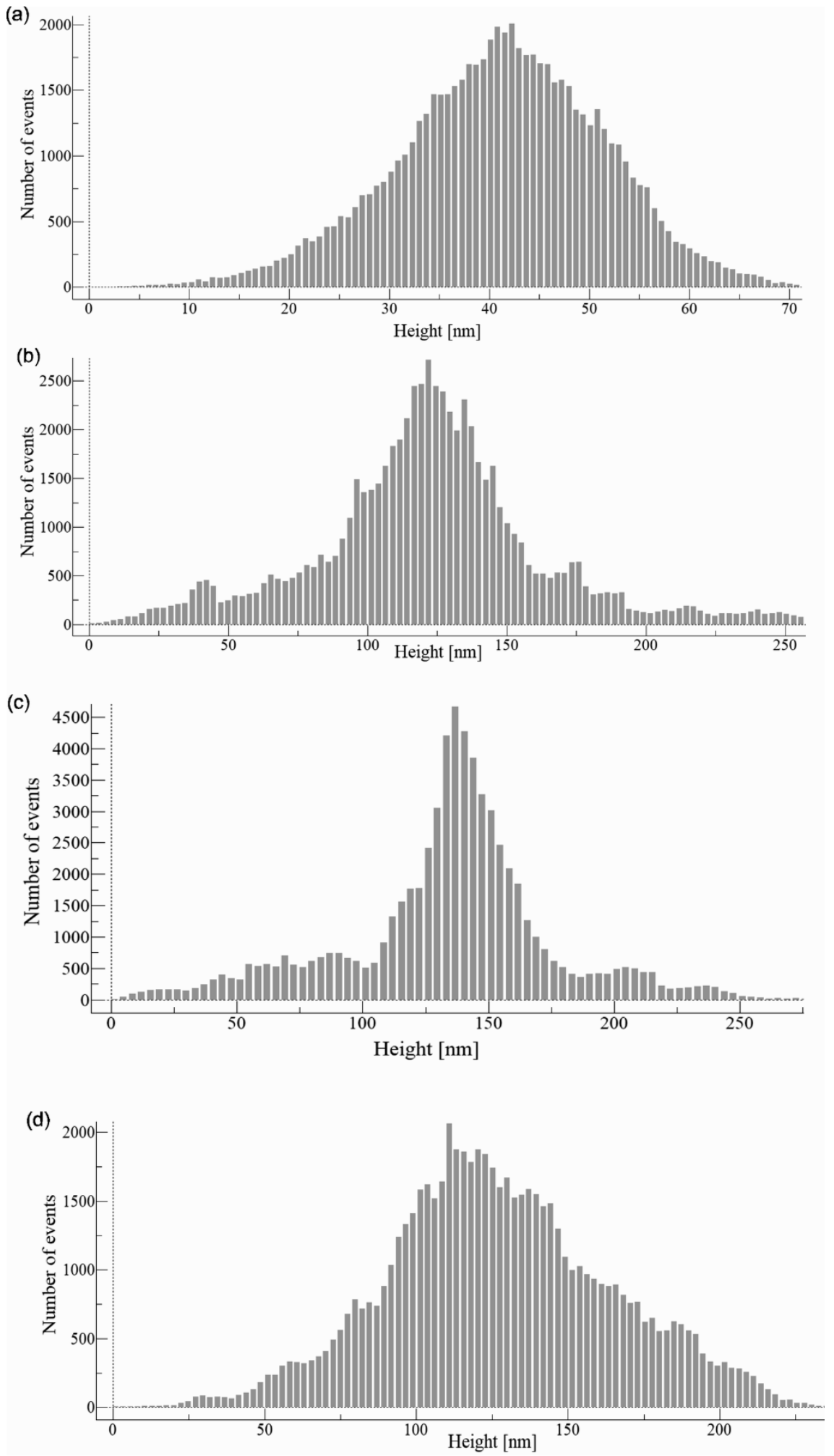

Fig. 15. Height distribution histograms from AFM 3D images for (a) char $\left(S_{\mathrm{BET}}=534 \mathrm{~m}^{2} / \mathrm{g}, V_{\mathrm{p}}=\right.$ $\left.0.902 \mathrm{~cm}^{3} / \mathrm{g}\right)$, and AC with different burn-off degree: (b) $29 \%\left(1042 \mathrm{~m}^{2} / \mathrm{g}, 1.310 \mathrm{~cm}^{3} / \mathrm{g}\right)$, (c) $47 \%\left(1433 \mathrm{~m}^{2} / \mathrm{g}, 1.675 \mathrm{~cm}^{3} / \mathrm{g}\right)$, and (d) $65 \%\left(2019 \mathrm{~m}^{2} / \mathrm{g}, 1.857 \mathrm{~cm}^{3} / \mathrm{g}\right)$; (WSxM5, dev. 10.2 [76] was used to analyze AFM images) 
(a)

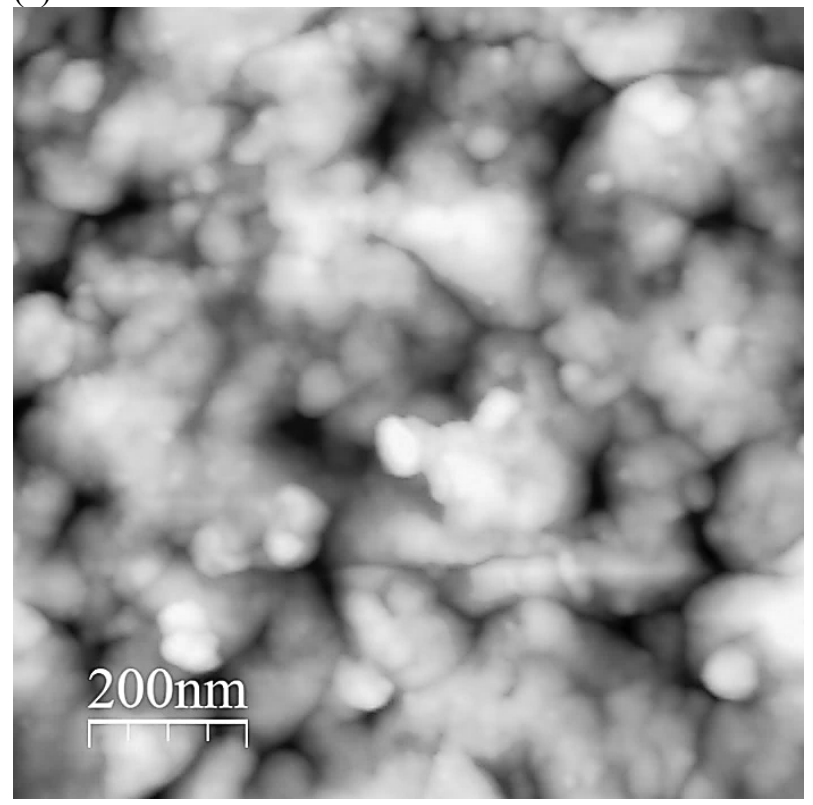

(c)

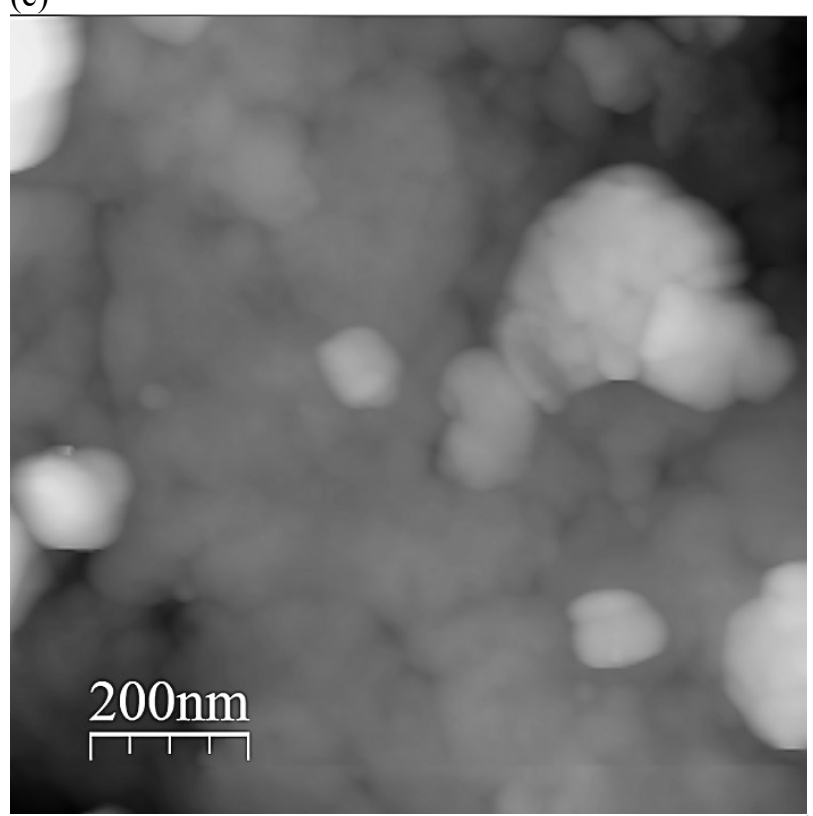

(b)

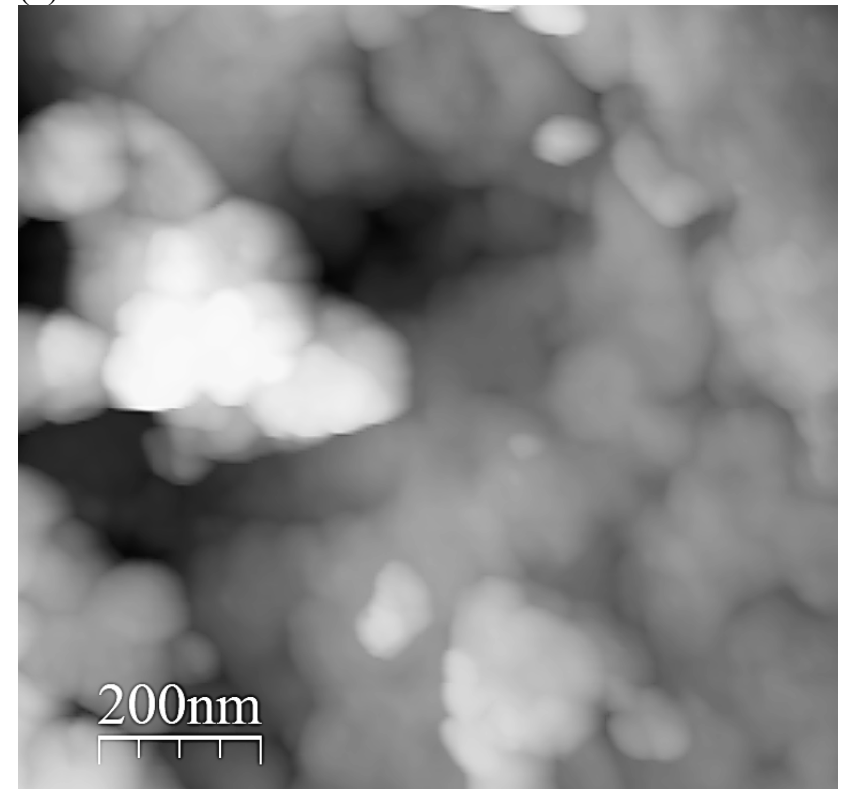

(d)

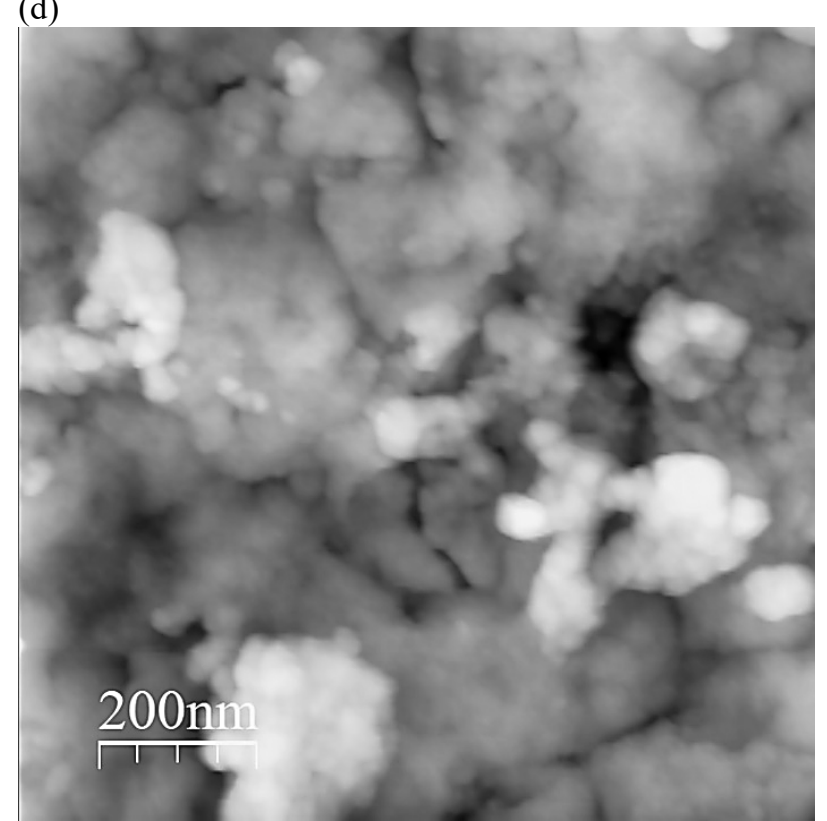

Fig. 16. AFM images of (a) char $\left(S_{\mathrm{BET}}=534 \mathrm{~m}^{2} / \mathrm{g}, V_{\mathrm{p}}=0.902 \mathrm{~cm}^{3} / \mathrm{g}\right)$, and AC with different burnoff degree: (b) $29 \%\left(1042 \mathrm{~m}^{2} / \mathrm{g}, 1.310 \mathrm{~cm}^{3} / \mathrm{g}\right)$, (c) $47 \%\left(1433 \mathrm{~m}^{2} / \mathrm{g}, 1.675 \mathrm{~cm}^{3} / \mathrm{g}\right)$, and (d) $65 \%\left(2019 \mathrm{~m}^{2} / \mathrm{g}, 1.857 \mathrm{~cm}^{3} / \mathrm{g}\right)$; (WSxM5, dev. 10.2 [76] was used to analyze AFM images) 
(a)

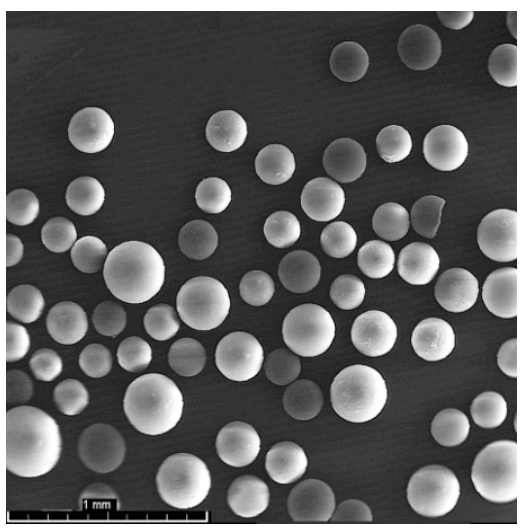

(c)

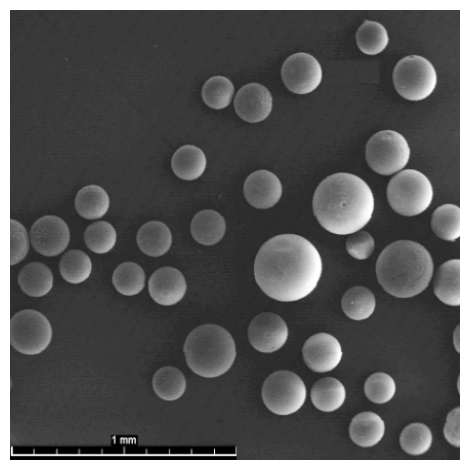

(e)

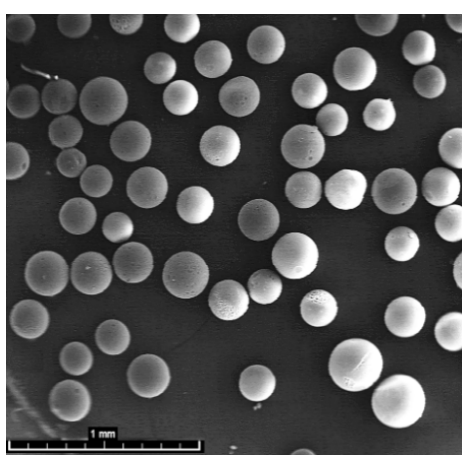

(g)

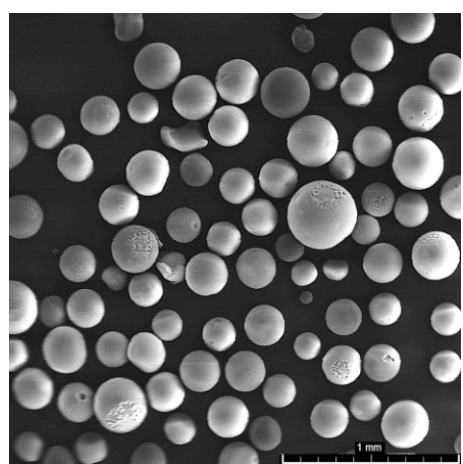

(b)

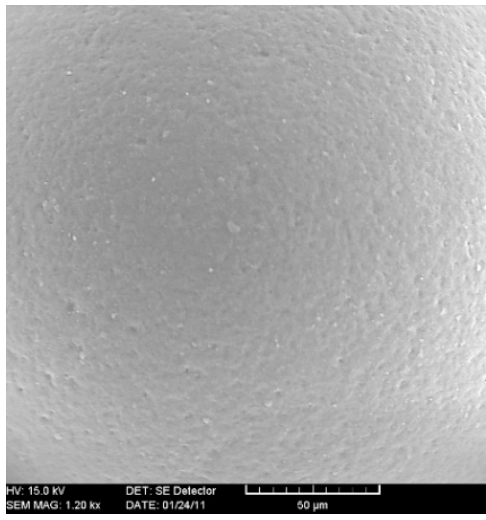

(d)

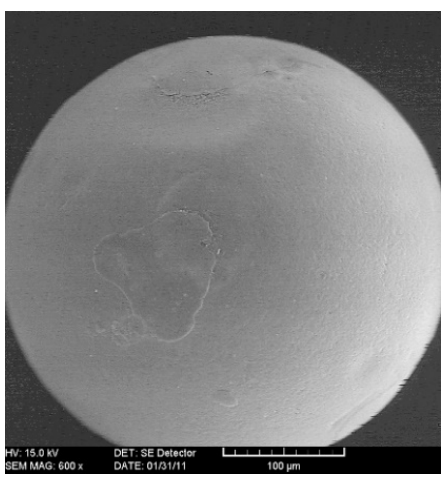

(f)

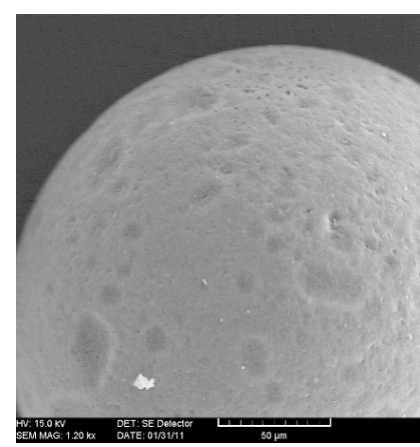

(h)

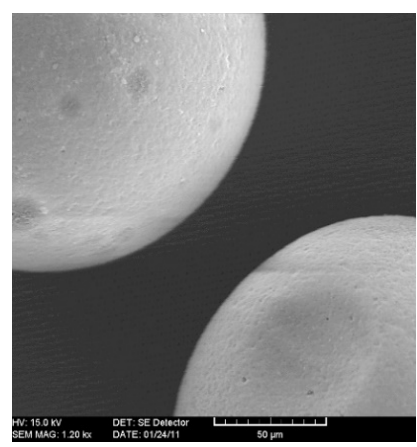

Fig. 17. SEM images of $(\mathrm{a}, \mathrm{b})$ char C-0 $\left(S_{\mathrm{BET}}=534 \mathrm{~m}^{2} / \mathrm{g}, V_{\mathrm{p}}=0.902 \mathrm{~cm}^{3} / \mathrm{g}\right)$, and AC with different burn-off degree: (c, d) $29 \%\left(1042 \mathrm{~m}^{2} / \mathrm{g}, 1.310 \mathrm{~cm}^{3} / \mathrm{g}\right)$, (e, f) $47 \%\left(1433 \mathrm{~m}^{2} / \mathrm{g}, 1.675 \mathrm{~cm}^{3} / \mathrm{g}\right)$, and $(\mathrm{g}, \mathrm{h}) 65 \%\left(2019 \mathrm{~m}^{2} / \mathrm{g}, 1.857 \mathrm{~cm}^{3} / \mathrm{g}\right)$ 
(a)

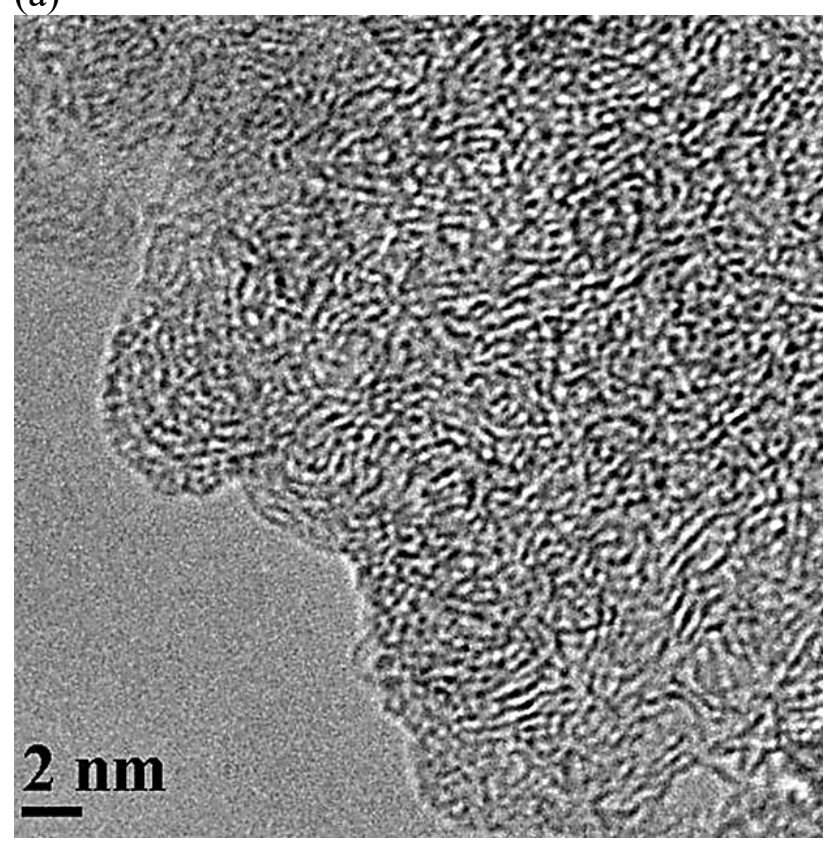

(c)

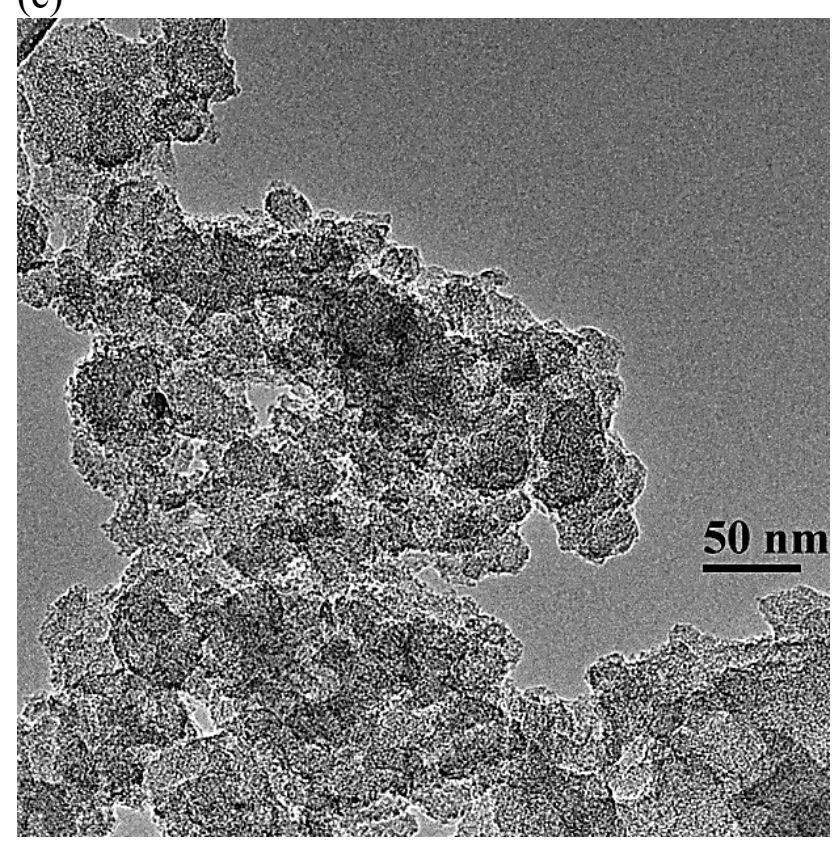

(b)

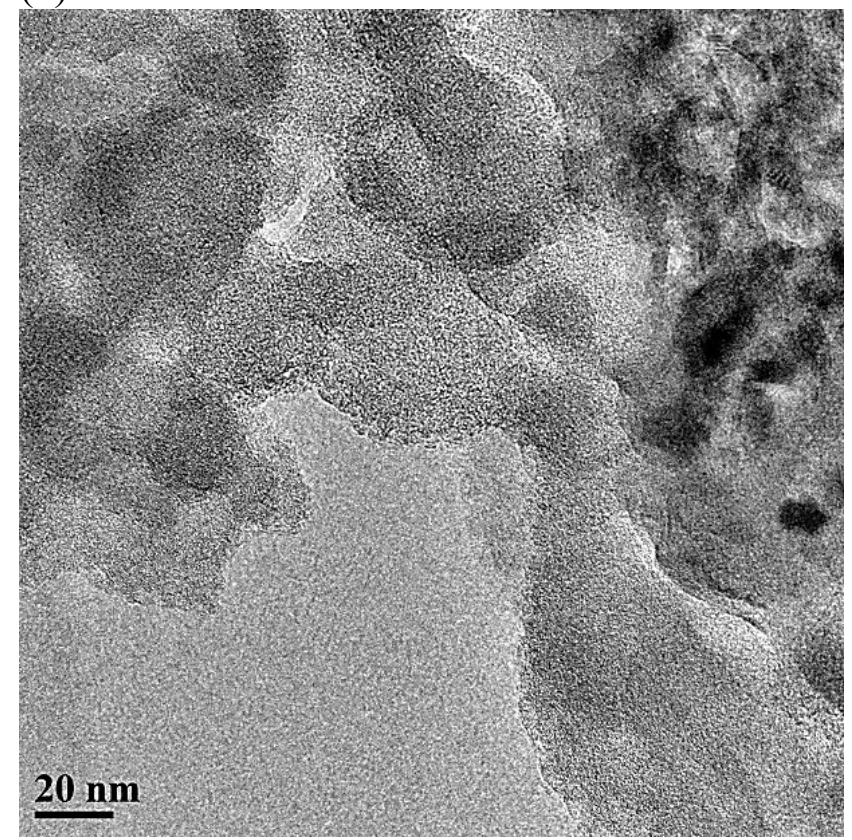

Fig. 18. TEM images of char C-0 with carbonized phenol formaldehyde resin (scale bar (a) $2 \mathrm{~nm}$, (b) $20 \mathrm{~nm}$, and (c) 50 $\mathrm{nm})$ 
(a)

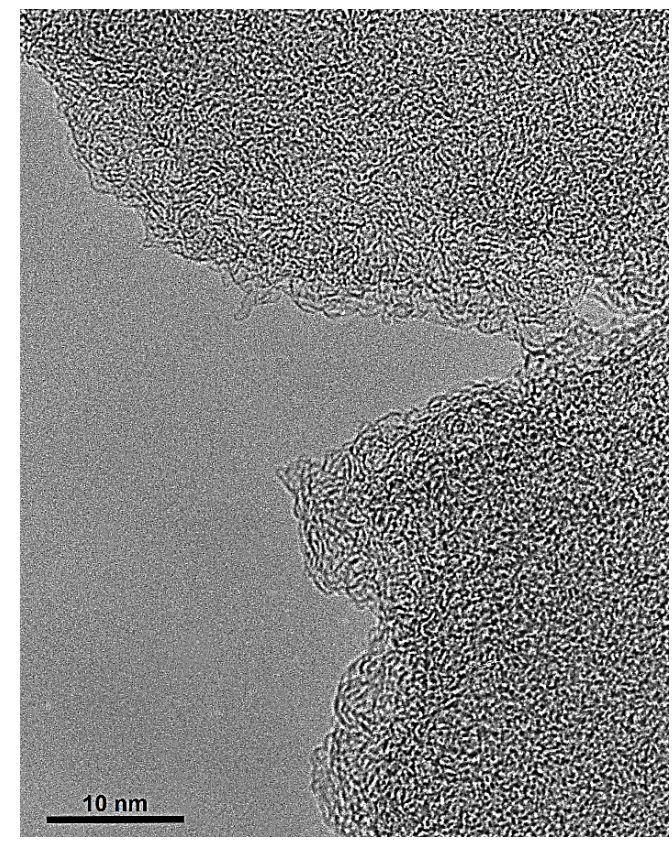

(b)

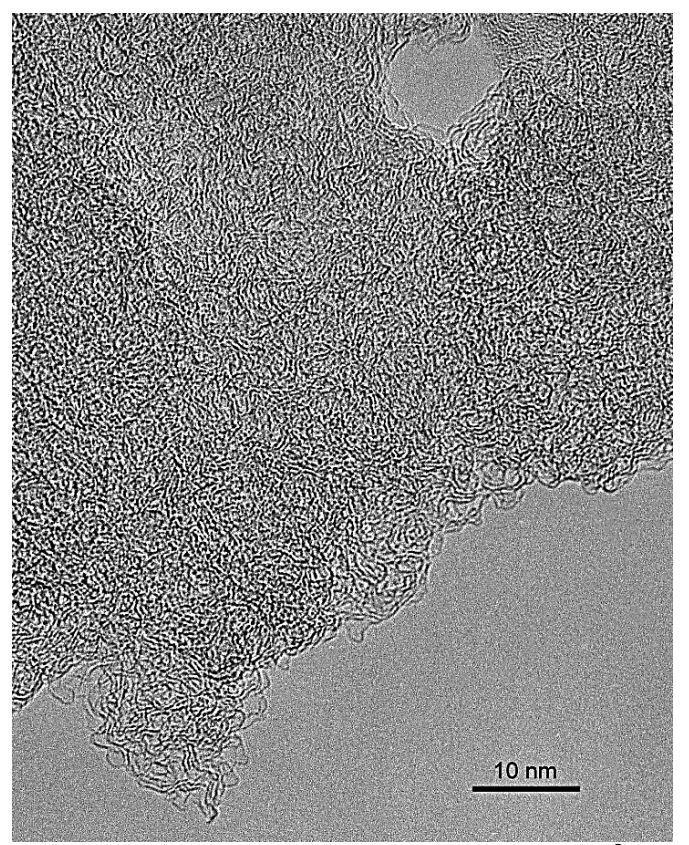

Fig. 19. TEM images of (a) char C-0 (carbonized phenol formaldehyde resin, $S_{\mathrm{BET}}=590 \mathrm{~m}^{2} / \mathrm{g}, V_{\mathrm{p}}=$ $\left.0.950 \mathrm{~cm}^{3} / \mathrm{g}\right)$ and related (b) AC C-50 with $50 \%$ burn-off degree $\left(S_{\mathrm{BET}}=1664 \mathrm{~m}^{2} / \mathrm{g}, V_{\mathrm{p}}=\right.$ $1.486 \mathrm{~cm}^{3} / \mathrm{g}$ )

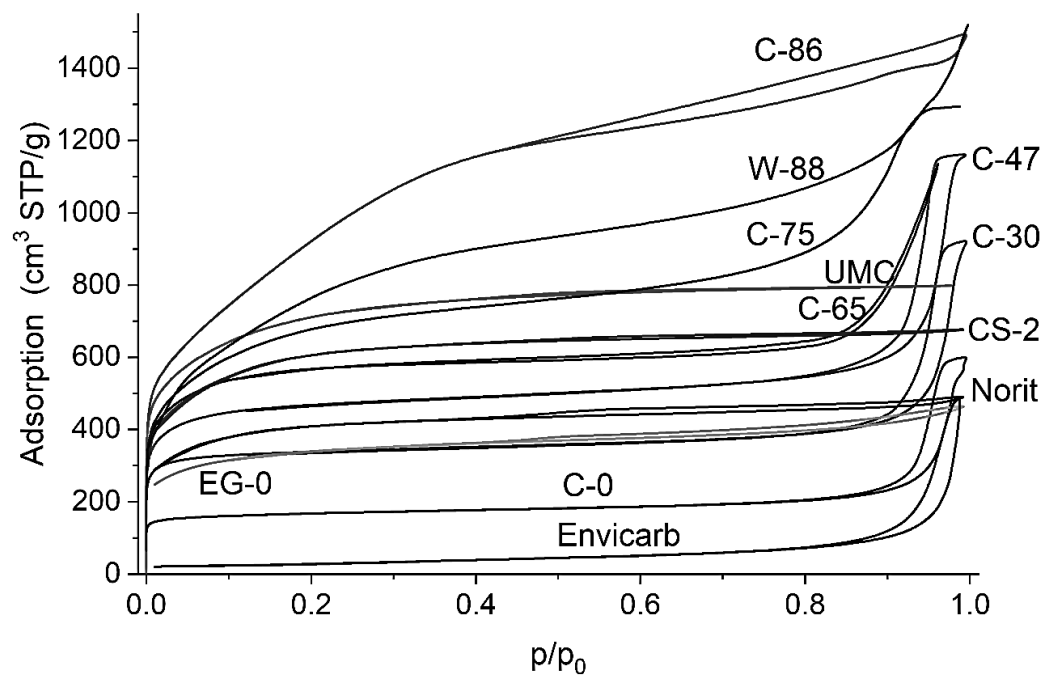

Fig. 20. Nitrogen adsorption-desorption isotherms for $\mathrm{AC}$ prepared by carbonization of phenol formaldehyde resin beads (C-0, $\left.S_{\mathrm{BET}}=549 \mathrm{~m}^{2} / \mathrm{g}, V_{\mathrm{p}}=0.98 \mathrm{~cm}^{3} / \mathrm{g}\right)$ and activated by $\mathrm{CO}_{2}$ at $1183 \mathrm{~K}\left(\mathrm{C}-30,993 \mathrm{~m}^{2} / \mathrm{g}, 1.08 \mathrm{~cm}^{3} / \mathrm{g} ; \mathrm{C}-47,1648 \mathrm{~m}^{2} / \mathrm{g}, 1.88 \mathrm{~cm}^{3} / \mathrm{g} ; \mathrm{C}-65,1840 \mathrm{~m}^{2} / \mathrm{g}, 1.66\right.$ $\left.\mathrm{cm}^{3} / \mathrm{g} ; \mathrm{C}-75,3047 \mathrm{~m}^{2} / \mathrm{g}, 2.35 \mathrm{~cm}^{3} / \mathrm{g} ; \mathrm{C}-86,3463 \mathrm{~m}^{2} / \mathrm{g}, 2.32 \mathrm{~cm}^{3} / \mathrm{g}\right)$ or water vapor $(\mathrm{W}-88$, $\left.2793 \mathrm{~m}^{2} / \mathrm{g}, 2.35 \mathrm{~cm}^{3} / \mathrm{g}\right)$, various AC: Norit R 0.8 Extra $\left(1553 \mathrm{~m}^{2} / \mathrm{g}, 0.80 \mathrm{~cm}^{3} / \mathrm{g}\right)$, CS-2 (coconut shells as a source, $2164 \mathrm{~m}^{2} / \mathrm{g}, 1.04 \mathrm{~cm}^{3} / \mathrm{g}$ ), UMC (ultramicroporous carbon, 2300 $\mathrm{m}^{2} / \mathrm{g}, 1.23 \mathrm{~cm}^{3} / \mathrm{g}$ ), EG-0 (plum stones as source, $1054 \mathrm{~m}^{2} / \mathrm{g}, 0.72 \mathrm{~cm}^{3} / \mathrm{g}$ ), and Envicarb (carbon black, Supelco, $99 \mathrm{~m}^{2} / \mathrm{g}, 0.75 \mathrm{~cm}^{3} / \mathrm{g}$ ) 
There are certain correlations in changes in the textural characteristics of chars and related activated carbons (AC) vs. the degree of burn-off (Tables 1 and 2, Figs. 21 and 22). These correlations may be weak or absent if $\mathrm{AC}$ are prepared using different precursors and chars since the activation results depend not only on the degree of burn-off but also on the chemistry of raw materials and activation agents, as well as on other conditions (treatment time, temperature, pressure, atmosphere, particle sizes, etc.).
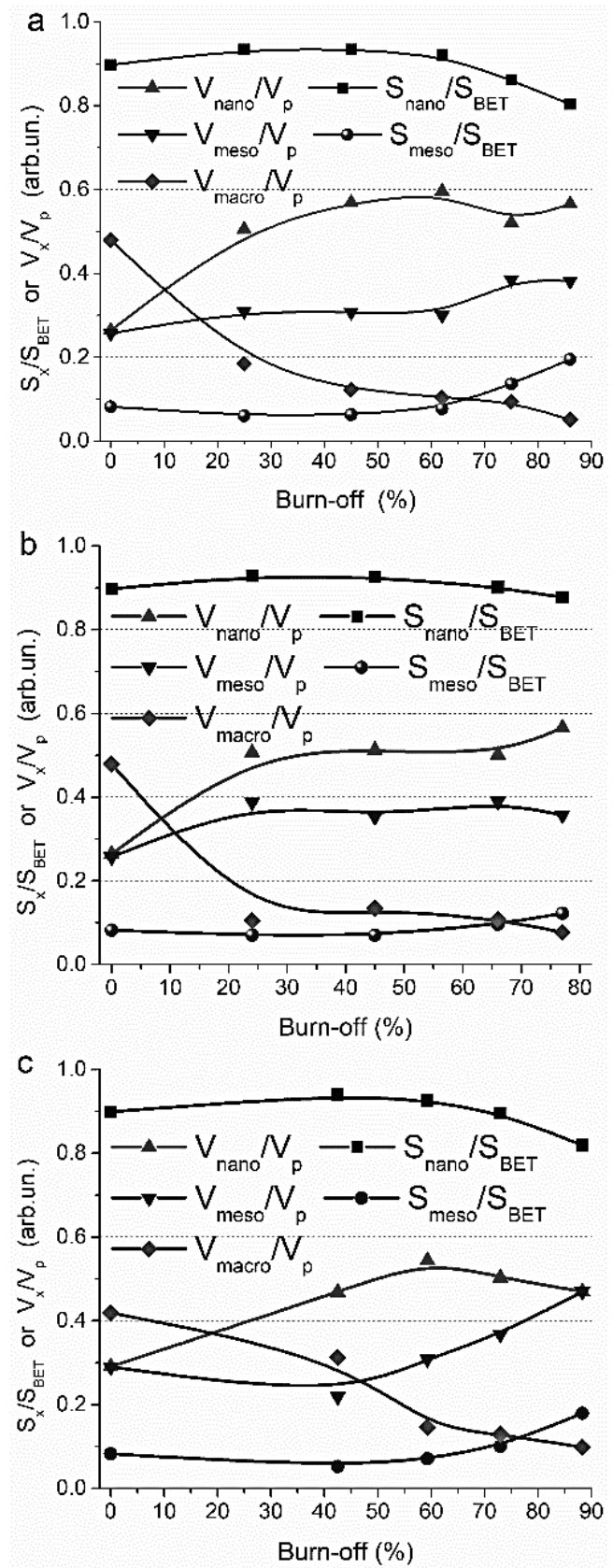

Fig. 21. $S_{x} / S_{\mathrm{BET}}$ and $V_{x} / V_{\mathrm{p}}$ vs. burn-off degree for $\mathrm{AC}$ activated by (a) $\mathrm{CO}_{2}$ and water vapor in (b) fixed and (c) fluidized bed reactors
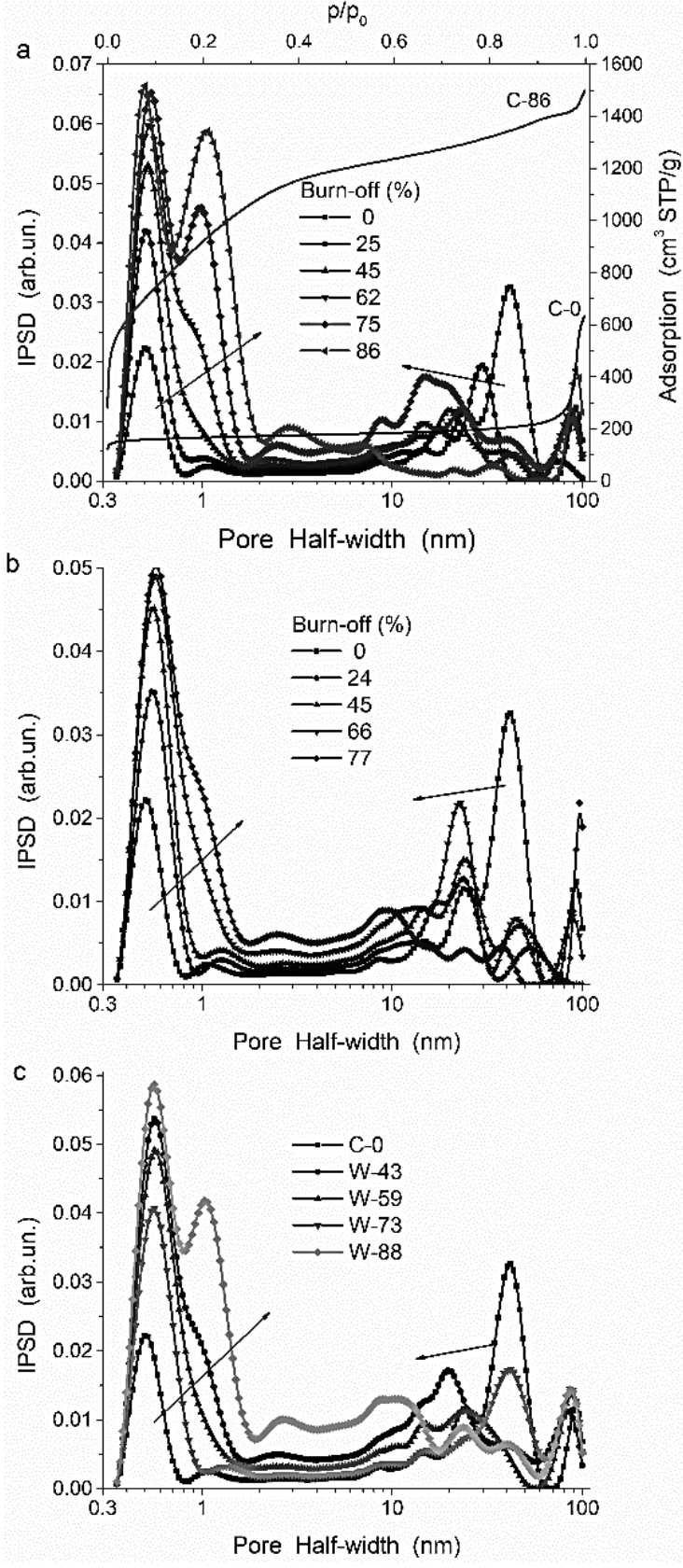

Fig. 22. PSD for $\mathrm{AC}$ activated by (a) $\mathrm{CO}_{2}$ and water vapor in (b) fixed and (c) fluidized bed reactors (DFT/S model); (a) isotherms are shown for $\mathrm{C}-0$ and $\mathrm{C}-86$ 
Carbon materials represent a large set of various systems of different particulate morphology and texture affecting the nitrogen adsorption-desorption isotherms and related PSD (Fig. 23).
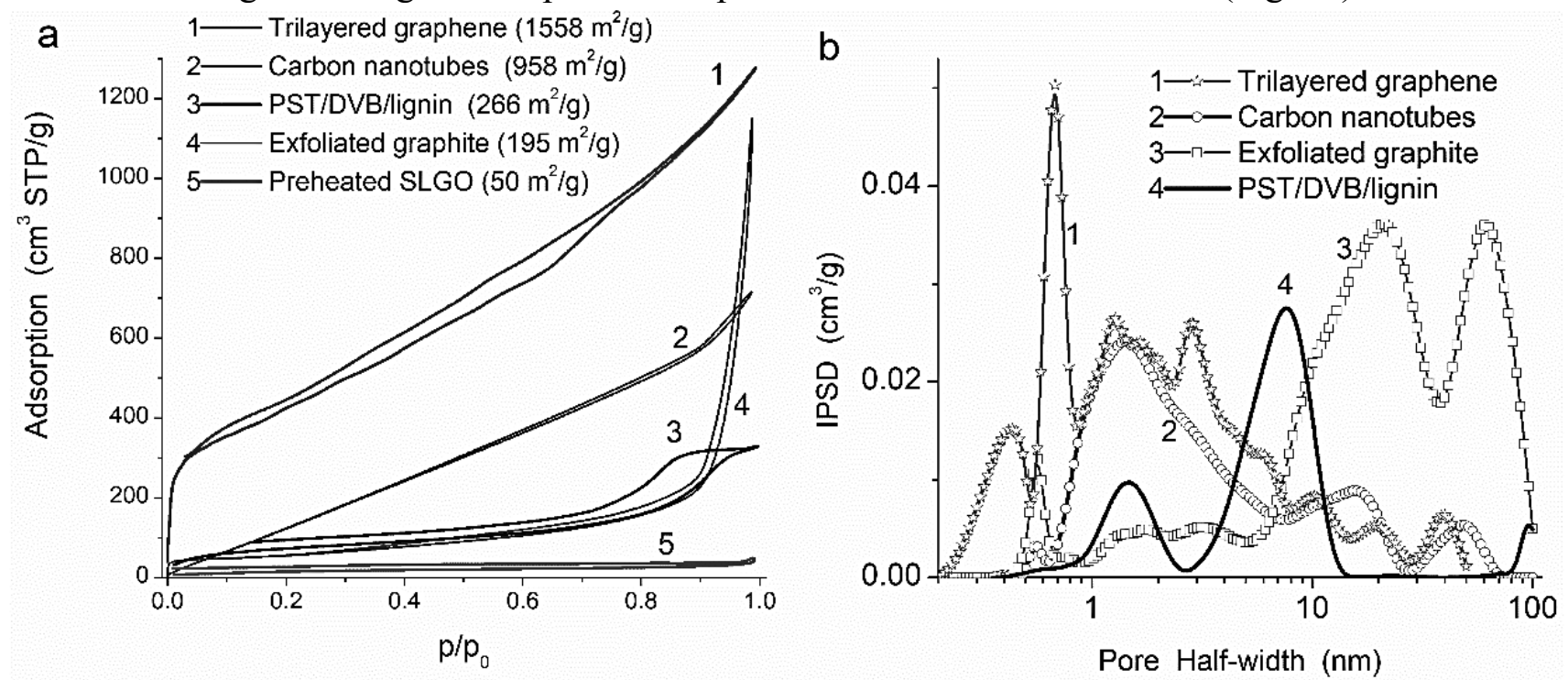

Fig. 23. Texture of nonrigid sorbents: SLGO is the single-layered graphene oxide collapsed due to preheating at $150{ }^{\circ} \mathrm{C}$ for $2 \mathrm{~h}$, polystyrene/divinylbenzene/lignin $(5 \mathrm{wt} . \%$ methacrylatemodified lignin): (a) nitrogen sorption isotherms with long $(1,2,4)$ or open $(3,5)$ hysteresis loops, (b) pore size distributions (MND SCV/SCR).

Table 1. The textural characteristics of activated carbons (carbonization of phenol formaldehyde resin beads with various subsequent activation) $v s$. the burn-off degree (numbers in sample labels)

\begin{tabular}{|l|c|c|c|c|c|c|c|c|}
\hline Sample & $\begin{array}{c}S_{\text {BET }} \\
\mathrm{m}^{2} / \mathrm{g}\end{array}$ & $\begin{array}{c}S_{\text {nano }} \\
\mathrm{m}^{2} / \mathrm{g}\end{array}$ & $\begin{array}{c}S_{\text {meso }} \\
\mathrm{m}^{2} / \mathrm{g}\end{array}$ & $\begin{array}{c}S_{\text {macro }} \\
\mathrm{m}^{2} / \mathrm{g}\end{array}$ & $\begin{array}{c}V_{\mathrm{p}} \\
\mathrm{cm}^{3} / \mathrm{g}\end{array}$ & $\begin{array}{c}V_{\text {nano }} \\
\mathrm{cm}^{3} / \mathrm{g}\end{array}$ & $\begin{array}{c}V_{\text {meso }} \\
\mathrm{cm}^{3} / \mathrm{g}\end{array}$ & $\begin{array}{c}V_{\text {macro }} \\
\mathrm{cm}^{3} / \mathrm{g}\end{array}$ \\
\hline $\mathrm{C}-0$ & 549 & 493 & 45 & 11 & 0.98 & 0.26 & 0.25 & 0.47 \\
\hline $\mathrm{C}-25$ & 1082 & 1011 & 65 & 6 & 1.01 & 0.51 & 0.31 & 0.19 \\
\hline $\mathrm{C}-45$ & 1615 & 1510 & 101 & 4 & 1.32 & 0.75 & 0.41 & 0.16 \\
\hline $\mathrm{C}-62$ & 2270 & 2090 & 175 & 4 & 1.68 & 1.00 & 0.51 & 0.18 \\
\hline $\mathrm{C}-75$ & 3047 & 2626 & 413 & 6 & 2.35 & 1.22 & 0.90 & 0.22 \\
\hline $\mathrm{C}-86$ & 3463 & 2181 & 1279 & 3 & 2.32 & 1.31 & 0.89 & 0.12 \\
\hline $\mathrm{Wf}-24$ & 963 & 894 & 67 & 3 & 0.91 & 0.46 & 0.35 & 0.10 \\
\hline $\mathrm{Wf}-45$ & 1194 & 1199 & 91 & 5 & 1.21 & 0.62 & 0.43 & 0.16 \\
\hline $\mathrm{Wf}-66$ & 1780 & 1606 & 171 & 5 & 1.61 & 0.81 & 0.63 & 0.17 \\
\hline $\mathrm{Wf}-77$ & 2080 & 1826 & 253 & 3 & 1.83 & 0.89 & 0.56 & 0.12 \\
\hline $\mathrm{W}-43$ & 1189 & 1118 & 62 & 9 & 1.24 & 0.58 & 0.27 & 0.39 \\
\hline $\mathrm{W}-59$ & 1677 & 1553 & 118 & 5 & 1.44 & 0.79 & 0.45 & 0.21 \\
\hline $\mathrm{W}-73$ & 2069 & 1855 & 208 & 6 & 1.83 & 0.92 & 0.67 & 0.24 \\
\hline $\mathrm{W}-88$ & 2793 & 2288 & 500 & 6 & 2.35 & 1.11 & 1.11 & 0.23 \\
\hline
\end{tabular}

Note. $\mathrm{C}-i$ activated $\mathrm{CO}, \mathrm{Wf}-i$ and $\mathrm{W}-i$ activated by water vapor in fixed bed and fluidized bed reactors, respectively. Pore ranges: nanopores at $\mathrm{R}<1 \mathrm{~nm}$, mesopores at $1 \mathrm{~nm}<\mathrm{R}<25 \mathrm{~nm}$, and macropores at $\mathrm{R}>25 \mathrm{~nm}$.

The adsorption and SAXS methods give a more comprehensive picture than that obtained within the scope of only one method (Figs. 24-28, Table 2). Addition information could be obtained using microscopic methods (Figs. 14-19). The microscopic images could be treated to obtain quantitative characteristics (e.g., PSD and PaSD) using various software (Figs. 29-32). Additional textural and other information could be obtained using various probe adsorbates (Fig. 33) or estimating energetic characteristics of the probe interactions with adsorbents (Fig. 34). The nitrogen 
adsorption energy depends more strongly on the pore sizes than on the chemical structure of a surface, e.g., the presence of various $\mathrm{O}$-containing functionalities.
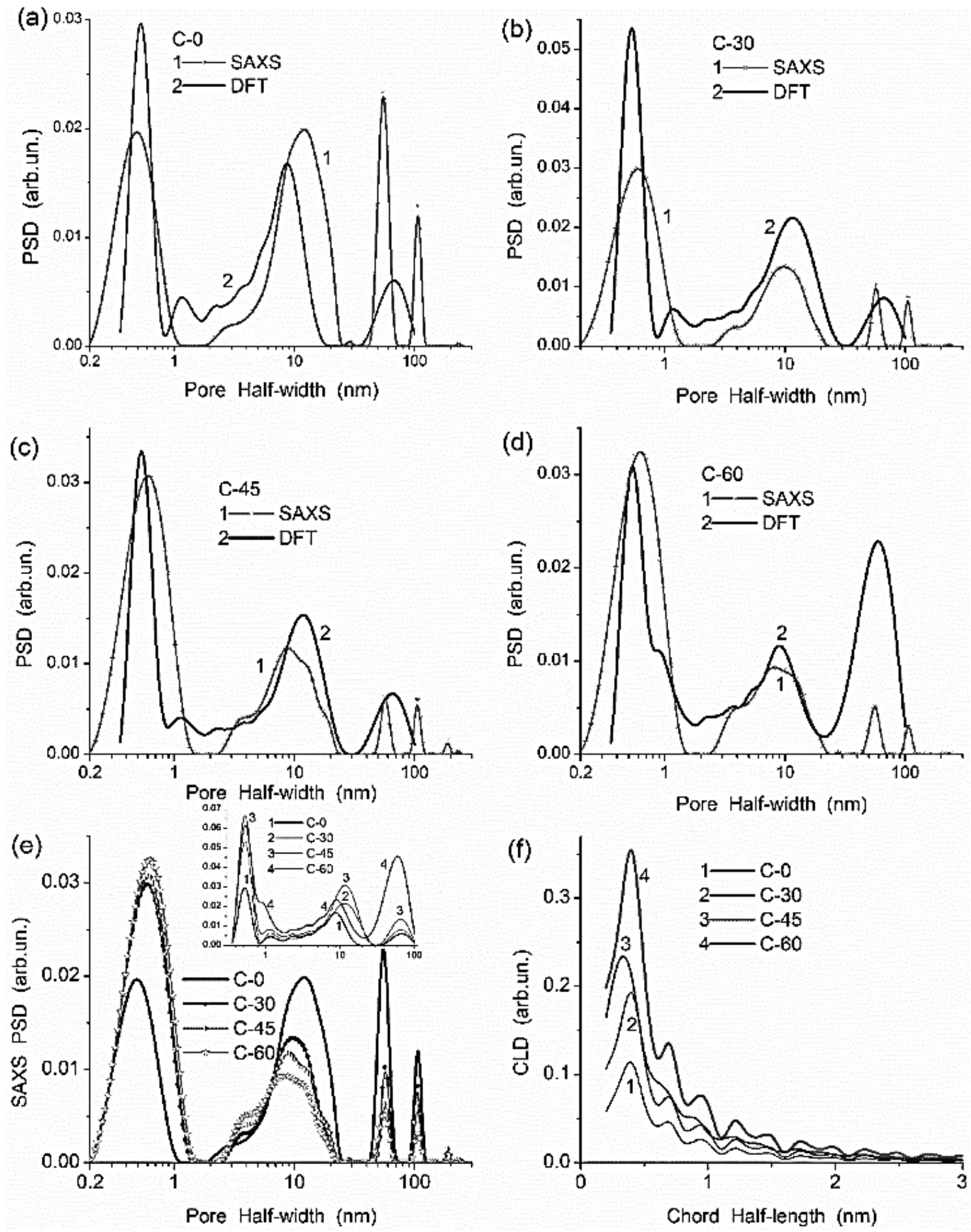

Fig. 24. SAXS and $\mathrm{N}_{2}$ DFT pore size distributions for (a) $\mathrm{C}-0$, (b) $\mathrm{C}-30$, (c) $\mathrm{C}-45$, (d) $\mathrm{C}-60$; and PSD for these AC with (e) SAXS and (insert in e) $\mathrm{N}_{2}$ DFT; and (f) chord length distributions. 

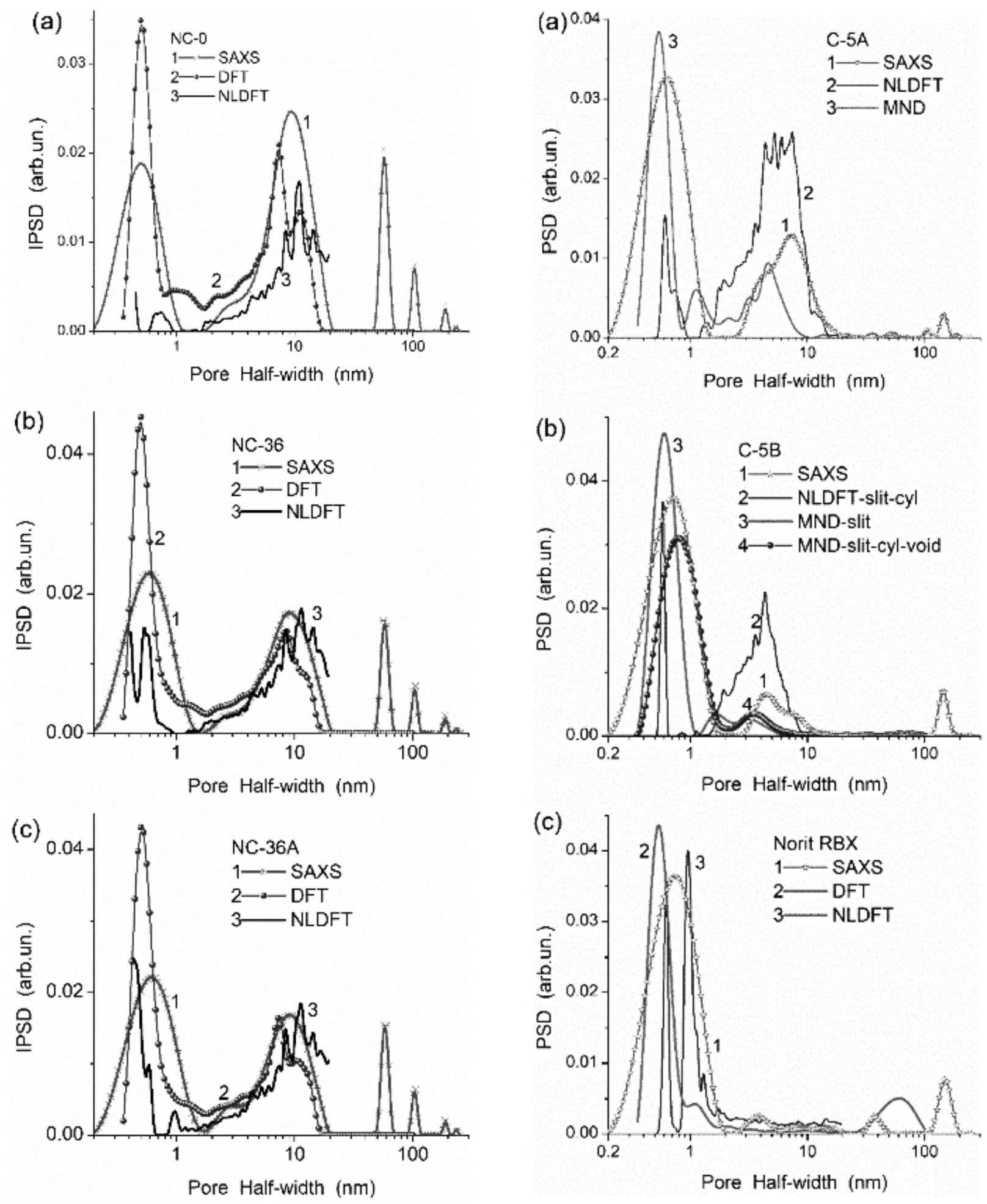

Fig. 25. SAXS and $\mathrm{N}_{2}$ DFT and NLDFT pore size distributions for (a) $\mathrm{NC}-0$, (b) $\mathrm{NC}-36$, and (c) $\mathrm{NC}-36 \mathrm{~A}$

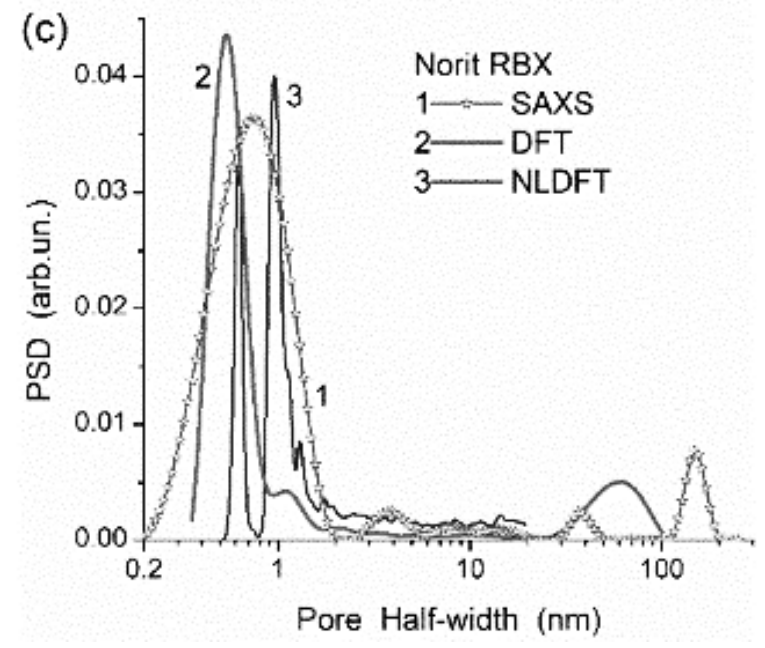

Fig. 26. $S A X S$ and $\mathrm{N}_{2}$ MND (slit or SCV model of pores) or DFT (slit), and NLDFT (SC) pore size distributions for (a) C-5A, (b) $\mathrm{C}-5 \mathrm{~B}$, and (c) Norit RBX 
Table 2. Textural characteristics of chars (carbonized phenol formaldehyde resin) and activated carbons.

\begin{tabular}{|c|c|c|c|c|c|c|c|}
\hline Sample & $\begin{array}{c}S_{\text {BET }} \\
\mathrm{m}^{2} / \mathrm{g}\end{array}$ & $\begin{array}{c}S_{\mathrm{SAXS}} \\
\mathrm{m}^{2} / \mathrm{g}\end{array}$ & $\begin{array}{c}S_{\text {nano }} \\
\mathrm{m}^{2} / \mathrm{g}\end{array}$ & $\begin{array}{c}S_{\text {meso }} \\
\mathrm{m}^{2} / \mathrm{g}\end{array}$ & $\begin{array}{c}S_{\text {macro }} \\
\mathrm{m}^{2} / \mathrm{g}\end{array}$ & $\begin{array}{c}V_{\mathrm{p}} \\
\mathrm{cm}^{3} / \mathrm{g}\end{array}$ & $\begin{array}{c}V_{\text {nano }} \\
\mathrm{cm}^{3} / \mathrm{g}\end{array}$ \\
\hline $\mathrm{C}-0$ & 568 & 611 & 486 & 81 & 1 & 0.65 & 0.25 \\
\hline $\mathrm{C}-30$ & 993 & 1081 & 884 & 108 & 2 & 1.08 & 0.45 \\
\hline $\mathrm{C}-45$ & 1351 & 1631 & 1205 & 144 & 3 & 1.44 & 0.59 \\
\hline $\mathrm{C}-60$ & 1999 & 2211 & 1729 & 250 & 19 & 1.97 & 0.66 \\
\hline & & & 1772 & 202 & 19 & 1.97 & 0.57 \\
\hline & & & 1125 & 860 & 13 & 1.97 & 0.42 \\
\hline $\mathrm{NC}-0$ & & & 1400 & 590 & 9 & 1.97 & 0.59 \\
\hline $\mathrm{NC}-36$ & 1158 & 1346 & 1046 & 112 & 0 & 0.65 & 0.29 \\
\hline $\mathrm{NC}-36 \mathrm{~A}-5 \mathrm{~A}$ & 1173 & 1268 & 1055 & 119 & 0 & 1.05 & 0.56 \\
\hline & 747 & 904 & 702 & 45 & 0 & 0.49 & 0.56 \\
\hline $\mathrm{C}-5 \mathrm{~B}$ & & & 610 & 137 & 0 & 0.49 & 0.27 \\
\hline Norit RBX & 1029 & 1120 & 996 & 31 & 2 & 0.51 & 0.47 \\
\hline & & & 793 & 235 & 0 & 0.51 & 0.31 \\
\hline
\end{tabular}

Continuation of table 2

\begin{tabular}{|c|c|c|c|c|c|c|}
\hline Sample & $\begin{array}{c}V_{\text {meso }} \\
\mathrm{cm}^{3} / \mathrm{g}\end{array}$ & $\begin{array}{c}V_{\text {macro }} \\
\mathrm{cm}^{3} / \mathrm{g}\end{array}$ & $\Delta w$ & Pore model & Method & Material \\
\hline $\mathrm{C}-0$ & 0.34 & 0.07 & 0.075 & Slit & DFT & Char \\
\hline $\mathrm{C}-30$ & 0.54 & 0.09 & 0.079 & Slit & DFT & AC \\
\hline $\mathrm{C}-45$ & 0.69 & 0.16 & 0.138 & Slit & DFT & AC \\
\hline $\mathrm{C}-60$ & 0.64 & 0.67 & 0.561 & Slit & DFT & AC \\
& 0.96 & 0.44 & 0.065 & Cyl & DFT & \\
\hline & 1.22 & 0.33 & 0.051 & Cyl & MND & \\
\hline NC-0 & 1.18 & 0.20 & 0.264 & S/C/V & MND & Char \\
\hline NC-36 & 0.37 & 0 & -0.029 & Slit & DFT & AC \\
\hline NC-36A & 0.47 & 0 & 0.014 & Slit & DFT & AC \\
\hline C-5A & 0.49 & 0 & 0.040 & Slit & DFT & AC \\
\hline & 0.12 & 0 & 0.028 & Slit & DFT & AC \\
\hline C-5B & 0.04 & 0.001 & 0.059 & Slit & DFT & AC \\
\hline Norit RBX & 0.04 & 0.07 & 0.417 & Slit & DFT & \\
\hline & 0.19 & 0.01 & -0.037 & Cyl & MND & \\
\hline
\end{tabular}

Note. $\Delta w$ is the relative deviation of the pore shape from the model (slitshaped - slit, cylindrical - cyl, slit-shaped and cylindrical pores and voids between spherical particles $-\mathrm{SCV}$ ). The $S_{\text {nano }}, S_{\text {meso }}$, and $S_{\text {macro }}$ values have been normalized that $S_{\text {nano }}+S_{\text {meso }}+S_{\text {macro }}=S_{\mathrm{BET}}$. *Relative contributions of slit-shaped and cylindrical pores and voids between nanoparticles are $0.616,0.302$ and 0.082 , respectively, for $\mathrm{C}-60$. 


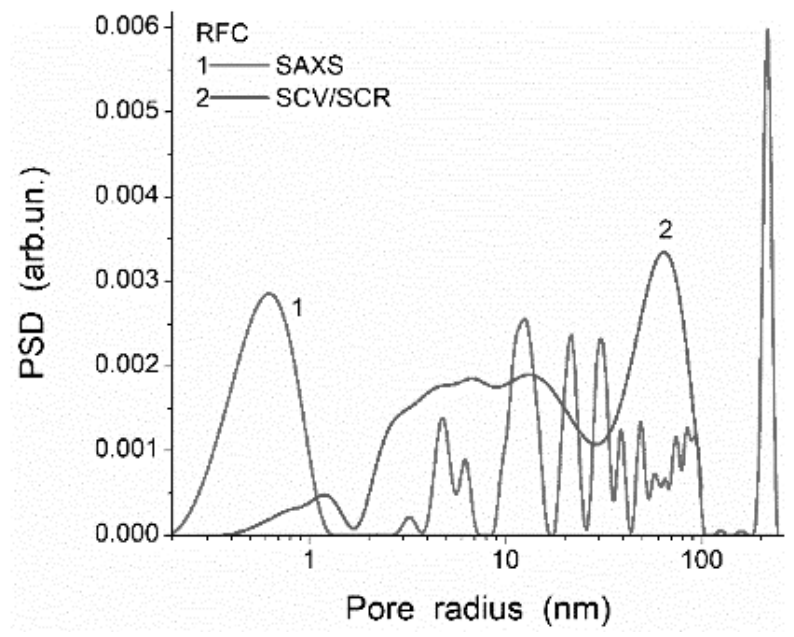

Fig. 27. PSD of a char/bentonite $(20 / 80 \mathrm{w} / \mathrm{w})$ composite $\left(S_{\mathrm{BET}}=122 \mathrm{~m}^{2} / \mathrm{g}\right.$ and $S_{\mathrm{SAXS}}=$ $262 \mathrm{~m}^{2} / \mathrm{g}$ ), prepared upon carbonization of RFR added to bentonite, computed using SAXS and SCV/SCR methods.

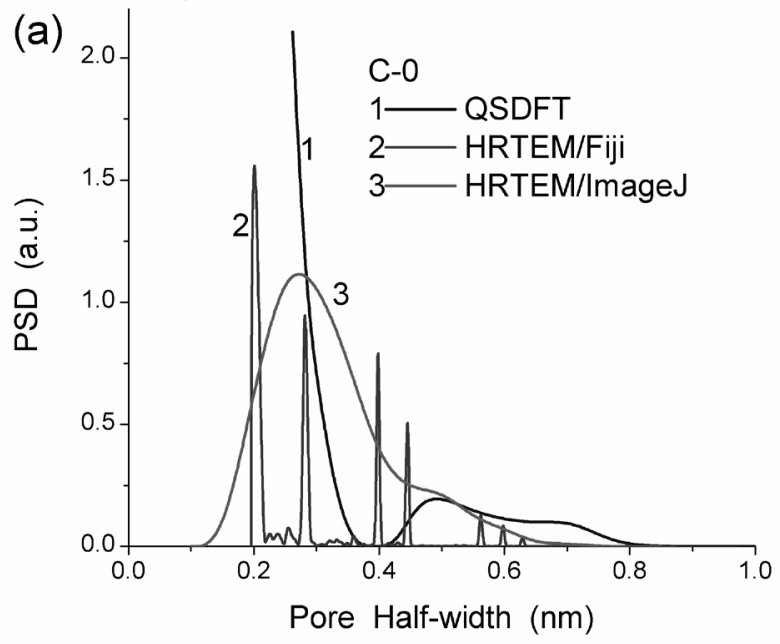

Fig. 29. Pore size distributions for (a) $\mathrm{C}-0$ and

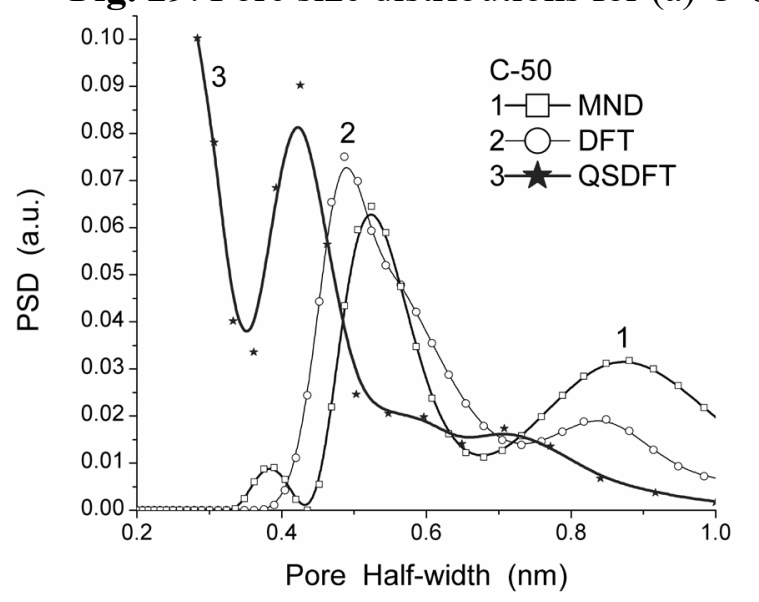

Fig. 30. Comparison of the PSDs of C-50 calculated using different methods with the slit-shaped pore model.

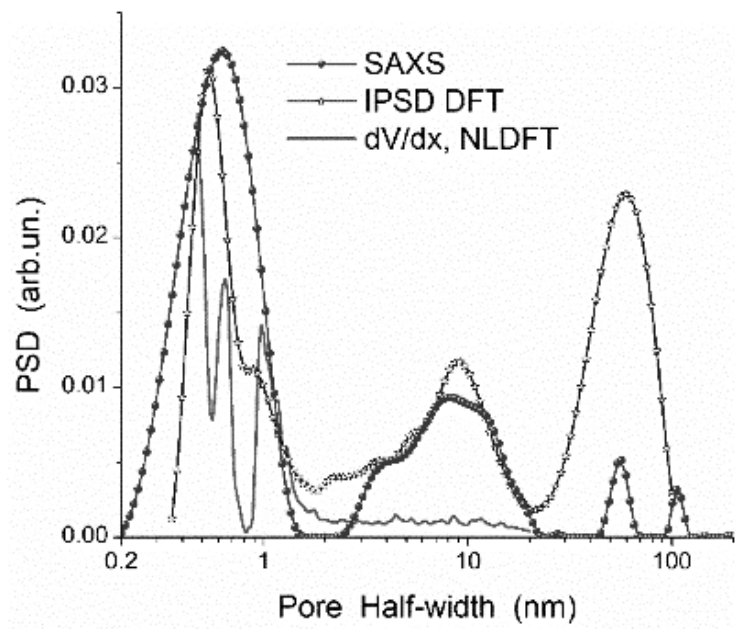

Fig. 28. PSD of AC (carbonized phenol formaldehyde resin activated by $\mathrm{CO}_{2}$ at $1183 \mathrm{~K}$ with $60 \%$ burn-off, $S_{\mathrm{BET}}=1999$ $\mathrm{m}^{2} / \mathrm{g}$ and $S_{\mathrm{SAXS}}=2211 \mathrm{~m}^{2} / \mathrm{g}$ ) computed using SAXS, DFT and NLDFT methods

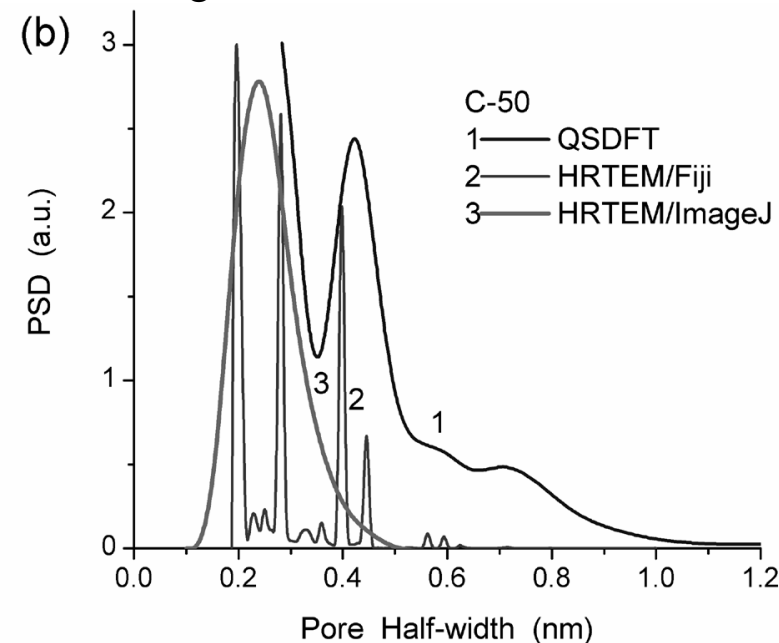

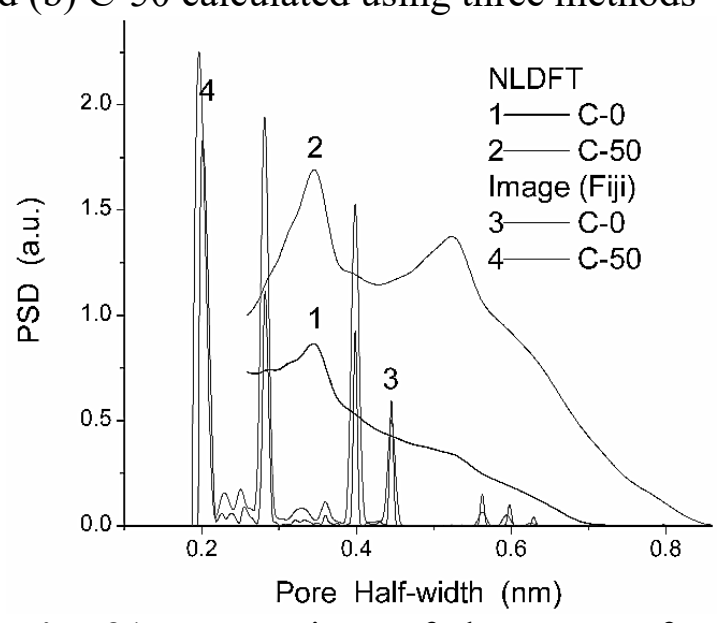

Fig. 31. Comparison of the PSDs of C-0 and C-50 based on nitrogen adsorption (NLDFT) and HRTEM image (Fig. 19) analysis (Fiji/local thickness https://imagej.net/software/fiji/) 

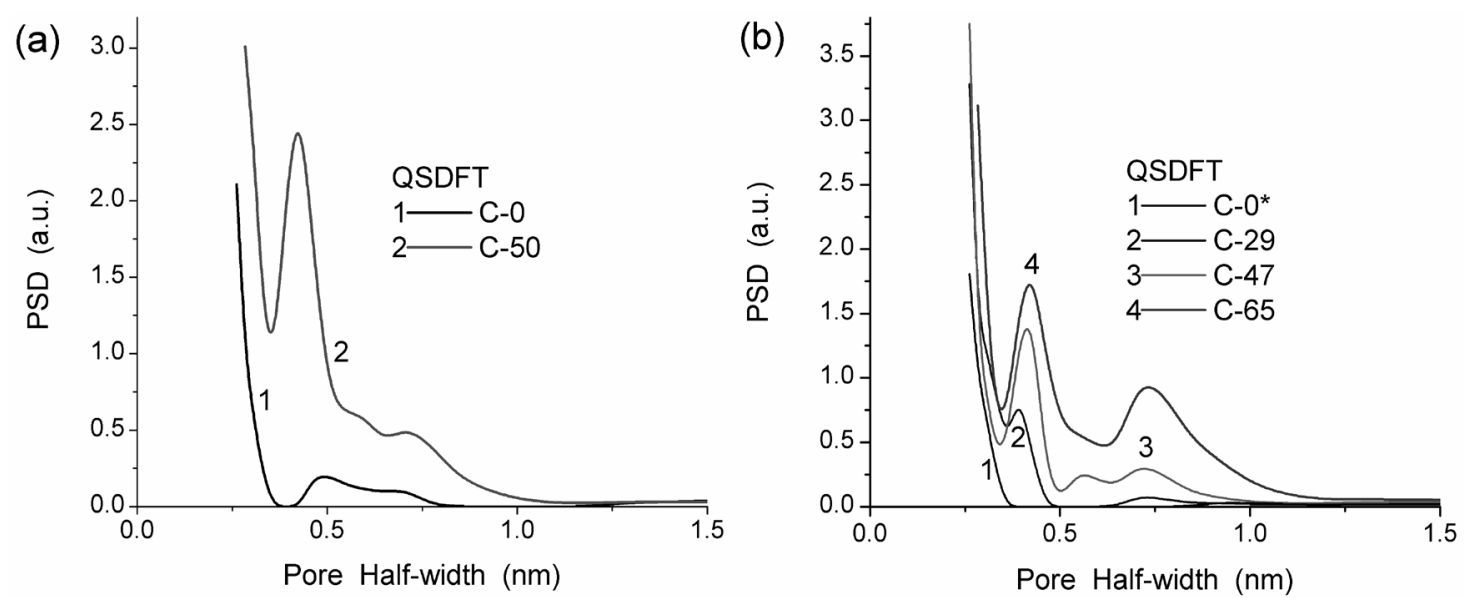

Fig. 32. QSDFT PSDs of (a) C-0 and C-50, and (b) C- $0 *$ and ACs with different burn-off degree.
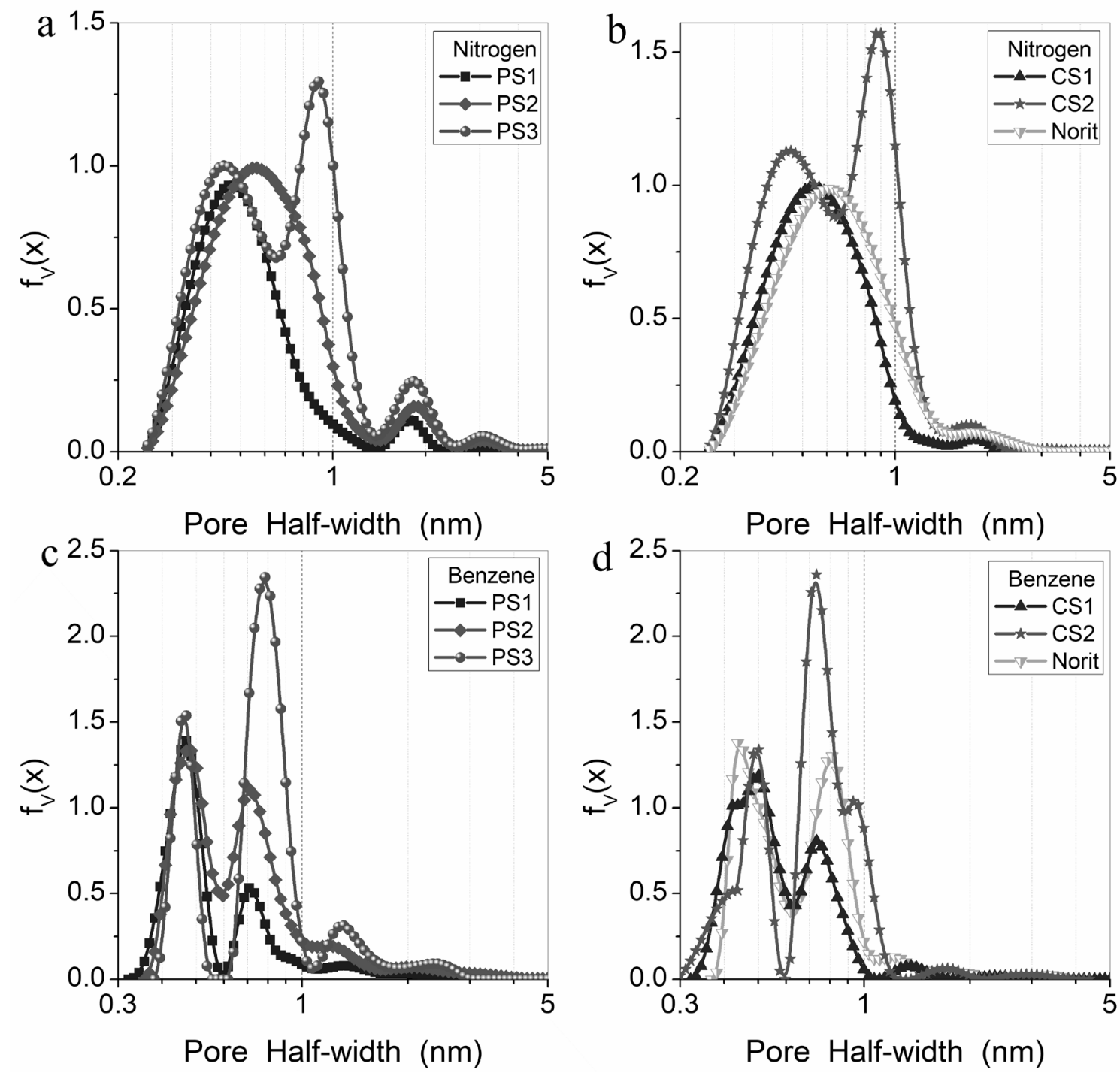

Fig. 33. Textural characteristics of various $A C$ estimated from nitrogen $(a, b)$ and benzene $(c, d)$ adsorption (PSD are probe dependent).

To calculate the adsorption energy distribution functions, the Fowler-Guggenheim (FG) equation was used to describe localized monolayer adsorption with lateral interactions $[4,13,37]$ :

$$
\theta_{i}(p, E)=\frac{K p \exp \left(z w \Theta / k_{B} T\right)}{1+K p \exp \left(z w \Theta / k_{B} T\right)},
$$


where $K=K_{0}(T) \exp \left(E / k_{B} T\right)$ is the Langmuir constant for adsorption on energetically uniformed sites and the pre-exponential factor $K_{0}(T)$ is expressed in terms of the partition functions for isolated gas and surface phases, $z$ is the number of nearest neighbors of an adsorbate molecule (assuming $z=4$ ), $w$ is the interaction energy between a pair of nearest neighbors, $k_{B}$ is the Boltzmann constant, e.g., $z w / k_{B}=380 \mathrm{~K}$ for nitrogen. The right term of Eq. (18) was used as the kernel in the overall adsorption isotherm equation to calculate the distribution function $f(E)$ of the nitrogen adsorption energy.

(a)

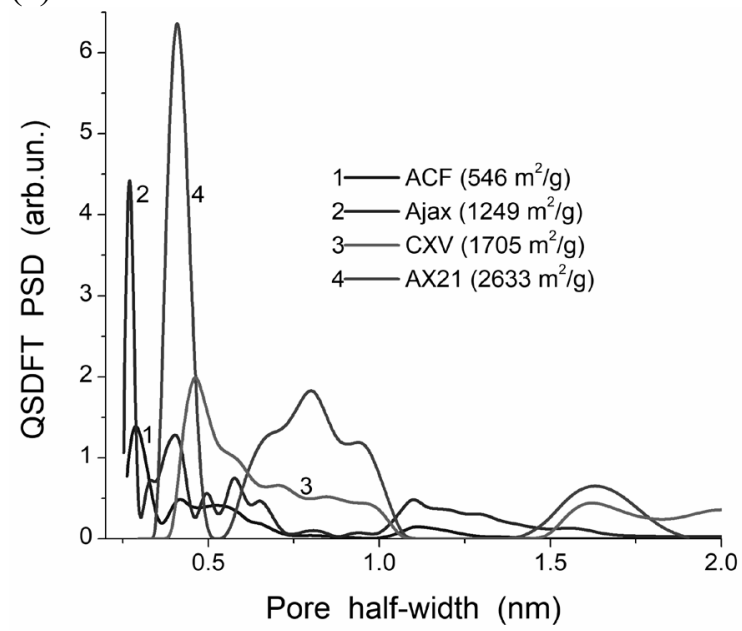

(b)

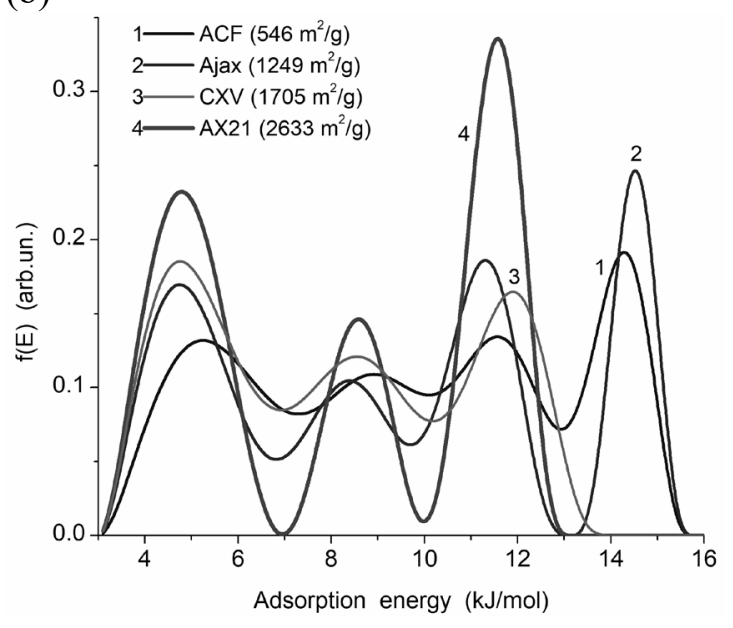

Fig. 34. (a) QSDFT PSD of carbons and (b) nitrogen adsorption energy distributions.

Carbons represent a large variety of porous or nanostructured materials such as exfoliated and oxidized graphite, graphene, graphene oxide, AC, carbon blacks, carbon nanotubes (CNT), fullerenes, and fullerites characterized by very different particulate morphology and texture [1,4,11-13,25-30,32,37-39,82,83]. The carbon materials can be divided into several classes with respect to their particulate morphology and porosity. First, purely nanoporous AC (microporous according to IUPAC; however, microporous nanoparticles are rather nonsense term, since micro is $10^{-6}$ and nano is $10^{-9}$, i.e., smaller one includes larger one) characterized by the nitrogen adsorption-desorption isotherms with a plateau onset at relatively low pressures $p / p_{0}=0.20-0.25$ without a hysteresis loop (Fig. 20). Second, nano/mesoporous AC (biporous, Figs. 23-33) with nanopores $(R \leq 1 \mathrm{~nm})$ and narrow mesopores $(<3 \mathrm{~nm})$ characterized by nearly horizontal plateau (plateau onset shifts toward higher pressures) and narrow hysteresis loops. Third, nano/meso/microporous AC characterized by broad hysteresis loops (onset at $p / p_{0}>0.8$ ) and broad PSD (Figs. 24-30). Thus, AC practically always include nanopores as the main attribute. Other types of carbons, e.g., carbon blacks, exfoliated graphite, CNT, etc., can be mesoporous or meso/microporous without nanopores [11-13,25-30,37,38]. One of the main differences in the particulate morphology and texture of carbons and silicas is that closed pores are present in carbons (especially in nonactivated chars) but practically absent in silicas. This is caused by the differences in the pore formation processes in these materials, since carbonization reactions can occur both inside and at outer surface of particles, but for silicas, the formation of subsequent layers occurs only at a surface of nuclei and primary particles. Therefore, a complete characterization of the particulate morphology and texture of carbons could be more complex than that of silicas, especially fumed silicas composed of NPNP synthesized at high temperatures. Therefore, the use of several methods, which are appropriate for describing both open and closed pores in carbons, is preferable. The morphological/textural features for chars and AC could be very different. For example, comparison of the SAXS and adsorption data for a char (Fig. 27) and $\mathrm{AC}$ (Fig. 28) shows that the difference strongly decreases for AC due to opening a significant part of closed pores (in abundance present in chars) during activation. 
(a)

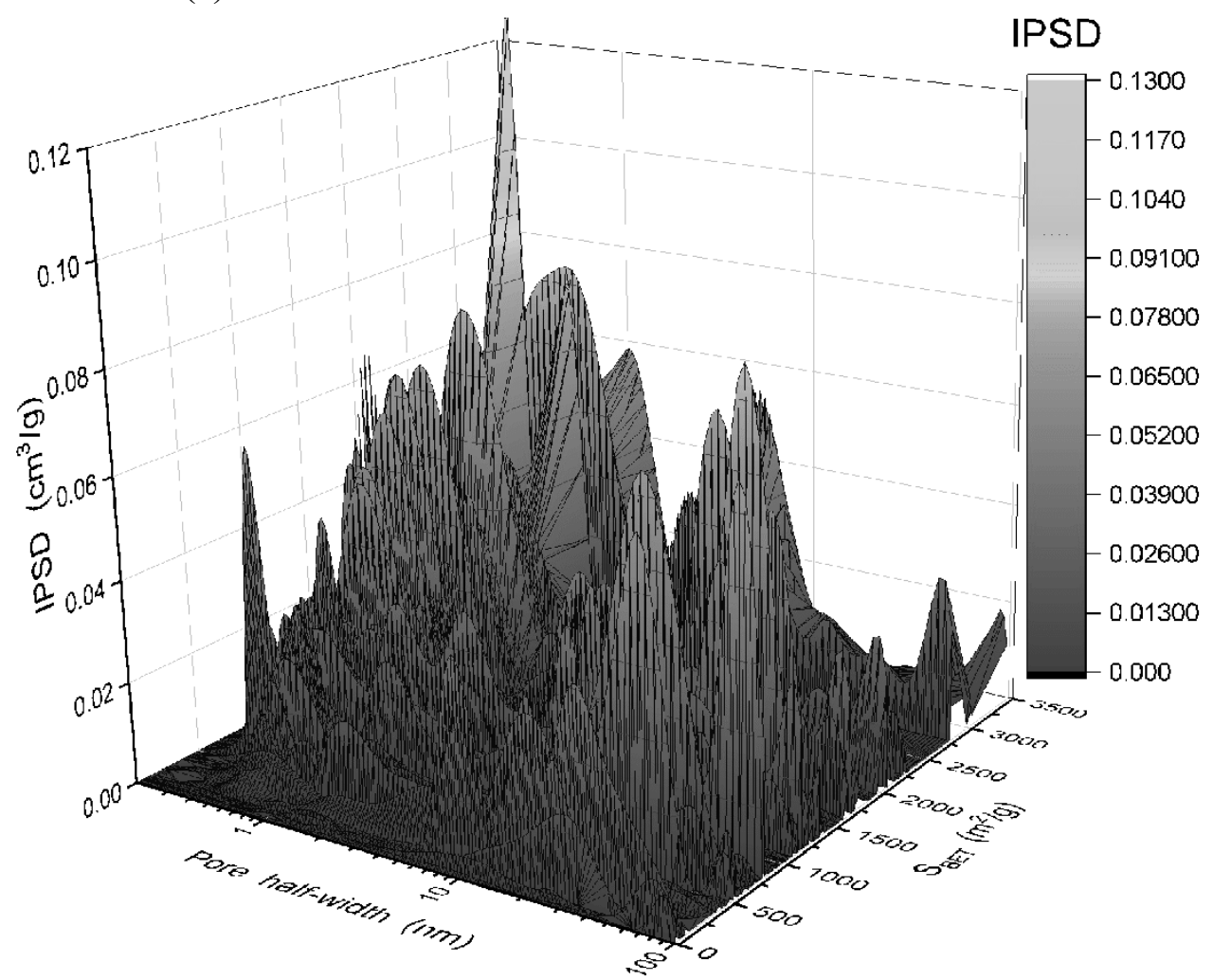

(b)

IPSD

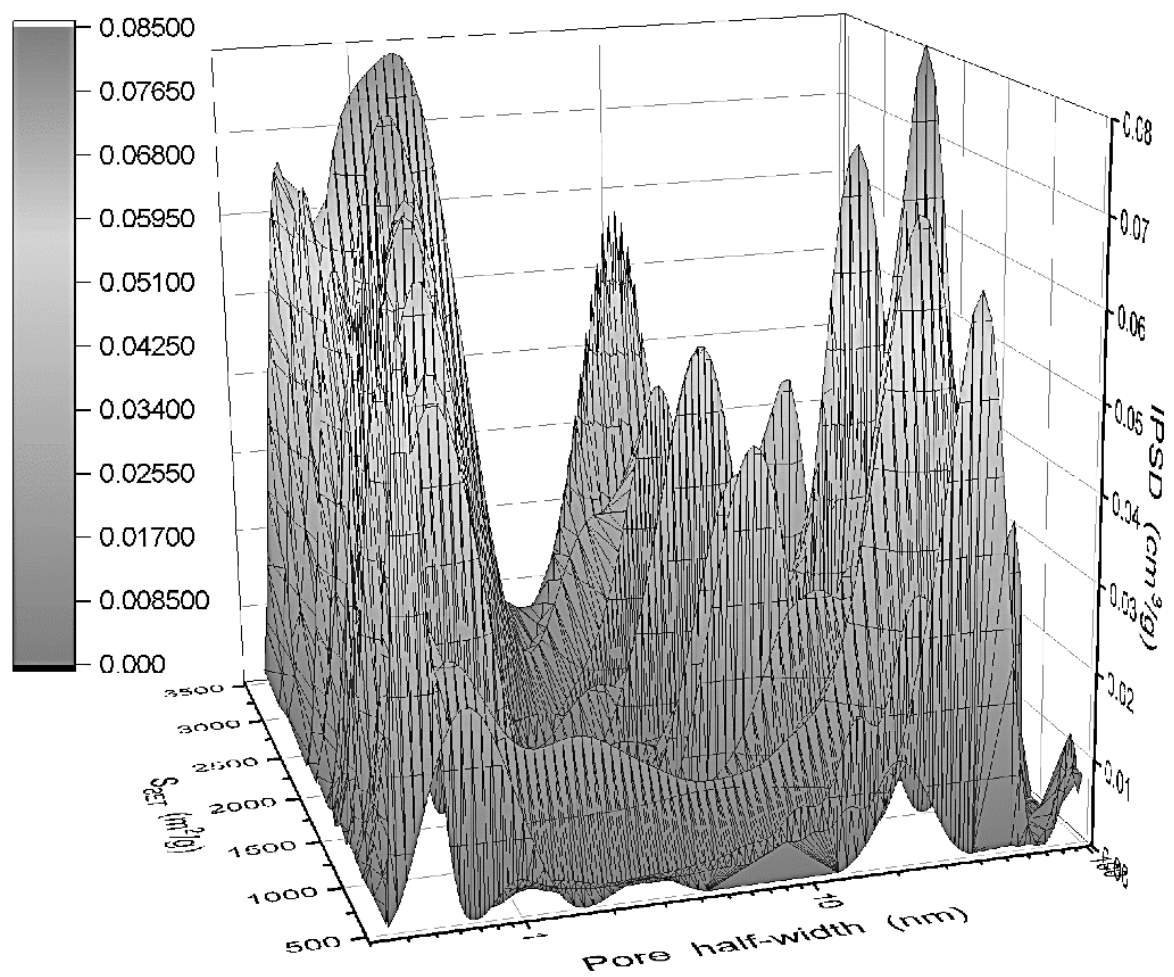

Fig. 35. DFT SCV/SCR IPSD for various carbons (a) 230 samples and (b) 29 samples prepared using phenol formaldehyde resin beads as precursors carbonized in a $\mathrm{CO}_{2}$ flow to $1073 \mathrm{~K}$ and char activated with $\mathrm{CO}_{2}$ (at $1183 \mathrm{~K}$ ) or $\mathrm{H}_{2} \mathrm{O}$ (in a fixed bed reactor at $1183 \mathrm{~K}$ or in a fluidized bed reactor at $1020-1050 \mathrm{~K}$ ) 
For carbons, the PSD could be broad with contributions of nano-, meso-, and macropores (Figs. 20-34). The textural features depending on the degree of burn-off are more clearly visible for AC produced using the same precursors and chars (Figs. 21 and 22, Table 1 and 2). Contribution of narrow mesopores of 3-5 nm in size is small for all carbons (Fig. 35). A similar result is observed for fumed silicas (Fig. 9), but it is absent for porous silicas (Fig. 13). This result for carbons and fumed silicas can be explained by features of voids (NP packing characteristics, see microscopic images above) between PNP and NPNP, respectively. For AC, pores at $R<2-3$ $\mathrm{nm}$ are in PNP, but pores at $R>5 \mathrm{~nm}$ are voids between PNP.

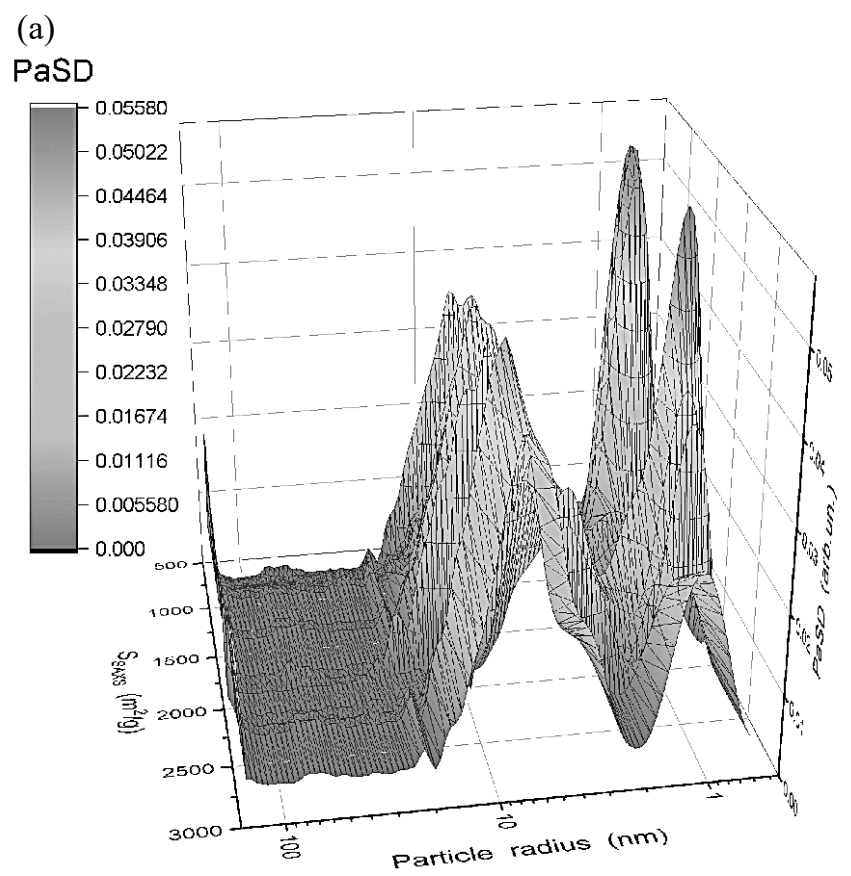

(b)

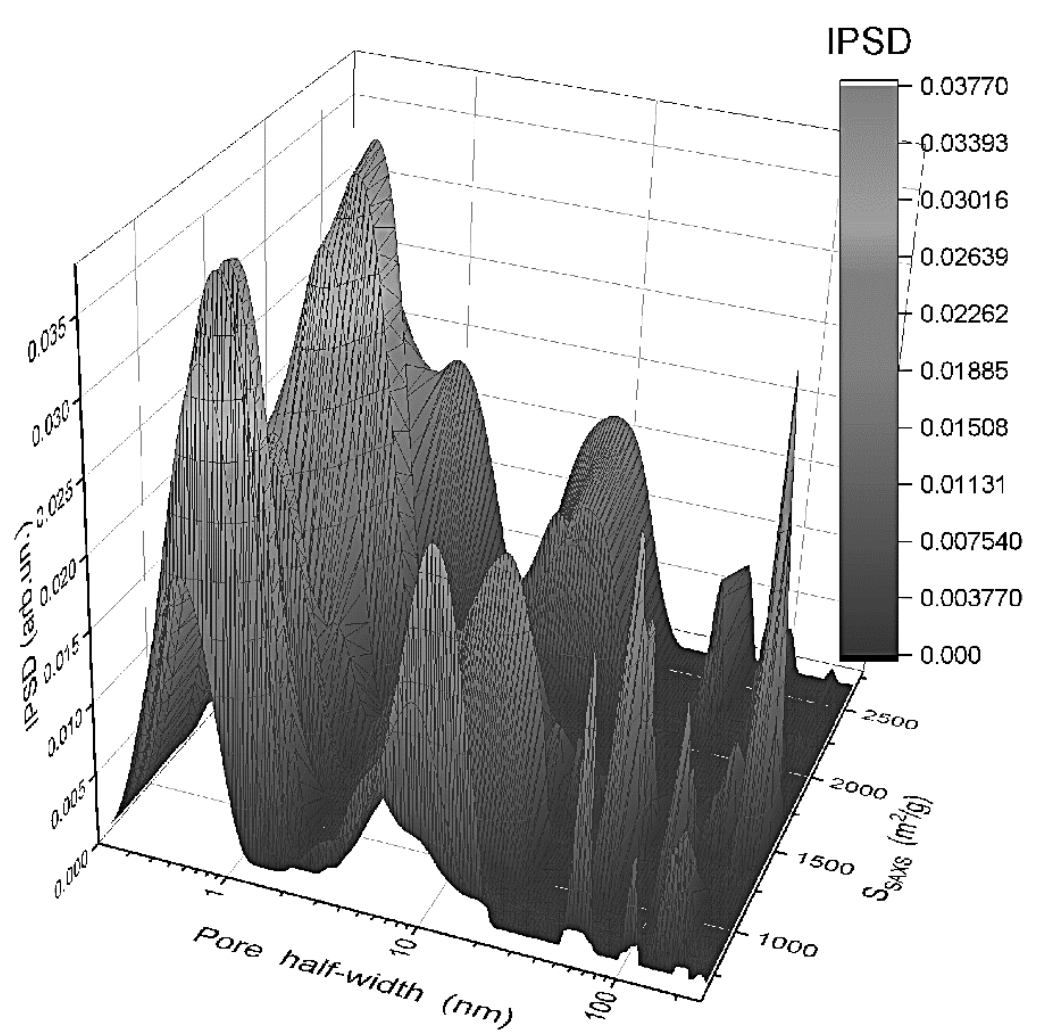

Fig. 36. (a) SAXS/SCR PaSD for various chars and AC (19 samples) and (b) SAXS IPSD for the same chars and AC (19 samples) 
For a relatively small set (19) of samples, there are more clear certain regularities in the particulate morphology of chars and related AC (Fig. 36a) that affect the PSD (Fig. 36b). According to the SAXS data, the chars include both small and larger nanoparticles and micro/macroparticles. These hierarchical structures are well visible in AFM (Figs. 14-16), SEM (Fig. 17) and TEM (Figs. 18 and 19) images. Upon activation of chars, the smallest nanoparticles are destroyed or sintered. The activation leads to thinning pore walls and certain broadening of nanopores partially transformed into narrow mesopores (Figs. 20-36, Tables 1 and 2). Clearly, charges in the precursors and char activation conditions result in the final AC of different morphological and textural characteristics, which are difficult to be compared since they affected by several different factors, e.g., char PaSD and PSD, pore size and length, activation temperature and agent, activation in static or dynamic reactors, etc. Therefore, for better control of these changes, a certain set of methods should be used including adsorption (open pores), SAXS (open and closed pores), AFM, SEM, and HRTEM (particular morphology form nano, micro to macroscales). It should be noted that different methods as well as different probe adsorbates could give different results, which can be difficult to be understood if only one-two characterization methods are used, that should be taking into account. Additionally, the interactions of probe molecules depend not only on their structure $[13,14]$ but also on the textural characteristics of adsorbents (Fig. 34) as well as the surface chemistry of the adsorbents [42-51].

\section{Some general regularities}

For various adsorbents, there is a tendency of an increase in the pore volume with increasing surface area (Fig. 37). The scatter degree of $V_{\mathrm{p}} v s$. $S_{\mathrm{BET}}$ increases with decreasing temperatures of the synthesis, activation or pretreatment of solid samples. For example, porous silicas (silica gels, mesoporous ordered silicas, aerogels, precipitated silicas) were synthesized (500-800 K) and preheated (typically $<1000 \mathrm{~K}$ ) at much lower temperatures than that of the synthesis of fumed silicas (1400-1600 K) [1-12]. Carbons (chars, activated carbons, carbon blacks) were synthesized and activated typically at $800 \mathrm{~K}<\mathrm{T}<1200 \mathrm{~K}[11,12,25-30,82,83]$. Therefore, the scatter degree in the $S-V$ relationships is maximal for porous silicas (Fig. 37). This can be explained by a variety of the synthesis techniques and routes (sol-gel, templating, precipitating, post-synthesis treatments at different conditions) used for preparation of porous silicas in contrast to fumed nanosilicas synthesized at high temperatures in the $\mathrm{H}_{2} / \mathrm{N}_{2} / \mathrm{O}_{2}$ flame. Fumed silicas are composed of NPNP, but porous silicas are composed of porous micro- or macroparticles with secondary narrow pores in the walls of the main mesopores. The Pearson correlation coefficient values for a linear approximation of $V_{\mathrm{p}} v s . S_{\mathrm{BET}}$ (Fig. 37a) increase in the same line that the temperature ranges of the synthesis/activation/treatment of the solid adsorbents. Note that porous polymers [81] synthesized at relatively low temperatures are characterized by the smallest scattering (maximal Pearson's $\mathrm{R}$ value) in the log-scale $S$ - $V$ relationships (Fig. 37b). However, for the linear-scale $S$ - $V$ relationships, the Pearson's R value is much lover for polymers but minimal for porous silicas (Fig. 37a).

Fumed silicas are composed of NPNP (Figs. 1-3), but polymers represent porous micro/macroparticles practically without pores (accessible for $\mathrm{N}_{2}$ molecules) in the walls of nano/meso/macropores. Some polymers, e.g., polymethylsiloxane could have a netlike structure similar to that of NPNP agglomerates. Carbons (chars, activated carbons, see microscopic images, Figs. 14-19) and porous silicas (Figs. 10-13) are composed of nanoparticles tightly packed in secondary structures, but carbon NP are porous in contrast to primary silica nanoparticles. However, porous silicas could have certain narrow pores in the walls (composed of adherent primary nonporous nanoparticles) of main pores in disperse micro/macroparticles. As a whole, there are certain differences in the linear-scale and log-scale $S$ - $V$ correlations for different classes of adsorbents (Fig. 37), and the scatter is greater for the linear-scale $S$ - $V$ correlations. A real $S$ - $V$ correlation is observed only for fumed silicas and carbons (Fig. 37a). Contributions of pores in the walls of the main pores or in NP depend strongly on a set of factors (structures and amounts of precursors and pore-forming agents, reaction and post-reaction treatment conditions, etc.), which affect the $S-V$ relationship scatters. Note that subsequent consideration of the materials is focused 
on solid (silica and carbon) adsorbents characterized by higher ordered hierarchical structures than polymeric adsorbents.

(a)

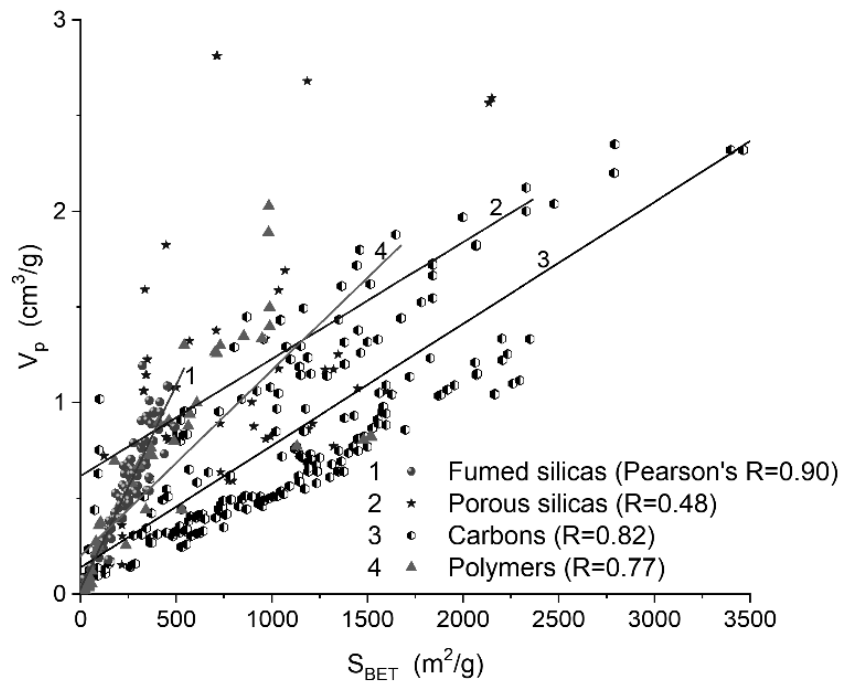

(b)

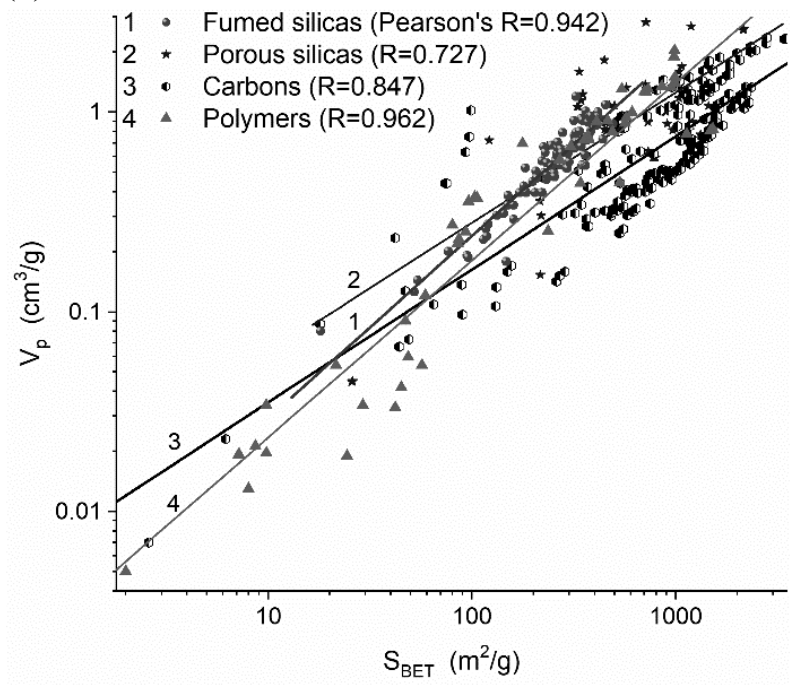

Fig. 37. Relationships between the $S_{B E T}$ and $V_{p}$ values for fumed and porous silicas, carbons, and polymers with (a) linear scale and (b) log-scale (Pearson correlation coefficients for linear approximation are shown)

\section{Conclusion}

A large set of silicas (93 and 56 samples of fumed and porous silicas, respectively) and carbons (230 samples), characterized by different $S_{\mathrm{BET}}$ and $V_{\mathrm{p}}$ values, PaSD and PSD functions, is analyzed with respect to the particulate morphology and texture using adsorption, SAXS, and microscopic methods. For different material classes, there are different linear correlations (line courses) between the pore volume and specific surface area increasing in parallel. The scatter in a linear approximation of $V_{\mathrm{p}} v s . S_{\mathrm{BET}}$ decreases with increasing synthesis or treatment temperatures. Despite the fumed silicas are composed of nonporous primary nanoparticles, but activated carbons are composed of porous nanoparticles weakly and strongly packed in secondary structures, respectively, there are certain general features of the PSD, e.g., minimal contribution of pores at radius (or half-width) of 3-5 nm. This PSD depression is caused by decreased contributions of voids between nanoparticles, packed in secondary and ternary structures, in this size range or such narrow mesopores in carbon PNP. A similar regularity is absent for a set of porous silicas.

For activated carbons produced from the same precursors and chars using the same activation agent with only varied time of activation, all textural characteristics demonstrate smooth changes and there is a tendency of transformation of nanopores into narrow mesopores with opposite shifts of the PSD peaks of broad mesopores and macropores due to changes in primary nanoparticle sizes and their compaction in secondary structures.

Comparison of the textural characteristics computed using adsorption (open pores accessible for probe molecules) and SAXS (open and closed pores) data for carbons (chars and AC) shows that their (adsorption and SAXS) difference decreases with increasing degree of burn-off activation.

Useful quantitative morphological and textural information could be obtained from AFM, SEM, and HRTEM images treated using appropriate software (e.g., Fiji/local thickness plugin, ImageJ/granulometry plugin, etc.). These data allow one to obtain information on the morphological and textural hierarchies of particles (nuclei, primary, secondary, ternary) and pores (nano, meso, and macropores).

Most clear pictures on the particulate morphology and texture of various materials could be obtained upon application of adsorption, SAXS, and microscopic methods with appropriate and correct treatments of the data. The application of one of these methods does not provide this 
possibility and some interpretations of the data could be incorrect that is of importance from a practical point of view.

\section{Acknowledgments}

The work was supported by NATO SPS (grant G5798) and the National Research Foundation of Ukraine (Support of advanced and young scientists, grant 2020.02/0057). The author thanks Dr. V. Bogatyrov, Dr. M. Galaburda, Dr. I. Protsak, Dr. O. Oranska (Chuiko Institute of Surface Chemistry, Kyiv, Ukraine), Prof. R. Leboda, Dr. J. Skubiszewska-Zięba, Prof. B. Gawdzik, Dr. B. Charmas, Dr. D. Sternik, Dr. M. Goliszek, and Prof. B. Podkościelna (Maria Curie-Sklodowska University, Lublin, Poland), Prof. J.P. Blitz (Eastern Illinois University, USA), Dr. O. Kozynchenko (MAST Carbon Technology Ltd., UK), and Prof. S. Mikhalovsky (University of Brighton, UK) for a set of various raw experimental data (adsorption isotherms, SAXS and XRD patterns, etc.).

\section{References}

[1] Ullmann's Encyclopedia of Industrial Chemistry. (Weinheim: Wiley-VCH, 2008).

[2] Hastie J.W. (editor). Materials Chemistry at High Temperatures. Vol. 1, Characterization. Vol. 2, Processing and Performance. (NJ: Clifton, Humana Press, 1990).

[3] Büchel K.H., Moretto H.-H., Woditsch P. Industrial inorganic chemistry. (Weinheim: Wiley-VCH Verlag $\mathrm{GmbH}, 2000)$.

[4] Somasundaran P. (editor). Encyclopedia of Surface and Colloid Science. Third Edition (Boca Raton: CRC Press, 2015).

[5] Iler R.K. The Chemistry of Silica. (Chichester: Wiley, 1979).

[6] Bergna H.E., Roberts W.O. (editors). Colloidal Silica: Fundamentals and Applications. (Boca Raton: CRC Press, 2006).

[7] Legrand A.P. (editor). The Surface Properties of Silicas. (New York: Wiley, 1998).

[8] Dabrowski A., Tertykh V.A. (editors). Adsorption on New and Modified Inorganic Sorbents; Studies in Surface Science and Catalysis. Vol. 99. (Amsterdam: Elsevier, 1996).

[9] Basic characteristics of Aerosil fumed silica (4th ed.). Tech. Bull. Fine Particles 11. (Hanau: Evonik Industries, 2014).

[10] Nicolais L., Borzacchiello A., Lee S.M. (editors). Wiley Encyclopedia of Composite. Materials, 5Volume set, 2nd ed. (Hoboken, NJ: Wiley, 2012).

[11] Marsh H., Rodríguez-Reinoso F. Activated Carbon. (London: Elsevier, 2006).

[12] Tascón J.M.D. (editor). Novel Carbon Adsorbents. (Amsterdam: Elsevier, 2012).

[13] Gun'ko V.M., Turov V.V. Nuclear Magnetic Resonance Studies of Interfacial Phenomena. (Boca Raton: CRC Press, 2013).

[14] Gun'ko V.M., Turov V.V., Zarko V.I., Goncharuk O.V., Pahklov E.M., Skubiszewska-Zięba J., Blitz J.P. Interfacial phenomena at a surface of individual and complex fumed Nanooxides. Adv. Colloid Interface Sci. 2016. 235: 108. http://dx.doi.org/10.1016/j.cis.2016.06.003.

[15] Kulkarni P., Baron P.A., Willeke K. (editors). Aerosol Measurement: Principles, Techniques, and Applications. Third Edition. (New York: John Wiley \& Sons, 2011).

[16] Auner N., Weis J. (editors). Oganosilicon Chemistry VI. (Weinheim: Wiley-VCH Verlag GmbH, 2005).

[17] Piemonte V., De Falco M., Basile A. (editors). Sustainable Development in Chemical Engineering Innovative Technologies. First Edition. (Chichester, UK: John Wiley \& Sons, 2013).

[18] Xu R., Pang W., Yu J. Chemistry of Zeolites and Related Porous Materials: Synthesis and Structure. (Hoboken, N.J.: Wiley-Interscience, 2007).

[19] Hench L.L. Sol-Gel Silica. (Norwich, N.Y.: William Andrew, 1998).

[20] Corma A., Kumar D., Bonneviot L., Béland F., Danumah C., Giasson S., Kaliaguine S. (editors). Mesoporous Molecular Sieves. Vol. 117. Studies in Surface Science and Catalysis. (Amsterdam: Elsevier, 1998). 
[21] Dodiuk H., Goodman S. (editors). Handbook of Thermoset Plastics. Third Edition. (Oxford, UK: Elsevier, 2014).

[22] Pietsch W. Agglomeration in Industry. (Weinheim: Wiley-VCH Verlag GmbH, 2005).

[23] Theodore L., Kunz R. G. Nanotechnology: Environmental Implications and Solutions. (Hoboken, N.J.: John Wiley \& Sons, 2005).

[24] Theodore L. Nanotechnology: Basic Calculations for Engineers and Scientists. (Hoboken, N.J.: John Wiley \& Sons, 2006).

[25] Bansal R.C., Donnet J.B., Stoeckli F. Active Carbon. (New York: Marcel Dekker, 1988).

[26] Smisek M., Cerny S. Active Carbon. (Amsterdam: Elsevier, 1970).

[27] Gregg S.J., Sing K.S.W., Stoeckli H.F. (editors). Characterization of Porous Solids. (London: Soc. Chem. Industry, 1979).

[28] McEnaney B., Mays T.J., Rodriguez-Reinoso F. (editors). Fundamental Aspects of Active Carbons. Special issue. Carbon 1998. 36(10).

[29] Cooney D.O. Activated Charcoal in Medical Applications. (New York: Marcel Dekker, 1995).

[30] Rodriguez-Reinoso F., McEnaney B., Rouquerol J., Unger K. (editors). Studies in Surface Science and Catalysis, Vol. 144, Characterisation of Porous Solids VI. (Amsterdam: Elsevier Science, 2002).

[31] Karlsson H.L., Toprak M.S., Fadeel B. Toxicity of metal and metal oxide nanoparticles. in: G.F. Nordberg, B.A. Fowler, M. Nordberg (editors). Handbook on the Toxicology of Metals, Fourth Edition (Amsterdam: Elsevier, 2015, pp. 75-112).

[32] Blitz J.P., Gun'ko V.M. (editors). Surface Chemistry in Biomedical and Environmental Science. NATO Science Series II: Mathematics, Physics and Chemistry. Vol. 228. (Dordrecht: Springer, 2006).

[33] Younes M., Aggett P., Aguilar F., Crebelli R., Dusemund B., Filipic M., Frutos M.J., Galtier P., Gott D., Gundert-Remy U., Kuhnle G.G., Leblanc J.-C., Lillegaard I.T., Moldeus P., Mortensen A., Oskarsson A., Stankovic I., Waalkens-Berendsen I., Woutersen R.A., Wright M., Boon P., Chrysafidis D., Gurtler R., Mosesso P., Parent-Massin D., Tobback P., Kovalkovicova N., Rincon A.M., Tard A., Lambre C. Re-evaluation of silicon dioxide (E 551) as a food additive. EFSA Journal. 2018. 16(1): 5088. http://dx.doi.org/10.2903/j.efsa.2018.5088.

[34] Cabot Corporation. http://www.cabotcorp.com/solutions/products-plus/fumed-metal-oxides/.

[35] DuPont. http://www.dupont.com/.

[36] Evonik Ind. http://corporate.evonik.com/en/Pages/default.aspx. http://www.aerosil.com/product/aerosil/en/services/downloads/Pages/test-methods.aspx.

[37] Adamson A.W., Gast A.P. Physical Chemistry of Surface. Sixth edition. (New York: Wiley, 1997).

[38] Gregg S.J., Sing K.S.W. Adsorption, Surface Area and Porosity. (London: Academic Press, 1982).

[39] Thommes M., Kaneko K., Neimark A.V., Olivier J.P., Rodriguez-Reinoso F., Rouquerol J., Sing K.S.W. Physorption of gases, with special reference to the evaluation of surface area and pore size distribution. IUPAC Technical Report. Pure Application Chemistry. 2015. 87: 1051.

[40] Biricik H., Sarier N. Comparative study of the characteristics of nano silica-, silica fume- and fly ash - incorporated cement mortars. Materials Research. 2014. 17: 570.

[41] Hashim A.A. (editor). Smart Nanoparticles Technology. (Rijeka, Croatia: InTech, 2012).

[42] Gun'ko V.M., Meikle S.T., Kozynchenko O.P., Tennison S.R., Ehrburger-Dolle F., Morfin I., Mikhalovsky S.V. Comparative characterization of carbon and polymer adsorbents by SAXS and nitrogen adsorption methods. J. Phys. Chem. C. 2011. 115: 10727.

[43] Gun'ko V.M. Polymer adsorbents vs. functionalized oxides and carbons: particulate morphology and textural and surface characterization. Polymers. 2021. 13(8): 1249. http://dx.doi.org/10.3390/polym13081249.

[44] Gun'ko V.M., Mironyuk I.F., Zarko V.I., Turov V.V., Voronin E.F., Pakhlov E.M., Goncharuk E.V., Leboda R., Skubiszewska-Zięba J., Janusz W., Chibowski S., Levchuk Yu.N., Klyueva A.V. Fumed silicas possessing different morphology and hydrophilicity. J. Colloid Interface Sci. 2001. 242: 90. 
[45] Gun'ko V. M., Zarko V. I., Goncharuk E. V., Andriyko L. S., Turov V.V., Nychiporuk Y. M., Leboda R., Skubiszewska-Zięba J., Gabchak A. L., Osovskii V. D., Ptushinskii Y. G., Yurchenko G. R., Mishchuk O. A., Gorbik P. P., Pissis P., Blitz J. P. TSDC spectroscopy of relaxational and interfacial phenomena. Adv. Colloid Interface Sci. 2007. 131: 1.

[46] Gun'ko V.M. Nano/meso/macroporous materials characterization affected by experimental conditions and features of the used methods. Chemistry, Physics and Technology of Surface. 2020. 11(1): 5 .

[47] Gun'ko V.M., Do D.D. Characterization of pore structure of carbon adsorbents using regularization procedure. Colloids Surf. A: Physicochem. Eng. Aspects. 2001. 193: 71.

[48] Gun'ko V.M., Mikhalovsky S.V. Evaluation of slitlike porosity of carbon adsorbents. Carbon. 2004. 42: 843 .

[49] Gun'ko V.M., Turov V.V., Kozynchenko O.P., Nikolaev V.G., Tennison S.R., Meikle S.T., Snezhkova E.A., Sidorenko A.S., Ehrburger-Dolle F., Morfin I., Klymchuk D.O., Mikhalovsky S.V. Activation and structural and adsorption features of activated carbons with highly developed micro-, meso- and microporosity. Adsorption 2011. 17: 453.

[50] Gun'ko V.M., Kozynchenko O.P., Tennison S.R., Leboda R., Skubiszewska-Zięba J., Mikhalovsky S.V. Comparative study of nanopores in activated carbons by HRTEM and adsorption methods. Carbon. 2012. 50: 3146.

[51] Shuttleworth P.S., Budarin V.L., White R.J., Gun'ko V.M., Luque R., Clark J.H. Molecular-level understanding of the carbonisation of polysaccharides. Chem. Eur. J. 2013. 19: 9351.

[52] Provencher S.W. A constrained regularization method for inverting data represented by linear algebraic or integral equations. Comp. Phys. Comm. 1982. 27: 213.

[53] Pujari P.K., Sen D., Amarendra G., Abhaya S., Pandey A.K., Dutta D., Mazubder S. Study of pore structure in grafted polymer membranes using slow positron beam and small-angle X-ray scattering techniques. Nuclear. Instr. Method Phys. Res. B. 2007. 254: 278.

[54] Sakurai S. SAXS evaluation of size distribution for nanoparticles. Chapter 5 (http://dx.doi.org/10.5772/105981). in A.E. Ares (editor). X-ray Scattering. (DOI: 10.5772/65049). (Rijeka Croatia: InTech, 2017, pp. 107-134).

[55] Brumberger H. (editor). Small Angle X-ray Scattering. (New York: Gordon \& Breach, 1965).

[56] Dieudonné Ph., Hafidi A.A., Delord P., Phalippou J. Transformation of nanostructure of silica gels during drying. J. Non-Crystal. Solid. 2000. 262: 155.

[57] Fairén-Jiménez D., Carrasco-Marín F., Djurado D., Bley F., Ehrburger-Dolle F., Moreno-Castilla C. Surface area and microporosity of carbon aerogels from gas adsorption and small- and wide-angle $\mathrm{X}$ ray scattering measurements. J. Phys. Chem. B. 2006. 110: 8681.

[58] Gun'ko V.M. Textural characteristics of composite adsorbents analyzed with density functional theory and self-consistent regularization procedure. Chemistry, Physics and Technology of Surface. 2020. 11(2): 163-174. https://doi.org/10.15407/hftp11.02.163.

[59] Gun'ko V.M. Composite materials: textural characteristics. Applied Surface Science. 2014. 307: 444. http://dx.doi.org/10.1016/j.apsusc.2014.04.055

[60] Tarazona P., Marconi U.M.B., Evans R. Phase equilibria of fluid interfaces and confined fluids non-local versus local density functionals. Mol. Phys. 1987. 60: 573.

[61] Lastoskie C., Gubbins K.E., Quirke N. Pore size distribution analysis of microporous carbons: a density functional theory approach. J. Phys. Chem. 1993. 97: 4786.

[62] Olivier J.P. Modeling physical adsorption on porous and nonporous solids using density functional theory. J. Porous Mater. 1995. 2: 9.

[63] Olivier J.P. Improving the models used for calculating the size distribution of micropore volume of activated carbons from adsorption data. Carbon. 1998. 36: 1469. 
[64] Occelli M.L., Olivier J.P., Perdigon-Melon J.A., Auroux A. Surface area, pore volume distribution, and acidity in mesoporous expanded clay catalysts from hybrid density functional theory (DFT) and adsorption microcalorimetry methods. Langmuir. 2002. 18: 9816.

[65] Lowell S., Shields J., Thomas M.A., Thommes M. Characterization of Porous Solids and Powders: Surface Area, Porosity and Density. (Dordrecht: Springer, 2004).

[66] Rouquerol J., Baron G.V., Denoyel R., Giesche H., Groen J., Klobes P., Levitz P., Neimark A.V., Rigby S., Skudas R., Sing K., Thommes M., Unger K. The characterization of macroporous solids: An overview of the methodology. Microporous Mesoporous Mater. 2012. 154: 2.

[67] Ravikovitch P.I., Neimark A.V. Density functional theory model of adsorption on amorphous and microporous silica materials. Langmuir. 2006. 22: 11171.

[68] Landers J., Gor G.Y., Neimark A.V. Density functional theory methods for characterization of porous materials. Colloids Surf. A: Physicochem. Eng. Aspects. 2013. 437: 3.

[69] Neimark A.V., Lin Y., Ravikovitch P.I., Thommes M. Quenched solid density functional theory and pore size analysis of micro-mesoporous carbons. Carbon. 2009. 47: 1617.

[70] Gor G.Y., Thommes M., Cychosz K.A., Neimark A.V. Quenched solid density functional theory method for characterization of mesoporous carbons by nitrogen adsorption. Carbon. 2012. 50: 1583.

[71] Jagiello J., Olivier J.P. A simple two-dimensional NLDFT model of gas adsorption in finite carbon pores. Application to pore structure analysis. J. Phys. Chem. C. 2009. 113: 19382.

[72] Nguyen C., Do D.D. A new method for the characterization of porous materials. Langmuir. 1999. 15: 3608 .

[73] Nguyen C., Do D.D. Effects of probing vapors and temperature on the characterization of micromesopore size distribution of carbonaceous materials. Langmuir. 2000. 16: 7218.

[74] Do D.D., Nguyen C., Do H.D. Characterization of micro-mesoporous carbon media. Colloids Surf. A: Physicochem. Eng. Aspects. 2001. 187-188: 51.

[75] Platzer B., Maurer G. Application of a generalized Bender equation of state to the description of vapour-liquid in binary systems. Fluid Phase Equilib. 1993. 84: 79.

[76] Horcas I., Fernández R., Gómez-Rodríguez J. M., Colchero J., Gómez-Herrero J., Baro A. M. WSXM: A software for scanning probe microscopy and a tool for nanotechnology. Rev. Sci. Instrum. 2007. 78: 013705 . https://doi.org/10.1063/1.2432410

[77] Fiji. https://imagej.net/software/fiji/ (last accessed on June 12, 2021).

[78] ImageJ. https://imagej.nih.gov/ij/ (last accessed on May 15, 2021).

[79] Gun'ko V.M., Oranska O.I., Paientko V.V., Sulym I.Ya. Particulate morphology of nanostructured materials. Chem. Phys. Technol. Surf. 2020. 11(3): 368. https://doi.org/10.15407/hftp11.03.368

[80] Gun'ko V.M., Turov V.V., Pakhlov E.M., Krupska T.V., Charmas B. Effect of water content on the characteristics of hydro-compacted nanosilica. Applied Surface Science. 2018. 459: 171. https://doi.org/10.1016/j.apsusc.2018.07.213.

[81] Gun'ko V.M., Leboda R., Skubiszewska-Zięba J., Gawdzik B., Charmas B. Structural characteristics of porous polymers treated by freezing with water or acetone. Applied Surface Science. 2005. 252: 612. https://doi.org/10.1016/j.apsusc.2005.02.075.

[82] Tennison S.R. Phenolic resin derived activated carbons. Appl. Cat. A Gen. 1998. 173: 289.

[83] Tennison S.R., Kozynchenko O.P., Strelko V.V., Blackburn A.J. Porous carbons. US patent 2004024074A1, 2004. 


\title{
ОСОБЛИВОСТІ МОРФОЛОГІЇ ТА ТЕКСТУРИ КРЕМНЕЗЕМНИХ І ВУГЛЕЦЕВИХ АДСОРБЕНТІВ
}

\author{
В.М. Гунько \\ Інститут хімії поверхні ім. О.О. Чуйка Національної академії наук України \\ вул. Генерала Наумова, 17, Київ, 03164, Україна, e-mail:vlad_gunko@ukr.net
}

Морфологію і текстуру різних кремнеземів (93 пірогенних $i$ 56 пористих), різних вуглечевих адсорбентів (230), і пористих полімерів (53) проаналізовано з використанням тестових адсорбатів (азот, аргон, бензол, декан, вода), мало-кутового розсіювання рентгенівських променів (SAXS), трансмісійної (TEM) $i$ скануючої (CEM) електронної $i$ атомно-силової (ACM) мікроскопії. $C$ певні кореляиії між об'ємом пор $\left(V_{p}\right)$ i питомою поверхнею $\left(S_{B E T}\right)$ для цих матеріалів. Температури синтезу і тренування впливають на цюю

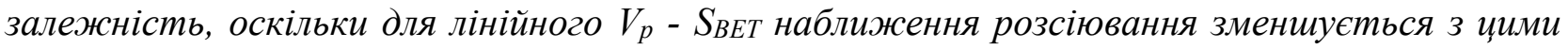
температурами. Кремнеземи складаються 3 непористих наночастинок (NPNP). Активоване вугілля (АС) складається з пористих наночастинок (РNP). Для різних матеріалів нанопор слабо або сильно упаковані у вторинних структурах. Проте, існують загальні особливості розподілів розмірів пор (PSD) для матеріалів на основі нанопор, наприклад, мінімальний внесок вузьких мезопор 3-5 нм радіусу внаслідок ефектів упаковки. Для АС на основі тих самих прекурсорів, карбонізатів та агентів активащії проте 3 варіюванням часу активаиії, текстурні характеристики демонструють плавні зміни в залежності від ступеня активації: нанопори перетворюються у вузькі мезопори $з$ протилежними зрушеннями PSD широких мезопор $i$ макропор. Порівняння адсорбиії (відкриті пори, щуо доступні для зондів) і SAXS (відкриті i закриті пори) даних для АC показує, щуо різниця зменшується зі збільшенням ступеня активачії за рахунок зменшення внеску закритих пор. Більшість чіткі уявлення щзодо морфології частинок $і$ текстури можуть бути отримані при паралельному застосуванні адсорбиії SAXS і мікроскопічних методів з відповідними методами числового аналізу даними.

Ключові слова: нанокремнеземи, пористі кремнеземи, вуглечеві адсорбенти, морфологія частинок, текстурні характеристики, співвідношення об'єм пор - питома поверхня 